VII.

Aus dem Kiewer städtischen Alexander-Krankenhaus.

\title{
Zur Frage von den gegenseitigen Beziehungen zwischen Nervensystem und Zuckerkrankhoit. ${ }^{1}$ )
}

\author{
(Experimentelle - klinische Untersuchung.) \\ Von
}

Dr. P. Zagorowsky.

Kinleitung.

Die Pathogenese der Krankbeitserscheinungen, welche auf dem Boden der Störung des Stoffwechsels entstehen, stellt ein Problem dar, dessen Lösung mit ausserordentlichen Schwierigkeiten verbunden ist, da der Forscher es hier mit zahlreichen und verschiedenartigen Einflüssen zu tun hat, die sich in manchen Fällen überhaupt gar nicht berechnen lassen. Eine der interessantesten und zugleich auch der am wenigsten aufgeklärten Fragen auf diesem Gebiete ist die Fragé von dem Wesen der Zuckerkrankheit. Der Diabetes, als besondere Krankheit, war schon den Aerzten des Altertums bekannt, und fast seit der Erhebung der Medizin zur Wissenschaft sehen wir neben der Beschreibung der Symptome dieser Erkrankung zugleich auch Versuche, die Ursache ibrer Entstehung zu erklären. Die ersten systematischen Angaben über die Zuckerkrankheit knüpten sich an den Namen Th. Willis und stammen aus dem XVII. Jahrhundert. Will is hat zuerst darauf aufmerksam gemacht, dass der diabetische Harn von so süssem Geschmacke sei, als wenn er mit Honig oder Zucker vermischt wäre (quasi melle aut saccharo imbuta). Aber erst im Jahre 1835 lieferte Ambrosiani einen vollkommen präcisen Beweis für das Vorhandensein des Zuckers nicht nur im Harne, sondern auch im Blute der Diabetiker. Allein bis zum Anfang des vorigen Jahrhunderts waren angesichts des Mangels an wissenschaftlichen Untersuchungsmethoden alle über diese Frage geäusserten Hypothesen auf Vernunftschlüsse a priori gegründet. Erst mit der Entwicklung der experimentellen Physiologie, die zur Aulgabe hat, die normale Funktion der einzelnen Organe zu erforschen, und der experimentellen Pathologie, welche es ermöglicht, bei Tieren diese oder jene pathologische Erscheinung hervorzurufen, die von Symptomen begleitet ist, welche bei den gleichen Erkrankungen beim Menschen beobachtet werden, ist die Frage von dem Wesen des Diabetes auf wissenschaftlichen Boden gestellt worden. Der erste, welcher die Glykosurie, das Hauptsymptom des Diabetes, experimentell beobachtete, war Cl. Bernard,

1) Mit Demonstration von mikroskopischen Präparaten im Aerzteverein des Kiewer städtischen Alexander-Krankenhauses vorgetragen am 9. Oktober 1912. 
der geniale Forscher des rorigen Jahrhunderts. Seine Versuche, diese Erscheinung zu erklären, haben das erste Licht auf dieses Gebiet der Pathologic geworfen und einen neuen Weg zur Lösung dieser dunklen Frage gewiesen - den Weg der experimentellen wissenschaftlichen Forschung. Auf Grund aller bis jetzt ausgeführten Untersuchungen ist eine ganze Reihe von Hypothesen und Theorien entstanden; allein eine Theorie, welche alle Formen der Zuckerkrankheit erklärt, existiert nicht, ja, selbst die Möglichkeit ihres Yorhandenseins wird von vielen Autoren nicht zugegeben. Im allgemeinen begregnen wir einer so grossen Zahl der verschiedenartigsten, mitunter sogar sich widersprechenden Theorien, dass es scheint, als wenn wir ungeachtet der Entwicklung der wissenschaftlichen Methoden uns noch immer nicht weit von der Vorstellung der Aerzte des Mittelalters entfernt hätten, welche, eines wissenschaftlichen leitenden Fadens bei der Erforschung dieser Frage entbehrend, die Ursache des Diabetes zu erklären suchten, indem sie nacheinander bald dem einen, bald dem andern Organe des menschlichen Körpers die Hauptrolle bei seiner Entstchung zuschrieben. In der Tat hält man gegenwärtig die Funktionsstörungen der verschiedenartigsten Organe für die Ursache dieser Erkrankung. In einer der letzten dieser Frage gewidmeten Arbeiten weist der Autor Meyer daraul hin, dass die einen in dem Diabetes eine allgemeine Ernährungsstörung sehen, dic andern ihn für den Ausdruck einer Funktionsstörung der Jeber halten, die dritten ihn als eine durch physische oder moralische Erschütterung bedingte nervöse Erkrankung ansprechen; die vierten glauben, dass der Diabetes infolge von Verringerung der Intensität der Glykolyse eintritt; einige Forscher weisen auf den Einfluss der $\mathrm{Na}$ - und $\mathrm{Ca}-\mathrm{Ionen} \mathrm{hin}$, die in den Säften unseres Körpers aufgelöst sind; andere dagegen nehmen an, dass der Diabetes infolge einer Erkrankung der Nebennieren entstehen könne. Am verbreitetsten ist jedoch gegenwärtig die Ansicht, nach we]cher die Hauptrolle bei der Entstehung des Diabetes dem Pankreas zufällt. Is gilt für eine feststehende Tatsache (Häusler), dass die Tätigkeit des Pankreas sich nicht auf seine Funktion als Verdauungsorgan beschränkt, sondern dass gleichzeitig hiermit eine besondere Substanz von ihm produziert wird, die nicht in den Darm ausgeschieden wird, sondern direkt ins Blut übergeht. Eben diese Ausscheidung die sogenannte innere Sekretion - spielt nun auch eine wichtige Rolle in dem Kohlehydratstoffwechsel. Von besonderer Wichtigkeit ist hierbei der Lmstand, dass die innere Sekretion durchaus nicht von der Verdauungsfunktion des Pankreas - der sogenannten äusseren Sekretion desselben - abhängt. Nach dem Zustande der einen Sekretion darüber zu urteilen, inwieweit regelrecht sich die andere vollzieht, ist keineswegs möglich, so dass die Verdauungsfunktion des Pankreas vollständig normal sein kann, während seine innere Sekretion fehlt und umgekehrt. Was den Linfluss des Pankreas auf die Entstehung des Diabetes betriff, so existieren auch über diese Frage wiederum mehrere Gesichtspunkte. Vor allem stossen wir hier auf zwei Annahmen, mit deren Hilfe man die Entstehung des Pankreasdiabetes zu erklären bemüht war: nach der einen derselben wird eine bedeutende Glukosemenge in dem Pankreas 
selbst zerstört, nach der anderen scheidet das Pankreas ein glykolytisches Ferment aus. Späterhin fanden einige Forscher eine Erklärung für diese Krankheit in der Anhäufung von diabetogener Substanz, die im Organismus produziert und in normalem Zustande dank der inneren Sekretion des Pankreas neutralisiert wird. Nach der Meinung anderer Autoren wirkt die innere Sekretion auf die Nervenzentren, von denen die Lebernerven entstammen, indem sie deren Tätigkeit paralysiert und die Leber hindert, eine zu grosse Glukosemenge in den Blutkreislauf auszuscheiden. Neben diesen Theorien existiert noch eine Jehre (Häusler), nach welcher dic Tätigkeit des Pankreas im Sinne der Ausscheidung eines inneren Sekrets von der /uckeranhäufung im Blute abhängt, und auf diese Weise erscheint die nüberschüssige Zuckermenge im Blute als Erreger der 'Tätigkeit des Pankreas, der unmittelbar auf das letztere einwirkt". Ferner hat Pflüger eine Theorie begründet, nach welcher die Tätigkeit des Pankreas durch den Einfluss des Nervensystems erklärt wird. Seiner Meinung nach, ist in der Wand des Zwölffingerdarms ein an Ganglienzellen reiches nervöses Centralorgan gelegen, unter dessen Leitung die Pankreasfunktion steht" . Als Resultat der Entfernung des Darmes ergibt sich Diabetes, - resp. in der Darmwand ist ein antidiabetisches Centrum gelegen. Endlich hat Loewy in jüngster Zeit eine neue Theorie aufgestellt, nach welcher das Pankreas eine Substanz produziert, welche auf die Hemmungsnerven des Plexus sympathicus einwirkt und so die Entstehung einer Hyperglykämie, die von den erregenden sympathischen Nerven hervorgerufen werden könnte, verhindert.

Die Aufgabe der gegenwärtigen Arbeit ist 1. eigene, die Erkrankung des Nervensystems beim Diabetes betreffende Beobachtungen nitzuteilen; 2. experimentelle, den Einfluss des sympathischen Nervensystems auf das Auftreten von Zucker im Harn betreffende Daten beizubringen.

\section{Ueberblick über die Literatur.}

(Patbologisch-anatomische Daten.)

Der erste in der Jiteratur reröffentlichte Fall von Pankreasdiabetes wurde im Jahre 1788 beobachtet. In diesem von $\mathrm{Cow}$ le $\mathrm{y}$ beschriebenen Falle erwies sich das Pankreas als vollständig mit Concrementen angefüllt. Dieselben waren von weisser Harbe und verschiedener, die Dimensionen einer Erbse jedoch nicbt übersteigender Grösse; die Oberfläche derselben war uneben, und sie bestanden deutlich aus mebreren kleineren Concrementen. Nacb Cowley wurden nicht wenig analoge Beobachtungen veröffentlicht. funden.

So wurden im Falle von Chopart in dem Pankreas ebenfalls Concremente ge-

Bright teilte oinen Fall mit, wo das Caput des Pankreas mit den benachbarten Drüsen eine kugelförmige, mit dem Duodenum fest verwachsene Masso bildete. Das ganze Pankreas war knorpelhart anzufühlen und hatte eine glänzende gelbe Farbe.

Bouchardat beobachtete eine Atrophie des Pankreas mit vollkommener Obliteration des Ductus Wirsungianus.

Martson sah einen Fall von Scirrhus des Pankreas mit Obliteration des Ductus pancreaticus.

Cl. Bernard hat uns über zwei Diabetiker berichtet, bei denen das Pankreas von äusserst kleinen Dimensionen und atrophiert war. 
Griesinger erwähnt, dass bei einer ron seinen während des Diabetes plötzlich verstorbenen Kranken das Pankreas atrophiert und weich befunden wurde; es wog nur $68,0 \mathrm{~g}$, während sein Normalgewicht $90,0-120,0 \mathrm{~g}$ beträgt.

Im Falle von Lecorché ist das Pankreas klein, atrophiert.

Harley hat einen Abscess im Caput des Pankreas mit nachfolgender Verstopfung und Erweiterung des Ausführungsganges beobachtet.

Recklinghausen beobachtete zwei Fälle; in einem derselben war nur ein Teil des Caput des Pankreas erhalten geblieben, der ganze mittlere Teil aber in eine Cyste von der Grösse eines Kindskopfes verwandelt - in dem anderen jedoch erwies sich das Pankreas, dessen Form und Umfang erhalten geblieben waren, als vollständig fettig degeneriert.

Lusk fand bei der Sektion eines Diabetikers ein völlig rerkalktes Pankreas als einzige Veränderung.

Klobs und Munk konnten bei der Sektion eines Diabetikers mit blossem Auge kein normales Pankreasgewebe finden und erst unter dem Mikroskop gelang es ihnen, das Vorhandensein von Zellresten zu constatieren. Gleichzeitig erwiesen sich auch im Plexus coeliacus Veränderungen, denen die Autoren die vornehmlichste Bedeutung für die Entstehung des Diabetes zuschreiben.

$\mathrm{Sch}$ aper fand in einem Falle Sklerose und fettige Degeneration des Drüsenepithels.

Harnack hat eine vollständige fettige Degeneration des Pankreas gesehen.

Israel teilte einen Diabetesfall mit, wo bei der Sektion Nekrose des Pankreas gefunden wurde.

Hartsen beobachtete in zwei Fällen von Diabotes eine soweit ausgeprägte Atrophie des Pankreas, dass es als solches nicht mehr zu erkennen war.

Fles sah eine völlige Umwandlung der Drüse in Bindegewebe.

Cruppi sah eine starke Atrophie und Sklerose des Pankreas.

Caplick fand in einem Falle das Pankreas vollständig fettig degeneriert.

Elliotson fand in einem Falle von Diabetes das Pankreas ganz und gar mit weissen Concrementen angefüllt.

Frerichs teilt die Resultate der Sektion von zwei Diabetikern mit, wobei sich in beiden Fällen das Pankreas verkleinert und schlaff erwies (es wog einmal nur $45,0 \mathrm{~g}$ ) mit gleichzeitiger Bindegewebswucherung und Atrophie der Drüsenlappen.

Rayer, Skoda und Flecles führen je einen Fall von Atrophie des Pankreas an.

Im Falle von Sylver wurdo das stark atrophierte Pankreas mit Mühe gefunden; es war fettig degeneriert und rund um den Hauptausführungsgang verkalkt.

Zenker fand in drei Fällen eine völlige fettige Degenoration des Pankreas. Die Patienten dieses Autors starben plötzlich infolge eines Blutergusses in die Substanz des Pankreas. Ausserdem fand sich in einem Falle eine starke venöse Hyperämie des Ganglion semilunare.

Im Falle von Seegen erwies sich das Pankreas als um die Hälfte verkleinert, weich, Plexus coeliacus klein, schlaff.

Bouchardat beschreibt einen Fall von Atrophie und einen Fall von Krebs des Caput des Pankreas.

Scheube sah eine Atrophie des Pankreas.

Cantani führt die Resultate von vier Sektionen bei Personen an, die an Diabetes gestorben waren; in allen Fällen wurden atrophische Veränderungen mit fettiger Degeneration des Drüsenepithels des Pankreas beobacbtet.

Lancereaux beobachtete zwei Diabetesfalle; in einem derselben war das Pankreas im mittleren Drittel verschwunden, indem es hier ein Bindegewebsbrückchen bildete, in dessen Bereich der Ausführungsgang obliteriert war; Caput und Cauda desselben waren atrophiert - Verdickung der bindegewebigen Scheidewände und fettige Degeneration des Epithels. Im zweiten Falle war das Pankreas stark atrophiert; 
die Ausführungsgänge erweitert und mit umfangreichen Concrementen aus kohlen. saurem Kalke angefüllt. Plexus solaris ein wenig hypertrophiert.

Goodmann sah einen Fall von Atrophie des Pankreas, in dem sich im Ausführungsgang Kalkconcremente vorfanden.

Servaix sah einen von bronzefarbener Hautverfärbung, Neuralgia coeliaca und Glykosurie begleiteten Pankreaskrebs.

Friedreich teilt einen Fall mit, wo das Pankreas von sebr kleinen Dimensionen und vollständig fettig degeneriert war.

Grossmann beobachtete fettige Degeneration des Pankreas; gleichzeitig war auch eine Hirngeschwulst vorhanden.

Rühle sah einen Fall von starker Cirrhose des Pankreas, verbunden mit einer apfelgrossen Geschwulst, welche mit frischen Blutgerinnseln angefüllt war, und mit bedeutender Ektasio des Ductus Wirsungianus.

Gille beschreibt einen Fall, wo das Pankreas infolge Vorhandenseins einer grossen Anzahl von Steinen atrophiert war.

Jaksch sah auch eine stark ausgeprägte Atrophie des Pankreas.

Notta sah einen Fall von Verfettung des Pankreas.

Guelliot beschrieb einen Fall, wo fettige Degeneration des Drüsenepithels, Hyperplasie des Bindegewebes und eine nussgrosse Geschwalst im Caput der Drüse vorhanden waren.

In drei Fällen von Baumel war einmal das Pankreas mit Concrementen angefüllt, einmal war eine Gewebswucherung mit gleichzeitiger fettiger Degeneration der atrophierten Ueberreste des Drüsengewebes vorhanden, und in einem Falle fand sich Hyperplasie des Bindegewebes mit stellenweise erfolgter fettiger Degeneration des Drüsengewebes.

Duffey fand bei der Sektion eines Diabetikers Pankreaskrebs.

In vier von Windle beobachteten Fällen war zweimal eine trübe Schwellung des Epithels mit Verkleinerung des Pankreas vorbanden; einmal Bindegewebswucherung mit fettiger Degeneration des Epithels, und einmal wurde statt des Pankreas ein Bindegewebsstreifen, der nicht einmal Spuren von Drüsengewebe aufwies, gefunden.

Besançon fand bei der Sektion das Pankreas klein $(50,0 \mathrm{~g})$ und fettig degeneriert.

Bouisson beobachtete Pankreassklerose, wobei der Ductus Wirsunginnus, wie anch das Caput der Drüse mit Concrementen angefüllt waren.

Saundby, der ein überaus eingehendes Verzeichnis der sowobl in seinen eigenen, als auch in früher von anderen veröffentlichten Fällen erhaltenen Sektions-

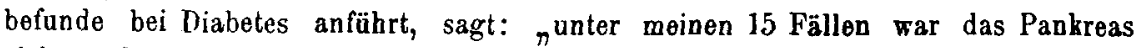
siebenmal atrophiert, viermal anormal hart, fibrös und viermal normal. ${ }^{\omega}$ Von allen bei der Sektion gefundenen Veränderungen hält Saundby die Veränderungen des Pankreas für am wichtigsten und lässt erst dann die in den abdominalen sympathischen Ganglien vorgefundenen gelten.

Lépine führt einen Fall an, wo in dem makroskopisch normalen Pankreas sich mikroskopisch eine Bindegewebswucherung um die Drüsenlappen zeigte.

Thiroloix fand bei der Sektion eines Diabetikers, dass das Pankreas in einen fibrösen Strang verwandelt war. Gleichzeitig war auch eine Hypertrophie des ganzen gangliösen Apparats, d. h. des Plexus solaris, vorhanden.

Im Falle von Sottas war das Pankreas ganz und gar mit Concrementen angefüllt. Unter dem Mikroskop zeigto sich ausserdem Hyperplasie des Bindegewebes und fettige Degeneration des Drüsenepithels.

Tollemer beschrieb einen Fall, wo das normal grosso Pankreas sich consistenter als in der Norm anfühlte. Unter dem Mikroskop wurde gefunden: Drüsengewebe stark atrophiert, Bindegewebe hingegen byperplastisch. Ihren normalen Um- 
fang verdankt die Drüse ihrer Verfettung: das Fett war $z$ wischen die atrophierten Drüsenlappen eingedrungen.

Leva fand in allen drei von ihm beobachteten Fällen eine mehr oder weniger stark ausgeprägte Atrophie des Pankreas.

Im Falle von Schabad war das Pankreas um das drei- bis vierfache verkleinert, von fester Consistenz. Das Drüsengewebe war atrophiert und wies stellenweise Pigmentund Vakuolendegeneration auf; hin und wieder war eine verstärkte Bindegewebswucherung bemerkbar.

Lemoine und Lannoix fanden in vier von ihnen untersuchten Fällen im Pankreas sklerotisohe Veränderungen, als deren Ausgangspunkt die Umgebung der Gefässe, besonders der Venen und Lymphgefässe diente.

Thiroloix fand in einem Falle ausgesprochene Atrophie des Pankreas mit gleichzeitiger multipler Obliteration der Ausführungsgänge.

Eich horst beschrieb 2 wei Fälle von Diabetes, wo bei der Sektion Veränderungen im Pankreas vorgefunden wurden. In dem einen Falle zeigte die sehr kleine Dimensionen aufweisende und auf dem Querschnitt der normalen Körnchenbeschaffenheit entbehrende Drüse unter dem Mikroskop das Bild einer sehr verbreiteten Coagulationsnekrose. In dem anderen erwies sich das Pankreas als von erstaunlich kleinen Dimensionen.

Harley teilt 2wei Fälle mit. In einem derselben waren Corpus und Cauda des Pankreas in einen fibrösen Strang umgewandelt. Im Caput waren eine kirschgrosse mit eiteriger graugelber Flüssigkeit angefüllte Höhle und eine Menge kleiner inmitten eines sklerotischen Gewebes gelegener Abscesse rorhanden. In dem anderen Falle bestand Krebs des Caput des Pankreas, welcher den Ductus choledochus zusammenpresste.

Williamson führt zwei Fälle von Diabetes an, welche von Veränderungen im Pankreas begleitet waren. In dem einen Falle wies die Drüse ein vergrössertes Gewicht auf und war stark cirrbotisch. Ductus pancreaticus erweitert, bildet stellenweise mit kleinen Steinchen angefüllte Vorstülpungen. In dem anderen ist das Pankreas atrophiert, weich, wiegt zweimal so wenig als in der Norm, ist stellenweise fettig degeneriert.

Thiroloix sah einen Fall, wo Epitheliom des Caput des Pankreas, Obliteration des Ductus Wirsungianus, Cirrhose und Atrophie des übrigen Teiles der Drüse rorhanden waren.

In einem von Freyhan beobachteten Falle war Lithiasis des Pankreas vorhanden, durch die eine in fettiger Degeneration zum Ausdruck gelangte Atrophie des genannten Organes hervorgerufen worden war. In einem andern Falle wurde an der Stelle des Pankreas ein Körper gefunden, welcher an Grösse und Form demselben gleichkam, aber fast ausschliesslich aus Fettgewebe bestand; ausserdem sassen im Schwanzteile des Ausführungsganges Steinchen (kohlensaurer Kalk und Cholesterin).

Fleiner beschrieb 2 Fälle, in denen Lithiasis pancreatica mit nachfolgender Atrophie des Pankreas bestand.

Lich theim teilte einen Fall von durch Lithiasis pancreatica bedingter Pankreascirrhose mit.

Williamson untersuchte das Pankreas in 15 Fällen von Diabetes mellitus: in 7 war das Pankreas normal, in zwei atrophiert, in zwei war die Atrophie von fettiger Degeneration begleitet, in zwei war eine mehr oder weniger begrenzte Cirrhose, und in einem eine äusserst verbreitete Cirrhose mit Bildung von Verlötungen vorhanden; (über den 15. Fall ist nichts gesagt). In einem von den 15 Fällen wurdo eine Hirngeschwulst gefunden.

Jarussow beschreibt 4 Fälle von Diabetes. Nur in einem derselben bestand makroskopisch eine stark ausgeprägte Atrophie des Pankreas. Die mikroskopische 
Untersuchung des Pankreas zeigte aber in allen vier Fällen eine fettige Degeneration der Zellelemente und eine vornehmlich um die Drüsengänge herum lokalisierte Bindegewebswucherung.

Bei der Durchsicht dieser Arbeiten sehen wir, dass ihrer im Grunde genommen nicht allzu viele sind, und dass unter den vorhandenen bei weitem nicht allen eine wesentliche Bedeutung für die eine oder andere Lösung der hier berührten Frage zukommt. Einige von ihnen sind auf ungenügend untersuchtes Material gegründet, andere betrachten die uns interessierende Frage nur beiläufig. Und nur einige berühren sie unmittelbar, und mehr oder weniger vollständig. Ausserdem ziehen nicht alle auch die mikroskopischen Veränderungen mit in Betracht. Es ist natürlich, dass solche Arbeiten (ohne mikroskopische Untersuchungen) kaum eine besondere Bedeutung beanspruchen können. Ferner zeigten sich in allen citierten Diabetesfällen die Veränderungen des Pankreas nicht als einziger postmortaler Befund; gewöhnlich waren sie neben Veränderungen anderer Organe vorhanden, denen jedoch von den Autoren gar keine Bedeutung für die Entwicklung des Diabetes zugeschrieben wurde. Nichtsdestoweniger erwähnen wir von diesen Veränderungen anderer Organe die des Plexus coeliacus, weil in denjenigen Fällen, wo ihnen Beachtung geschenkt wurde, ausser dem Pankreas auch diese sich als verändert erwies. Als Beleg für das Obengesagte mögen folgende Fälle dienen:

1. Munk: Atrophio des Pankreas; Atrophie des Plexus coeliacus.

2. Seegen: Diabetes mit Abmagerung; Plexus coeliacus klein, schlaff, von deutlich grauer Farbe.

3. Jaccoud: Bronzefärbung und Glykosurie; Magenkrebs; die benachbarten Nerven durch die peripankreatischen Ganglien zusammengepresst; Pankreas normal.

4. Bouisson: Nn. vagi von den Mediastinalganglien umgeben; Pankreas von normalem Umfang, Lithiasis.

5. Richer: Magenkrebs und Glykosurie; Pankreas hart, vergrössert, Plexus solaris von gangliösen umfangreichen festen Massen umgeben.

6. Lancereaux: Die Ganglien des Plexus coeliacus von fester Consistenz und vergrössertem Umfang.

7. Recklinghausen: Plexus solaris von fester Consistenz und weisser Farbe.

8. Auscher: Pankreas normal; Hypertrophie des Plexus solaris.

9. Besançon constatierte in einem Falle von Pankreasdiabetes eine ungeheure Hypertrophie der Semilunarganglien mit gleichzeitiger Atrophie des Pankreas.

10. Cavazzani sah einen Fall von Diabetes mit normalem Pankreas, wo aber starke Veränderungen des Sympathicus vorhanden waren.

11. Hale-White fand in vier Fällen von Diabetes tiefgreifende Veränderungen im Sympathicus mit gleichzeitiger Veränderung des Ganglion semilunare.

12. Poniclo fand auch eine starke Atrophie des sympathischen Nerven in 5 Diabetesfällen.

Die bisher angeführten Fälle sprechen für den vermutlichen Zusammenhang zwischen den Erkrankungen des Pankreas, als dem ursächlichen Moment, und dem Auftreten des Diabetes, als einer sichtbaren Folge einer solchen Erkrankung.

Doch sind in der Literatur auch Fälle von Diabetes mitgeteilt, die in ihrem Verlaufe das zuerst von Lancereaux geschilderte klinische 
Bild des Pankreasdiabetes aufwiesen, und wo nichtsdestoweniger Veränderungen im Pankreas bei der Sektion fehlten.

Hierher gehören die von den folgenden Autoren beschriebenen Fälle: 1. Mollard, 2. Ascher, 3. Lépine, 4. Carazzani, 5. Jaccoud.

Aus der Durchsicht der oben angeführten pathologisch-anatomischen Daten geht hervor, dass von den im Pankreas vorgefundenen Veränderungen die atrophischen am häufigsten vorkommen. Es wurden solche Veränderungen unter den 109 angeführten Sektionen 73 mal beobachtet $(66,9 \mathrm{pCt}$.). Sodann folgt die fettige Degeneration mit $13 \mathrm{mal}$ (11,9 pCt.), ferner: Steine (Lithiasis) $12 \mathrm{mal} \mathrm{(11} \mathrm{pCt.),} \mathrm{Krebs} 7 \mathrm{mal}$ $(6,4$ pCt.), Cysten 2 mal (1,8 pCt.), Abscess und Nekrose des Pankreas je $1 \mathrm{mal}(0,9 \mathrm{pCt}$.).

Was nun die Veränderungen des Nervensystems beim Diabetes betrifft, so finden wir die ersten Hinweise hierüber bei Steinthal, der eine sehr kurzgefasste Beobachtung über diesen Gegenstand in der Deutscher. Klinik 1858 veröffentlicht hat. Etwas vollständiger und ausführlicher ist eine Untersuchung des französischen Gelehrten Maréchal do Calvi, welcher im Jahre 1864 bereits die Möglichkeit hatte, eine diese Frage behandelnde Monographie zu veröffentlichen. Im Jahre 1873 erschien eine umfangreiche französisobe Arbeit über die Veränderangen des Nervensystems beim Diabotes. Der Aator derselben, Christi de Buoli, bringt in seinen Untersuchungen sebr viel Neues für seine Zeit, und das in seinen Händen befindliohe Material bearbeitet or mit viel grösserom Verständnis and viel umfassender als seine Vorgänger. Diese ersten, die Nervenerkrankungen bei der Zuckerkrankheit behandelnden Arbeiten haben gegenwärtig nur ein historiscbes Interesse. Nichtsdestoweniger ist das Verdienst dieser Autoren gross, denn sie haben die Aufmerksamkeit der Gelehrten auf eine gauz neue detiologie der Nervenerkrankungen, welche bis dahin völlig unbekannt war, gelenkt. Mit ihrer persönlichen Arbeit und ibren Kenntnissen haben sie nur die ersten Schritte für den Aufban der zakünftigen Lehre getan, aber mit dem Fortschritt der klinischen Untersuchungsmethoden, mit der Erweiterung des medizinischen Gesichtskreises und dank dem ungeheuren Fortschritt in der Erforschung der Nervenkrankheiten - wurden die ron ibnen gelegten Grundlagen sebr bald weiter ausgebaut. Es entstanden neue präcisere Arbeiten; einzelne Versuche, die schon bekannten Talsachen zu systematisieren, wurden gemacht und eine rationelle und zugleich völlig neue Gruppierung des Materials vorgenommen. Allmählich stellte sich heraus, dass beim Diabetes nicht nur die Ganglien und Verzwoigungen des sympathischen Nerven Veränderungen ausgesetzt sind, sondern anch das Centralnervensystem - Gehirn und Rückenmark - und seine peripheren Abschnitte. Ferner hat sich bei sorgfältiger klinischer Beobachtung der Diabetiker ergeben, dass sogar die höheren psychischen Centren bei dieser Erkrankungsform in Mitleidenschaft gezogen werden können. So wurde hauptsächlich durch die Arbeiten der französischen Autoren (Legrand du Saulle; Marie, Fassy) beim Diabetes Veränderung des Charakters vermerkt. Zuweilen entwickeln sich bei Kranken dieser Art Geiz, Hochmut, Ehrgeiz, Egoismus und andere moralische Schwächen. In den späteren und böchsten Stadien des Diabetes haben Legrand du Saulle und gleichzeitig Landenheimer, FéréBernard, Lecorché und andere Veränderung der Gemütsverfassung, Apathie, Verfall der geistigen Frische, lirteilsschwäche und Verlust des Gedächtnisses vermerkt. Aehnliche Symptome veranlassten die Autoren (Holstein, Sekeyan, Bond and andere) zu behaupten, dass der Diabetes sogar zur Entwicklung von echten psychischen Erkrankungen führen könne. Wirklich bestätigen einzelne klinische Beobachtungen diese Voraussetzung. So beobacbtete Binswanger aknte Verwirrtheit beim Diabetes nach Amputation eines gangrünösen Fusses, die im weiteren Verlauf in Schwachsinn 
ï'oerging. Landenheimer, der diese Frage sorgfältig bearbeitet hat, unterscheidet akute und chronische psychische Störungen beim Diabetes. Die ersteren kommen sehr bäufig vor. Zu den akuten psychischen Leiden bei der Zuckerkrankheit rechnet er das Coma diabeticum, sowie sein Aequivalent, welches in akater psychischer Erregung zum Ausdruck gelangt und gewöhnlich in den letzten Perioden der Krankheit auftritt. Viel seltener werden nach der Meinung dieses Autors beim Diabetes chronische Erkrankungsformen beobachtet. Charpantier, der bekannte Pariser Psychiater (in der Salpetrière), der sich ganz besonders für die Frage von den Veränderungen der Psyche beim Diabetes interessiert hat, erklärt nachdrücklich, dass die Zuckerkrankheit sogar eine Dementia paralytica verursachen kann. Diese Bebauptung ist um so wertvoller, als eine ganze Reihe andrer Autoren, von denen wir Schülo, Maréchal de Calvi, Frerichs, Sommer, Landenbeimer erwähnen, die Entwicklung einer typischen progressiven Paralyse (Dementia paralytica) während der Zuckerkrankbeit beobachtet haben. Die Symptome dieser Geisteskrankheit verschwanden jedoch bald nach Verordnung einer antidiabetischen Kur. Infolgedessen schlägt Landenheimer vor, eine solche psychische Erkrankungsform Pseudoparalysis diabetica zu nennen.

Viel bäufiger als psychische Leiden wurden Affektionen einzelner Hirncentren beobachtet. Maréchal de Calvi, Lépine et Blanc, Drouineau, Corneille, $\mathrm{Nauny} n$ und viele andere, welche sicb für diese Frage interessierten und die Möglichkeit hatten, ihre Beobachtungen pathologisch-anatomisch zu prüfen, constatierten beim Diabetes eine Affektion sowohl der Hirnrinde, als auch der tiefgelegenen Teile des Centrum Vieussenii, Klinisch kamen diese Affektionen verschieden zum Ausdruck. In einigen Fällen waren sie von dauernder Erregung des Centralnervensystems begleitet und äusserten sich als Zittern der Extremitäten, Zucken derselben, Krämpfe, Zuckungen und sogar als echte Anfälle von Convulsionen mit Verlust des Bewusstseins und den übrigen für die Epilepsie charakteristischen Erscheinungen. Jacoby machte mehrere solcher Beobachtungen an Diabstikern, bei welchen anfangs leichte Zuckungen bemerkt wurden, die im weiteren Verlauf in Convulsionen mit Bewusstseinsverluşt und den übrigen für die Epilepsie typischen Kennzeichen übergingen. In einem seiner Fälle, wo keine antidiabetische Behandlung angewandt wurde, gingen die Krampfanfälle in dauernde Schlafsucht über, die mit dem Tode endete. In einem anderen verschwanden die schweren Anfälle mit der Verordnung der antidiabetischen Behandlung, während das petit mal weiter bestand. In einem dritten Falle erholte sich sein Patient, der schon früher an Diabetes gelitten hatte und nun an Epilepsie erkrankt war, seit der Verordnung der antidiabetischen Therapie: der Zucker verschwand aus dem Harne, das Körpergewicht und seine Kräfte nabmen zu, gleichzeitig verschwanden auch die Krämpfe und die anderen Erscheinungen der Hirnreizung. Bekannter jedoch sind diejenigen Hirnaffektionen bei Diabetes, die nicht von Reizung bestimmter Centren, sondern von dem Verlust ibrer Funktion oder von einer Abschwächung der letzteren begleitet sind. Klinisch gelangt dieses in $\mathrm{Ab}$ hängigkeit von der Lokalisation des betroffenen Centrums in Hemiplegie, Monoplegien, $\Lambda$ phasie usw. zum Ausdruck. Hemiplegien werden bei den an der Zuckerkrankheit Leidenden von vielen Autoren vermerkt, zu denen Maréchal de Calvi, Corneille, Drouineau, Naunyn, Marinesco u. a. gehören. Als eine sehr typische Form der Hemiplegie beim Diabetes gilt die Hemiplegia alternans, die eine besonders sorgfältige Untersuchung durch Bernard-Féré erfahren haben. Angeregt durch Charcot, haben diese Gelehrten diese Form der Affektion der Hirnnervencentren beim Diabetes sehr ausführlich beschrieben, und ihre Untersuchungen sind durch die Arbeiten ihres Landsmannes $0 \mathrm{gle}$ in vollem Umfange bestätigt worden.

Etwas später als die Hirnleiden wurden die organischen Affektionen des Rückenmarks und der peripheren Nerven vermerkt. Ueber die Lejden dieser Bezirke, welche ein grosses praktisches Interesse darbieten und eingehender behandelt zu werden verdienen, ist jedoch nur eine überaus spärliche Literatur vorhanden. 
Was die Affektionen des Rückenmarks betrift, so ist sowohl ihre Symptomatologie, als auch die Verteilung der organischen Veränderungen in demselben überhaupt sehr unbestimmt und sebr wenig erforscbt. Aus den Beobachtungen, die weiter unten citiert werden, ist jedoch ersichtlich, dass in den bisher veröffentlichten Fällen die Degeneration selten ein einzelnes gesondertes Funktionssystem erfasst, sondern meistenteils sind mebrere derselben gleichzeitig betroffen. Der grösseren Gienauigkeit halber führen wir hier in extenso die ganze in der Literatur vorhandene Casuistik der organischen Affektionen des Rückenmarks an.

Nonne hat eine Patientin von 64 Jabren beschrieben, welche während der letzten vier Lebensjahre an dor Zuckerkrankbeit gelitten hatte. Im zweiten Jabre dieser Krankheit entwickelten sich bei ihr Parese und absteigende Muskelatrophie in beiden oberen Extremitäten obne irgend welche Schmerzen und Parästhesien. Bei der objektiven Untersuchung wurde die Sensibilität normal befunden; hingegen zeigten die Nerven der betreffenden Extremitäten eine partielle Degenerationsreaktion. Sehnenund Periostreflexe derselben Körperteile leicht geschwächt, Nervenstämme unempfindlich gegen Compression; Muskelkraft stark herabgesetzt; bei passiven Bewegungen erwiesen sich die betroffenen Extremitäten als vollkommen schlaff. Nach oinem halben Jahre wurden beide unteren Extremitäten von einer analogen Affektion betroffen mit Wiederbolung des analogen Bildes: Entwicklung von Muskelatrophie mit partieller Degenerationsreaktion, Verlust der (Knie-) Sehnenreflexe, ohne Rigidität der passiven Bewegungen und ohne Sensibilitätsstörungen. Bei der mikroskopischen lntersuchung wurde im Rückenmark eine starke Verminderung der Zellen in den Vorderbörnern des Halsabschnittes vorgefunden; unter den erbalten gebliebenen Zellen war nicht eine einzige normale. Das Myelinfasernetz der grauen Substanz war sehr viel spärlicher geworden; die Vorderbörner waren stark degeneriert. Der gleiche Krankheitsprozess wurde auch in den Vorderbörnern des Brust- und Lendenabschnitts des Rückenmarks gefunden, allerdings war derselbe hier schwächer ausgeprägt; hier und da konnte man eine normale Zelle mit sichtbarem Kern antreffen; die Vorderbörner der Brust- und Lendensegmente enthielten nur eine unbedeutende Anzahl normaler Myelinfasern. Degeneriert waren ausserdem die Seiten- und Vorderstränge; die Fasern derselben waren deutlich, obschon nicht sehr intensiv rarefiziert; die Neuroglia erschien leicht verdichtet und verdiokt. Diesen letzteren Prozess spricht der Autor als primäre einfache Atrophie der Myelinfasern an, und sieht in der Verdickung der Neuroglia eine sekundäre Erscheinung. Die Hinterbörner waren in der ganzen Ausdebnung des Rückenmarks normal; die Rückenmarksgefässe waren nicht verändert. Die peripheren Nerven zeigten eine deutlich ausgeprägte Atrophie der Myelinfasern. Die von den betroffenen Nerven innervierten Muskeln waren gleicbfalls atrophiert. Der Autor qualifiziert seinen Fall als Poliomyelitis anterior und liefert den Nachweis, dass der Diabetes eine isolierte Affektion der Vorderbörner nach sich ziehen kann. Er gründet seine Diagnose bauptsächlich erstens auf das klinische Bild, zweitens auf die durch die pathologischanatomische Untersuchung erhaltenen Daten, d. b. die erwähnten, stark ausgeprägten Veränderungen der Zellelemente. Diese Beobachtung von Nonne, welche eine ausschliessliche Affektion der Vorderhörner vermerkt, steht in der Literatur ganz vereinzelt da. Etwas häufiger sind die in den Hinterbörnern lokalisierten Veränderungen vermerkt. Kalmus beschrieb zwei Diabetiker, nach deren Tode er die Möglichkeit hatte, das Rückenmark zu untersuchen. In dem einen Falle, wo das klinische Bild nur sehr kurz gefasst ist, hatte der Kranke eine antisyphilitische Behandlung durchgemacht, und während seines Aufentbaltes zur Behandlung der '/uckerkrankheit im Krankenhause deutliche Anzeichen von Mercurialismus aufgewiesen. Dio mikroskopische Untersuchung stellte in diesem Falle eine scharf ausgeprägte Veränderung der Burdacb schen und Gollschen Stränge in der Intumescentia cervicalis des Rückenmarks fest, welche sich als besonders stark betroffen erwiesen. Ihre Nerrenfasern waren ganz verschwuaden, während die bindegewebige Stützsubstanz ein vollkommen normales 
Aussehen zeigte. Die Entartung der Fasern der Hinterhörner nahm in der Richtung nach oben und unten schnell ab, so dass im verlängerten Mark und in den Brustsegmenten des Rückenmarks gar keine Abweichungen von der Norm zu bemerken waren. Anlässlich dieser Beobachtung ron Kalmus muss bemerkt werden, dass die von ihm beschriebenen Veränderungen schwerlich ausschliesslich für den Diabetes typisch sind. Die im gegebenen Falle höchst verwickelte Aetiologie - Syphilis, Mercurialismus und Diabetes - gestattet es nicht, die im Rückenmark rorgefundenen Veränderungen ausschliesslich der Zuckerkrankheit zuzuschreiben. Der zweite Fall desselben Autors ist, was die klinische Seite anbetrifft, ebenso dunkel, vom ätiologischen Standpunkt aus jedoch einwandfreier; ausser Diabetes war in demselben keine einzige andere vorausgegangene schwächende Krankheit $2 u$ finden; leider ist das Rückenmark dieses Patienten nicht mikroskopisch untersucht worden; bei der Besichtigung mit blossem $\Lambda$ uge wurden aber nur in den Burdach schen Strängen Veränderungen vermerkt. Hensay untersuchte das Rückenmark von sieben Diabetikern, die sich in der Strassburger Klinik unter Nanny n Beobachtung befunden hatten, und fand in zwei Fällen Veränderungen. In einem derselben bestand eine schwache Degeneration einer geringen Anzahl von Fasern des oberen T'eiles des Halsmarks in den den Hinterhörnern des XI. Nerven anliegenden Bündeln. Die Wurzeln dieses Nerven selbst erwiesen sich als unverändert. Auf dem Boden des 4. Ventrikels, nahe vom Kern des X. Hirnnerven, fand sich ein unbedeutender Bluterguss. Ausserdem waren die kleineren Hirngefässe hyperämisch obne Veränderungen ihrer Wände und obne Degeneration des sie umgebenden Nervengewebes. Im zweiten Falle umfasste die Degeneration zwei nmschriebene Stellen in den Hintersträngen mit vollkommen symmetrischer Anordnung auf der Grenze 2 wischen den Goll schen und Burdachschen Străngen; die vorderen Teile dieser degenerierten Bezirke gingen ineinander über, indem sie sich in einem stumpfen Winkel hinter der hinteren Commissur begegneten; die hinteren Abschnitte dieser dreieckigen Figur, in deren Umrissen der entartete Faserbereich in die Erscheinung trat, reichten nicht bis an den Rand des Rückenmarks; diese Veränderung der Hinterstränge erstreckte sich nach oben und nach unten in der ganzen Ausdehnung des Rückenmarcks rom Hals- bis zum Lendenabschnitt. Eine sehr merkwïrdige Erscheinung boten die Hinterwarzeln des Lendenmarks dar. Auf dem Querschnitt wies nur der centrale Teil der Wurzel Myelinfasern auf, die sich noch nach Weigert und Pal färbten; die Randpartien aber waren vollständig degeneriert. Die erhalten gebliebenen Myelinfasern aus dem centralen Teile der Wurzel waren jedoch nicht völlig normal. Ihre Myelinhülle färbte sich in den peripheren Schichten nach Weigert, wäbrend die dem Achsencylinder anliegenden Teile entweder farblos oder trübe erschienen. Recklinghausen, der diese Präparate gesehen bat, hielt diese Veränderungen der Wurzeln für Artefakte.

Sandmeyer untersuchte einen Fall von Diabetes und fand, nachdem er das Rückenmark nach Marchi bearbeitet hatte, überall eine Degeneration der Gollschen Stränge im Anfangsstadium. Die angeführten Beobachtungen der drei letzten Autoren vermerken Veränderungen bauptsächlich in den Hintersträngen des Rückenmarks. Wie schon erwähnt, sind auch combinierte Rückenmarksleiden beim Diabetes besohrieben worden, wo ausser der Veränderung in den hinteren Bahnen gleichzeitig auch die Vorderhörner der grauen Substanz betroffen waren. Gewöhnlich erweist sich hierbei auch das periphere Neuron als in Mitleidenschaft gezogen. Eine sehr interessante Ausnabme bildet in dieser Beziebung die Beobachtung von Williamson, in dessen Falle dieser Abschnitt des Nervensystems keinerlei besondere Veränderungen aufwies. Die Untersuchung Williamsons betrifft einen 52 jährigen Diabetiker mit Arteriosklerose und Atrophie der Muskeln des Schultergürtels und des Oterarms; seine Sensibilität war normal geblieben, die Kniereflexe fehlten eine Zeit lang, stellten sich aber nach kurzdauerndem Ausbleiben wieder ein. Nach dem Tode fand man bei diesem Patienten Degeneration der Hinterstränge in den Hals- und Brustsegmenten 
des Rückenmarks. Die Achsencylinder von zahlreichen Fasern waren stark angeschwollen. Die Neuroglia ist nur im Halsabschnitt leicht vermehrt. Die Zellen der Vorderhörner sind in dem unteron Brnstabschnitt des Rüokenmarks leicht atrophiert. Hingegen erwiesen sich die an den atrophierten M. biceps berantretenden Nerven als unverändert.

Im zweiten Falle desselben Autors, und zwar bei einem sehr schweren Diabetes, der sebr bald mit dem Tode im Krankenhause endete, fehlten die Patellarreflexe zur Zeit der Beobachtung. Die Veränderungen im Rückenmark waren bier dieselben, wie in seinem vorstehend aufgefübrten Falle, und erstreckten sich bis zum Lendenabschnitt des Rückenmarks. Der N. cruralis wies keine Veränderung auf.

Sehr lehrreich ist die Bescbreibung eines Diabetesfalles, die Leichtentritt gibt. Bei seiner Patientin, einer Frau von 60 Jahren, mit stark ausgeprägter Arteriosklerose wurde inı letzten Lebensjahre Zuckerkrankheit festgestellt und zugleicb eine Reibe von Sensibilitätsstörungen, sowie der Verlust der Kniereflexe gefunden, was gestattete, die Diagnose Pseudotabes diabetica zu stellen. Kurz vor dem Tode entwickelten sich bei der Kranken Muskelatrophie and totalo Paralyse der Extremitäten, begleitet von Schmerzen und Parästhesien. Ausserdem traten Affektionen der Augen, der Haut auf, und endlich stellte sich Gangraena spontanea ein. Post mortem tand der Autor im gegebenen Falle bei der mikroskopischen Untersuchung des Rückenmarks eine Degeneration der Gollschen und Burdachschen Stränge im ganzen Rückenmark (den Sakralabschnitt ausgenommen). Die Hinterhörner erwiesen sich als normal. Die Zabl der Zellen der Vorder- und Hinterhörner war nicht verringert, aber ibr Protoplasma war sebr körnig und der Kern nicht überall gut zo seben. Ihre Fortsätze waren stumpf geworden und stellenweise wi abgebrochen. In den Hintersträngen wurden reichlich spinnenartige Zellen und amyloide Körperchen gefunden. Die peripheren Nerven, besonders der N. cruralis und N. peroneus waren im gegebenen Falle ebenfalls stark verändert. Die Wände ibrer Vasa nervorum waren stark rerdickt, ibr Lumen war an einigen Stellen verengert, an anderen erweitert. Die Gesamtmasse des Epineuriums ist vergrössert; ihre Fasern verdickt; im Gewebe des Epineuriums werden stellenweise Blutergüsse angetroffen. Das Perineurium ist reichlich mit Kernen infiltriert. Verdickt sind auch die Fasern des Endoneuriums; seine Capillargefässe sind hyperämisch. Das Myelin der einzelnen Nerrenfasern ist in starkem Zerfall begriffen. Der Autor hält die beschriebenen Veränderungen für hämorrhagische Neuritis diabetischen Ursprungs. Es ist jedoch sehr schwer, dieselben dem Finfluss des Diabetes allein zuzuschreiben. Die Vergrösserung der bindegewebigen Stützsubstanz in Nerven, die Verdickung seiner Scheide und die typischen Gefässveränderungen (auch die Blutergüsse mit eingeschlossen) entsprechen demjenigen Zustande der Nerven, der sich in den letzteren bei chronischer Arteriosklerose entwickelt. Souques und Marinesco vermuten in dem von ihnen untersuchten Rückenmark einer an diabetischem Marasmus gestorbenen Frau, deren klinisches Krankheitsbild leider nicht angeführt ist, ebenfalls eine gewisse Atrophie der Vorderhornzellen des Halsmarks. Ausserdem fanden sie eine im höchsten Grade zarte Veränderung der beiden Hinterhörner im Lenden- und Brustabschnitt. Diese Veränderung konnte man nur auf Grund der blassen Färbung nach Pal feststellen, während Gefässe und Neuroglia keinerlei Degenerationszeichen aufwiesen. Die Autoren finden eine grosse $\Lambda$ ebnlichkeit zwischen der bescbriebenen Veränderung der Hinterstränge und derjenigen, welche bei der absteigonden Degeneration der letzteren nach der Durcbschneidung der Hinterwurzeln der höher gelegenen Segmente beobachtet wird. Bonardi (die Originalarbeit dieses Autors ist uns nicht zugänglich gewesen) beobachtete einen Fall von Diabetes, in dem sich beim Patienten Muskelatrophio der Extremitäten entwickelte, die Sehnenreflexo schwanden und eine Keihe von Symptomen sich zeigte, die dem Autor gestattete, in der Erkrankung das Bild der Pseudotabes diabetica zn erkennen. Post morten wurde bei der Untersuchung des Rückenmarks unterm Mikroskop in diesem Falle Degeneration der Vorder-Seiten- 
stränge gefunden; die Zellen der Vorderhörner der grauen Substanz waren nach Zahl und Dimensionen vermindert und wiesen die ersten Zeichen des Zerfalls auf. Die peripheren Nerven der Extremitäten waren von Neuritis betroffen; die von den de. generierten Nerven innervierten Muskeln boten das typische Bild der Degeneration dar. Im Falle von Bouardi wiesen also die organischen Veränderungen der peripheren Nerven in Gestalt von degenerativer Neuritis viel klarere Symptome auf als die organischen Affektionen des Rückenmarks. Nach den Untersuchangen von Pryce, Ziemssen, Charcot, Auscher, Gregoire, Williamson, Althaus, Buzard, Naunyn, Bach, Vanderlinden und anderen Autoren äussert sich dieses Leiden in dauernden und lanzinierenden Schmerzen, Beeinträchtigung der motorischen Funktion, Herabminderung oder Verlust der Sensibilität, der Reflexe, in der Degenerationsreaction, in Muskelatrophie und trophischer Veränderung des Integuments (Glanzhaut oder mal perforant du pied). Diese Affektionen sind überaus verschieden lokalisiert. Gegenwärtig sind Neuritiden des N. facialis (Gregoire, Nannyn), die dazu noch bisweilen bilateral auftreten (Gregoire), des N. vagus (Eichborst), des N. axillaris (Althaus), des $N$. cruralis (Bruns, Eichborst, Leichtentritt), des N. peroneus (Bruns, Leichtentritt), des N. opticus (Fraser und Bruce), des N. obturatorius (Bruns), des N. tibialis (Pryce) beschrieben. Ausser den aufgezählten sind jedoch wahrscheinlich auch alle übrigen Nervenstämme nicht gegen diese Erkrankung geschützt und können gleichfalls beim Diabetes betroffen werden.

Pryce kommt das Verdienst zu, als einer der ersten pathologisch-anatomische Veränderungen der Nerven beim Diabetes festgestellt zu haben. Er hat mehrere Beobachtungen veröffentlicht. In seinem ersten Falle handelt es sich um einen 56 jährigen Syphilitiker und Alkoholiker mit scharf ausgeprägter Arteriosklerose, bei welchem sich, nach den pathologisch-anatomischen Daten zu urteilen, in den letzten anderthalb Lebensjabren Diabetes entwickelt hat. Von Nervenstörungen wurden beim Patienten herabgesetzte Sensibilität, Verlust der Knie- und Schwächung der Pupillenreflexe vermerkt. Bei der postmortalen Untersuchung des Nervensystems des Patienten erwiesen sich die peripheren Nerven als sehr verdickt (N. tibialis) und von entzündlichem Gowebe umgeben. Die Myelinscheideu der einzelnen Fasern waren granulös und färbten sich mit Osmiumsäure nicht. Die Achsencylinder waren zum grössten Teil atrophiert. Das interstitielle bindegewebige Stützgerüst des Nerven war etwas hyperplastisch. In der Lendenanschwellung des Rückenmarks waren die Zellen der Vorderhörner gleichfalls affiziert. Ein grosser Teil derselben war verschwunden, andere granulös atrophiert; bei vielen von ihnen waren die Fortsätze ahgebrochen. In der grauen oder weissen Substanz wurde keinerlei Infiltration bemerkt. In einer anderen Beobachtung von Pryce wiesen die Störungen des Nervensystems bei einem Diabetiker bei dessen Lebzeiten alle Anzeichen der Neurotabes diabetica auf, und wirklich wurde nach dem Tode in diesem Falle eine typische periphere Neuritis gefunden.

Auché beschrieb mehrere Kranke, an welchen die pathologisch-anatomische Untersuchung vorgenommen werden konnte.

1. Eine Frau von 74 Jahren mit scharf ausgeprägter Arteriosklerose leidet schon mehr als 10 Jahre an erhöbtem Durstgefühl. Während der letzten Lebensjahre klagt sie ausserdem über lanzinierende Schmerzen und Jucken in den Extremitäten; kurz vor dem Tode traten bei ihr am Fusse Geschwüre und an der 4. Zehe Gangraena spontanea auf. Schmerzempfindlichkeit und thermische Sensibilität unverändert, dagegen ist die willkürliobe Beweglichkeit sebr herabgesetzt. Bei der postmortalen mikroskopischen Untersuchung wurde die Mehrzahl der Myelinfasern in den Nervenstämmen vollkommen normal befunden. Ihr Myelin färbte sich ganz regelrecht und hatte seire natürliche Form bewahrt. Hingegen wiesen die Myelinscheiden einer geringen Zahl von Fasern ungleichmässige Ränder mit Zacken auf und zerfielen in Segmente, Schollen und Kugeln. Stellenweise hatten einzelne Fasern ihr Myelin und 
ihren Achsencylinder eingebüsst und sich nur in Gestalt einer leeren Schwannschen Scheide erbalten, die an den Stellen, wo die angeschwollenen Schwannschen Kerne und die Myelintropfen lagen, verdickt war. Das Rückenmark wurde nicht untersucht; irgend welche andere ätiologische Momente ausser Diabetes und Arteriosklerose liessen sich nicht vermuten.

II. Bei einem 50jährigen Manne, der während der letzten 6 Jahre an erhöhtem Durstgefühl gelitten hatte und an diabetischem Coma gestorben war, erwiesen sich folgende Veränderungen in den peripheren Nerven: vollkommen gesunde Fasern waren nicht zu sehen; ibre Myelinscheide erwies sich als sehr verändert; stellenweise befand sie sich im Zustande völligen Zerfalls, während der Achsencylinder intakt geblieben war. Ueber den Zustand des Gefässsystems erwähnt der Autor kein Wort.

III. In seiner dritten Beobachtung beschreibt A uché einen 19 jährigen Jüngling, bei welchem sich die ersten Anzeichen des Diabetes drei Monate vor dem Tode oinstellten. Bei der Untersuchang des Patienten im Krankenhause wurde die willkürliche Beweglichkeit bei ihm überall normal befunden; die Schmerzempfindlichkeit (gegen Stiche) erwies sich auf der Dorsalseite des Unterarms als herabgesetzt; die Kniereflexe fehlten gänzlich. Die Antopsie ergab bei der makroskopischen Besichtigung normale Gefässe. Bei der mikroskopischen Untersuchung färbten sich die markhaltigen Nervenfasern gut mit Osmiumsäure, zeigten aber äusserst unregelmässige zerrissene Umrisse ; stellonweise waren tiefgreifende Substanzverluste vorhanden, welche bis zum Achsencylinder reichten. Daneben fanden sich sebr viel leere $S \mathrm{chwannsch \theta}$ Scheiden, innerhalb welcher verdickte und vermehrte Kerne sichtbar waren. Im allgemeinen entspricht das Bild der Nervenaffektion dem der parenchymatösen Neuritis. Der Autor behauptet, dass der Patient keine Syphilis gehabt bat und dass die Blutgefässe vollständig normal befunden worden waren.

Dreschfeld fand bei der Untersuchung des Nervensystems eines Diabetikers in den peripheren Nerven, besonders im N. ischiadicus eine Kernveränderung in seiner Scheide, eine Wucherung des interstitiellen Bindegewebes, Myelinzerfall und Schwund der Acbsencylinder.

Fraser und Bruce machten eine sehr interessante Beobachtung, welche zum Teil auch hierzu in Beziehung steht. Ein 36jähriger Diabetiker mit centralem Skotom und Verlust des Pupillenreflexes auf Licht litt an lanzinierenden Schmerzen im Auge. Nach dem Tode wurde bei der mikroskopischen Untersuchung im N. opticus Myelinzerfall seiner Fasern constatiert. Hingegen war der Achsencylinder mebr oder weniger gut erhalten.

Eichhorst beschrieb 2 Fälle von Diabetes mit Affektion des Nervensystems, die einen letalen Ausgang hatten.

I. Eine Frau von 47 Jahren, Diabetikerin, klagt über qualvolles Gürtelgefühl. Plantar- und Achillessehnenreflex erbalten; Kniereflex gänzlich verloren gegangen. Nach dem Tode wurden bei der mikroskopischen Untersuchung Rückenmark und $N$. isohiadicus normal befunden. $N$. cruralis hingegen bot das typische Bild einer scharf ausgeprägten parenchymatösen Neuritis mit Schwellung der Kerne der Schwannschen Scheide, Vermehrung derselben und Zerfall der Myelinscheide. Epi-, Peri-, Endoneurium erwiesen sich als unverändert.

II. Ein Mädchen von 23 Jahren, mit beträchtlichem Kräfteverfall ins Krankenhaus gebracht, verfiel Tags darauf in einen tiefen komatösen Zustand und starb an diesem Tage. Im Krankenhause wurde testgestellt: normaler Pupillenreflex auf Licht, Nackensteifigkeit und Verlust der Kniereflexe. Nach dem Tode ergab die Untersuchung des Nervensystems unterm Mikroskop - bei normalem Rückenmark - parenchymatöse Neuritis im N. ischiadicus und N. cruralis vom gleichen Cbarakter wie im ersten Falle.

Sehr gut erforscht ist auch eine andere Krankheitsform des peripheren Nervensystems, die von den Autoren zur Kategorie der funktionellen Leiden gerechnet wird. Es sind das die diabetischen Neuralgien. Dieselben sind bereits vor sehr langer Zeit 
Gegenstand von Untersuchungen gewesen, die infolge der immer wiederkehrenden Klagen der Patienten selbst vorgenommen wurden. Die Aufmerksamkeit der Autoren wurde nämlich sehr oft durch Schmerzen in verschiedenen Körperteilen erregt, die auf der Höhe des Verlaufs des Diabetes auftraten und den Patienten die furchtbarsten Qualen verursachten. Eine charakteristische Eigentümlichkeit dieser Schmerzen war das Auftreten derselben in Gestalt von anhaltenden Anfällen und dabei in symmetrischen Körperteilen. Bei der objektiven Untersuchung wiesen diese Kranken nur eine erhöhte Schmerzreaktion bei Druck auf die Nervenstämme auf. Motorische Sphäe, Sensibilität, Reflexe und elektrische Realition blieben vollständig normal. Ebenso fehlten auch trophische Störungen im betroffenen Gebiet. Griesinger, Worms, Hösslin, Ziemssen, Charcot, Bruns und Berger, die zu den ersten gebörten, welche diese Krankheitsform erforschten, haben bewiesen, dass man es hier mit einer besonderen Form von Neuralgien diabetischen Ursprungs za tun habe. Später glaubten Ziemssen, Berger und Cornillon, zum Teil auf ihre eigenen Beobachtungen, hauptsächlich aber auf in der Literatur vorgefundenes Material gestützt, sich dazu berechtigt, mehrere typische Kennzeichen für die diabetischen Neuralgien aufzustellen. Erstens tritt nach der Meinung dieser Autoren die besprochene Form von Neuralgien auf dem Höhepunkt der zugrunde liegenden Krankheit, d. h. des Diabetes, auf. Anfangs treten die Schmerzen nur des Morgens nach schlaflosen Nächten auf; im weiteren Verlauf nehmen sie bei Bewegungen zu und erreichen des Nachts ihren Höhepunkt. Zweitens treten sie in symmetrischen Körperteilen auf. Drittens ist der Verlauf dieser Neuralgien ein chronischer; die Beseitigung des Zuckers ist nicht immer von völliger Genesung begleitet, und die antidiabetische Behandlung führt nur zu einer Besserung des Zustands. Mikroskopische Untersuchungen wurden bei dieser Affektion der Nervenstämme nicht ausgeführt, aber auf Grund vieler Erwägungen werden diese erkrankten Stämme als anatomisch unverändert angesprochen, und ihre Affektion wird daher für funktionell angesehen. Ausser dieser Erkrankung, die nach der Meinung der meisten Gelehrten in den peripheren Nerven localisiert ist und von den Autoren zur Kategorie der funktionellen Affektionen gezählt wird, existiert beim Diabetes noch eine Art funktionellen Leidens, dessen Lokalisierung jedoch nicht ganz klar begründet erscheint. Bei dieser letzten Form treten auch Schmerzen auf, sie stehen aber in scharfem Gegensatz zu den soeben erwähnten peuralgischen Schmerzen. Ein solcher Patient nennt seine Schmerzen nicht ziehend, oder beständig und anhaltend, wie bei der Neuralgie, sondern lanzinierend; ihre Lokalisierung ist nicht durch Symmetrie ausgezeichnet. Ausser den Klagen über Schmerzen sind auch nocb andero Symptome vorhanden. Die Kranken weisen auf ein sie beständig quälendes Gürtel- oder Korsettgefühl hin; sie klagen über Abnahme der Potenz und Störungen der Sphinkteren. In sehr vielen Fällen geht das Gleichgewicht verloren, es tritt eine scharf ausgeprägte Ataxie bis zur völligen Unmöglichkeit im Dunkeln zu gehen u. a. m. ein.

Bei der objektiven Untersuchung solcher Patienten findet man gewöhnlich Störungen seitens der Pupillen, ungleiche Weite derselben und Feblen der Reaktion auf Licht. Dieses letzte Symptom, welches Leyden und Fischer für das Hauptmerkmal von Tabes halten, das bei Diabetes nie vorkommen soll, wurde von vier Autoren: Grube, Pryce, Fraser und Bruce bei Diabetikern dieser Kategorie unstreitig festgestellt. Die Sehnenreflexe gehen meistenteils verloren. Die Kranken weisen tiefgehende Sensibilitätsstörungen auf. Muskelgefühl, taktile Sensibilität, Schmerzempfindlichkeit und thermische Sensibilität sind herabgesetzt oder völlig verloren gegangen. Vergeli konstatierte eine scharf ansgeprägte Dissoziation der Sensibilität und eine Verlangsamung der Fortleitung bei den Kranken dieser Kategorie. In einer seiner Beobachtungen sah er Verlust der thermischen bei Erhaltensein der taktilen Sensibilität. In einem anderen Falle war die Fortleitung der Schmerzreize im Vergleich zu der der taktilen Reize um 5 Sek. verlangsamt. Die Muskelkraft war bei den Patienten dieser Gruppe in den meisten Fällen erhalten geblieben oder 
sehr unbedeutend herabgesetzt. Der beschriebene komplizierte Symptomenkomplex wurde überaus sorgfaltig von Leval-Piquescheff untersucht und bearbeitet, der teils auf Grund von der Literatur entnommenen Daten, teils auf Grund von eigenen Untersuchungen eine vollkommene Analogie der beschriebenen Erlirankung beim Diabetes mit der Tabes fand, und angesichts dessen, dass die antidiabetische Therapie gewöhnlich sehr schnell alle oder jedenfalls viele der erwähnten subjektiven oder objektiven Symptome beseitigt, den Vorschlag machte, die gegebene Erkrankung Pseudotabes diabetica zu nennen. Die gleichzeitigen und späteren Beobachtungen von Charcot, Leyden, Pryce, Kaymond, Fischer, Strümpell, Oppenheim und vielen anderen bestätigten die Untersuchungen des französischen Gelehrten, und jetzt gilt die Bezeiohnung Psendotabes diabetica in der medizinischen Terminologie als allgemein anerkannt. Bei diesem Symptomenkomplex sind weder im Rückenmark, noch in den peripheren Nerven organische Affektionen gefunden worden; diese Gebiete gelten daher bei der Psendotabes diabetica für rollkommen normal.

Aus der vorstehend angeführten Kasuistik ist ersichtlich, dass die liehre von den Erkrankungen des Nervensystems beim Diabetes zu den noch ungenügend erforschten Gebieten der Medizin gehört. Deshalb scheint uns jeder neue, die Affektionen des Nervensystems bei Diabetes betreffende casuistische Beitrag der Veröffentlichung wert.

\section{Beobachtung.}

Am 21. 6. 1912 worde der 45 jährige Bauer W. ins Alexanderkrankenhaus aufgenommen. Er klagte über starkes Hunger- und Durstgefühl, qualvolle ziehende Schmerzen in beiden Beinen, unsichern Gang und Impotenz.

Anampese. Im Februar 1908 war der Kranke von einem Dache abgestürzt und dabei auf die linke Seite gefallen. Sodann empfand er im Mai desselben Jabres während der Feldarboit nach starker Muskelanstrengung und Drehung des Rumpfos einen jähen unerträglichen Schmerz im Epigastrium, der ungefähr 24 Stunden anhielt. Späterhin sind beim Kranken in diesem Bereich niemals mehr Schmerzen aufgetreten. $\mathrm{Da}$ er sich für vollständig gesund hielt, kam or im August 1908 nach Kiew und erfüllte hier die Obliegenbeiten eines Wächters, als er plötzlich zu Anfang des November 1908 im Alter von 41 Jahren iibermässigen Hunger und Durst empfand. Diese Symptome stellten sich nach den Angaben des Kranken obne irgend welche vorhergegangenen Erscheinungen ein und erreichten ihren Höhepunkt in einigen 'T'agen; der Kranke trank 12-15 Liter und genoss 3 - 4 Pfund Brot und noch viel andere Speise. Der Ḱranke war sich seines erhöhten Essbedürfnisses um so mehr bewusst, als er in seiner Eigenschaft als Nachtwächter zur Nacht grosse Mengen von Speise und Trank mit sich nebmen musste. Allmählich fingen die Kräfte des Kranken an abzunehmen und er ermüdete leicht bei der geringsten Anstrengung. Die geschlechtliche Potenz nahm auch allmählich $a b$, und bald wurdo der Kranke, der bisher täglich den Coitus ausgeübt hatte, gänzlich impotent. Alle diese Symptome bildeten sich in kurzer Zeit, und zwar ungefäbr im Laufe eines Monats heraus und wurden stationär. Bald gesellte sich hierzu eine Herabminderung der Sehscbärfe. 18 Monate später nahm der äusserste Kräfteverlust dem Kranken die Möglichkeit, seine Arbeit weiter fortzusetzen. Um diese Zeit zeigte die vom behandelnden Arzte angestellte Harnanalyse, dass sein Harn $70 \mathrm{~g}$ Zucker auf 1 Liter bei einer Harnmenge von 8-9 Liter in 24 Stunden enthielt. Gerade zu dieser Zeit waren alle Symptome am stärksten ausgeprägt. Seit dieser Zeit persistierten die genannten Symptome, aber in gemässigterera Grade, die Polydipsie und Polyphagie batten etwas abgenommen, zugleich aber stellten sich lanzinierende und ziebende Scbmerzen und für den Patienten äusserst qualvolle Parästbesien (ein Gefühl, als bätte or Watte unter den Fusssoblen, 
Ameisenlaufen, Vertauben der Beine usw.) ein; später nahm das Gedächtnis bedeutend $a b$, es traten Unsicherheit des Ganges, Impotenz und Schwindel auf, wesbalb sich der Kranke denn auch gezwungen sab, am 21. 6. 1912 ins Krankenbaus einzutreten. Die Anamnese verzeichnet weder Syphilis, noch Alkoholismus.

Status praesens: Wuchs des Patienten - über Mittelgrösse; Körperbau - im allgemeinen normal, recht kräftig. Stellenweise sind kleine erythematöse Flecken und Pusteln vorhanden. Das subcutane Zellgewebe ist stark abgemagert; die Muskelmassen der unteren Extremitäten, besonders des Fussrückens und der Unterschenkel sind scharf ausgeprägt vermindert und dazu nicht ganz gleichmässig, so dass einige Muskeln ganz und gar geschwunden scheinen, andere hingegen nur in ihrem Umfange verkleinert oder aber völlig unverändert sind. Oedeme sind nicht vorbanden. Hauttemperatur nirgends berabgesetzt. Puls ca. 72 in der Minute, nicht verlangsamt, ziemlich roll, nicht hart und nicht arhythmisch. Alle der Untersuchung zugänglichen Gefässe sind weich, elastisch, nicht gewunden und weisen überhaupt gar keine Anzeichen von Arteriostlerose auf. Der Blutdruck in der A. brachialis nach Riva-Rocci 115. Seitens des Thorax gelangt eine leichte Dämpfung in beiden Lungenspitzen and rauhes Vesiculäratmen zur Beobachtung. Unbedeutende Hypertrophie des Herzens mit Verstärkung des zweiten Tones. Die Bauchorgane sind gesund. Die Muskelkraft der oberen Extremitäten weist keine grossen Veränderungen auf, die der unteren ist stark herabgesetzt. Die vom N. peroneus innervierten Muskeln sind auf beiden Seiten sebr paretisch. Die Bewegung der Zehen völlig paralysiert. Gang ataktisch-paretisch. Das Stehen auf einem Fusse sogar bei offenen Augen unmöglich. Die Schmerzempfindlichkeit, thermische und taktile Sensibilität in beiden unteren Extremitäten, den Geschlechtsteilen und dem unteren Bauchabschnitt stark herabgesetzt. Muskelgefühl in den Zehen und im Fuss verloren. Der Raumsinn ist in beiden Beinen in bedeutendem Massu gestört. Kopf, oberer T'eil des Rumpfes und obere Extremitäten weichen, was ibre Sensibilität anbelangt, nicht von der Norm ab. Die Reflexe auf Kitzeln des Fusses fehlen. Cremasterreflex träg. Bauch- und Schlundreflex normal. Sehnenreflexe von der Achillessehne und Kniereflexe nicht vorhanden; Reflexe von der gberen Extremität normal. Die Sphinkteren der Blase und des Dickdarms funktionieren normal. Schon 6 Monate keine Erektion vorhanden. Pupillenreflexe unverändert. Sehkraft auf beiden Augen herabgesetzt. Das rechte Auge $\mathrm{V} 20 / 30$, das linke V $20 / 40$. Katarakte nicht vorbanden.

\section{Elektrische Reaktion der Nerven und Muskeln.}

Tabelle I. Faradischer Strom.

\begin{tabular}{|c|c|c|c|c|c|c|}
\hline \multirow{2}{*}{\multicolumn{3}{|c|}{$\begin{array}{l}\text { Benennung der Nerven } \\
\text { oder Muskeln }\end{array}$}} & \multicolumn{2}{|r|}{ Rechterseits } & \multicolumn{2}{|r|}{ Linkerseits } \\
\hline & & & $\begin{array}{l}\text { Rollen- } \\
\text { abstand } \\
\text { ill cm }\end{array}$ & Wirkung & $\begin{array}{l}\text { Rollen- } \\
\text { abstand } \\
\text { in cm }\end{array}$ & Wirkung \\
\hline $\begin{array}{l}\text { N. facialis . } \\
\text { N. medianus : } \\
\text { N. ulnaris . } \\
\text { N. radialis . } \\
\text { N. cruralis. } \\
\text { N. ischiadicus } \\
\text { N. peroneus . } \\
\text { N. tibialis . } \\
\text { M. quadriceps. } \\
\text { M. tibialis antic. } \\
\text { M. tibialis postic } \\
\text { M. suralis . } \\
\text { Die klein en Fussm }\end{array}$ & $\begin{array}{l}. \\
\dot{.} \\
.\end{array}$ & 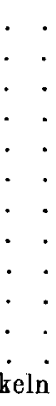 & $\begin{array}{r}1,0 \\
1,0 \\
10,8 \\
10,5 \\
8,6\end{array}$ & $\begin{array}{l}\text { momentane Zuckung } \\
\text { träge Zuckung } \\
\text { reagiert gar nicht } \\
\text { träge Zuckung } \\
\text { etwas träge Zuckung } \\
\text { träge Zuckung } \\
\text { etwas träge Zuckung } \\
\text { reagieren gar nicht }\end{array}$ & $\begin{array}{r}11,0 \\
10,5 \\
11,0 \\
10,5 \\
7,2 \\
7,5 \\
6,0\end{array}$ & $\begin{array}{l}\text { träge /uckung } \\
\text { reagiert gar nicht } \\
\text { träge Zuckung } \\
\text { träge Zuckung } \\
\text { etwas träge Zuckung } \\
\text { reagieren gar nicht }\end{array}$ \\
\hline
\end{tabular}


Tabelle II. Galvanischer Strom.

\begin{tabular}{|c|c|c|c|c|c|c|}
\hline \multirow{2}{*}{$\begin{array}{c}\text { Benennung } \\
\text { der Nerven } \\
\text { oder Muskeln }\end{array}$} & \multicolumn{3}{|c|}{ Rechterseits } & \multicolumn{3}{|c|}{ Linkerseits } \\
\hline & $\begin{array}{l}\text { Milli- } \\
\text { amp. }\end{array}$ & & Wirkung & $\begin{array}{l}\text { Milli- } \\
\text { amp. }\end{array}$ & & Wirkung \\
\hline $\begin{array}{l}\text { N. facialis . } \\
\text { N. medianus : } \\
\text { N. ulnaris . } \\
\text { N. radialis. } \\
\text { N. cruralis. } \\
\text { N. ischiadicus } \\
\text { N. peroneus . } \\
\text { N. tibialis . } \\
\text { M. quadriceps } \\
\text { M. tibialis antic. } \\
\text { M. tibialis postic. } \\
\text { M. suralis . . }\end{array}$ & $\left.\begin{array}{r}2,0 \\
2,5 \\
2,0 \\
2,0 \\
6,0 \\
\\
8,0 \\
6,0 \\
7,0 \\
9,0 \\
8,0\end{array}\right\}$ & $\begin{array}{l}\mathrm{KSC}>\mathrm{ASC} \\
\mathrm{KSC}>\mathrm{ASC} \\
\mathrm{ASC}>\mathrm{KSC} \\
\mathrm{KSC}>\mathrm{ASC} \\
\mathrm{ASC}>\mathrm{ASC}\end{array}$ & $\begin{array}{l}\text { momentane } \\
\text { Zuckung } \\
\text { träge Zuckung } \\
\text { reagiert nicht } \\
\text { träge Zuckung } \\
\text { leicht träge Zuck. } \\
\text { träge Zuckung }\end{array}$ & $\left|\begin{array}{c}2,0 \\
2,2 \\
2,5 \\
2,0 \\
6,0 \\
\\
7,0 \\
6,0 \\
7,0 \\
8,0 \\
8,0\end{array}\right|$ & $\begin{array}{l}\mathrm{KSC}>\mathrm{ASC} \\
\mathrm{KSC}>\mathrm{ASC} \\
\mathrm{ASC}>\mathrm{KSC} \\
\mathrm{KSC}>\mathrm{ASC} \\
\mathrm{ASC}>\mathrm{KSC}\end{array}$ & $\begin{array}{l}\text { momcntane } \\
\text { Zuckung } \\
\text { träge Zuckung } \\
\text { reagiert nicht } \\
\text { träge Zuckung } \\
\text { leicht träge Zuc] } \\
\text { träge Zuckung }\end{array}$ \\
\hline
\end{tabular}

Die kleinen Fussmuskeln reagieren sogar bei 20 Milliamp. beiderseits nicht.

Die Untersuchung der Psyche des Patienten ergab trübe Gemütsstimmung, beständige Reizbarkeit, Abnahme des Gedächtnisses, Schwächung der Fähigkeit, Schlüsse zu ziehen. Schlaf schlecht, mitunter schreckenerregende l'räume. Harn hell, klar, enthält kein Eiweiss, aber viel Zucker. Das Körpergewicht des Kranken, das vor der Erkrankung $80 \mathrm{~kg}$ betragen batte, ist auf $68 \mathrm{~kg}$ heruntergegangen. Subjektivo Klagen: Gürtelgefühl im Bereich des Abdomens, starkes Hunger- und Durstgefühl.

Tabelle III. Verlanf der Krankheit.

\begin{tabular}{|c|c|c|c|c|c|c|c|}
\hline Datum & $\begin{array}{l}\text { Harn- } \\
\text { menge }\end{array}$ & $\begin{array}{l}\text { Spezif. } \\
\text { Gewicht }\end{array}$ & $\begin{array}{c}\text { Zucker } \\
\text { in } 0 / 0\end{array}$ & Datum & $\begin{array}{l}\text { Harn- } \\
\text { menge }\end{array}$ & $\begin{array}{c}\text { Spezif. } \\
\text { Gewicht }\end{array}$ & $\begin{array}{c}\text { Zucker } \\
\text { in } 0 \%\end{array}$ \\
\hline 21. Juni & 2200 & & 5,4 & 4. Juli & 1800 & 1032 & 5,9 \\
\hline 22 . & 2800 & 1026 & 5,2 & $5 . \quad \pi$ & 3400 & 1032 & 5,7 \\
\hline 23. & 2900 & 1027 & 4.8 & $6 . "$ & 2200 & 1027 & 5,2 \\
\hline 24. & 3600 & 1031 & 7,8 & & 3500 & $103 \bar{j}$ & 4,4 \\
\hline & 3700 & 1025 & 5,0 & & 2500 & 1035 & 5,8 \\
\hline 27. & 600 & 1023 & 3,0 & 9 & 4300 & 1025 & 4,7 \\
\hline 28. & 3500 & 1030 & 6,2 & 10. & 5500 & 1022 & 5,3 \\
\hline 29. & 3600 & 1031 & 5.9 & 11. & 5000 & 1021 & 5,0 \\
\hline 30. & 3500 & 1032 & 6,0 & 12. & 5800 & 1025 & 5,5 \\
\hline 1. Juli & 2400 & 1042 & 7,7 & 13. & 6200 & 1027 & 5,8 \\
\hline 2. & 2400 & 1027 & 6,0 & 14. & 2500 & 1025 & 4,9 \\
\hline 3. & 2600 & 1035 & 6,6 & 15. & 1800 & 1018 & 1,7 \\
\hline
\end{tabular}

Ende Juni fing der Kranke an zu husten, es stellten sich Auswurf und Nachtschweisse ein. In den Lungenspitzen sind Rasselgeräusche hörbar. Am 2. Juli trat leichte Hämoptoë auf, die 10 Tage wäbrte. Gleichzeitig entwickelte sich das Bild einer tuberkulösen Erkrankung, es machten sich dio Anzeichen von beginnender Cavernerbildung bemerkbar. Am 16. Juli wünschte der Kranke das Krankenhaus zu verlassen; er befindet sich im Zustande äusserster Kachexie, sein Gewicbt ist auf $48 \mathrm{~kg}$ gefallen; die Kräfte sind rollständig geschwunden, so dass er keinen Schritt ohne fremde Hilfe machen kann. Am 3. September trat der Kranke wieder ins Krankenhaus ein. Bei der eingehenden Untersuchung des Nervensystems wurde Status quo ante gefunden, irgend welche progressierende oder neue, früher nicht bemerkte Störungen seitens des Nervensystems wurden nicht vermerkt. Der Kranke isst nur ein wenig Bouillon; er hat überhaupt einen Widerwillen gegen Speise. Die tuberkulösen Veränderungen in den Lungen sind bis zur Bildung von beträchtlichen Carernen vor- 
geschritten. Im Auswurf wurden Tuberkelbacillen gefunden. Harnmenge gering (2 Liter); spezifisches Gewicht 1025. Zucker ist gar nicht in ihm enthalten. Eiweiss nicht vorhanden. 25,0 g Harnstoff auf 1 Liter Harn. Temp. 37,4\%.

Der Harn wird täglich untersucht; Zucker ist nicht in ihm enthalten. Der Kranke unterscheidet sich jetzt in nichts von einem gewöhnlichen Phthisiker.

9. 9. Aeusserste Abmagerung. Das Gewicht des Kranken beträgt $42 \mathrm{~kg}$. Mit Mühe antwortet der Kranke auf die an ihn gerichteten Fragen. Stimme schwach, ununterbrochener Stupor. Die Augen liegen tief in ibren Höhlen, sind von schwarzen Rändern umgeben, die Haut ist erdfahl, Nase und Backenkuochen stehen stark hervor. Die Haut ist schuppig, trocken, rauh anzufühlen. Oedem der Extremitäten nicht vorbanden. Harnmenge 1 Liter; spezifisches Gewicht desselben 1026. Er enthält keinen Zucker und kein Eiweiss. Harnstoffmenge 20,125 g auf 1 Liter. Phosphorsäuremenge $4,1 \mathrm{~g}$.

12. 9. Die Nacht brachte der Kranke unruhig zu, nichtsdestoweniger sind die Antworten desselben verständlicher als früher. Aeusserste Abmagerung. Zange trocken, mit einem bräunlichen Belag bedeckt. Temp. $35^{\circ} \mathrm{C}$. Harnmenge $400 \mathrm{~g}$; spezifisches Gewicht 1022. Kein Zucker, kein Eiweiss. Harnstolfgehalt 35 g, Phosphorsäuregehalt $6,8 \mathrm{~g}$ auf 1 Liter.

13. 9. Den ganzen vorhergehenden Tag hat der Patient rubig zugebracht. Von Zeit zu Zeit stöbnte er kläglich. Um 7 Uhr morgens Exitus. Der in den letzten Lebensstunden ausgeschiedene Harn enthielt keinen Zucker.

Die Sektion wurde von Herrn Prof. W. Konstantinowitsch, Privatdozent an der Kiewer Universität, 12 Stunden nach dem Tode vorgenommen.

Sektionsprotokoll. Körperbau recht kräftig; wenig Unterhautzellgewebe. Haut blass. Schädelwände nicht brüchig, von normaler Dicke. Pia mater lässt sich leicht ablösen. Plexus chorioideus, Seitenventrikel normal. Hirnsubstanz von normaler Consistenz, keine Hämorrhagien. Verlängertes Mark; Gefässgeflecht des 4. Yentrikels normal. Die Querschnitte der Varolsbrücke and des Kleinhirns zeigen keinerlei Abweichungen von der Norm. Die Gefässe der Hirnbasis weisen stellenweise arteriosklerotische Plättchen auf, ihre Durchgängigkeit ist jedoch nirgends aufgehoben.

Brusthöhle. In den Pleuralböhlen keine Flüssigkeit. Rechte und linke Lunge weisen am hinteren Rande an mehreren Stellen Verwachsungen auf. In beiden Spitzen Cavernen. Im oberen 'T'eile des oberen Lappens sind beiderseits mebrere fibröse Knötchen von der Grösse eines Stecknadelkopfes verstreut. Bronchialdrüsen bis zu Haselnussgrösse vergrössert, locker, zum 'Teil pigmentiert, zum Teil an dor Peripherie von blassgrauer Farbe.

In der unveränderten Pericardialhöhle keine Flüssigkeit. Im Herzen Hypertrophio des linkien Ventrikels. Die Wände des letzteren rerdicht, von bräunlich-roter Farbe, schlaff. Mitralklappen normal, Aortenklappen stellenweise durchlöchert. Das Lumen der Kranzgefässe normal. Der rechte Ventrikel nicht erweitert; seine Wand normal (Dicke $5 \mathrm{~mm}$ ). Tricuspidal- und P'ulmonalklappen normal. Gewicht des Herzens $360 \mathrm{~g}$. Auf der Vorderfäche Macula lactea.

Bauchhöhle. In der Bauchhöhle ca. 4 Liter blassgelber Flüssigkeit.

Lebor. Gewicht $1200 \mathrm{~g}$. Oberfläche uneben; Consistenz normal. Gallenblase erweitert, enthält durchsichtige gelbliche Galle. Steine nicht vorbanden. Das Lebergewebe erweist sich beim Durchschneiden als von etwas festerer Consistenz als normal, zeigt auf der Schnittfäche eine rotbraungraue Färbung, schwach ausgeprägte Muskatnussleber.

Milz. Gewicht $180 \mathrm{~g}$. Spuren ron Perisplenitis, Consistenz fost, im Parencbym Bindegewebszüge sichtbar. Gewebe von bräunlich-rotel Färbung, von festerer Consistenz als in der Norm; Schnittnäcbe normal. Pulpa lässt sich in geringer Menge abschaben. 
Die Nieren sind ungefähr von normaler Grösse. Die Kapsel lässt sich leicht ablösen. Das Nierengewebe ist rosafarben mit schwach ausgeprägten Venensternchen, die Rinde etwas verdickt, die Pyramiden mit den Papillen entfärbt, fibrös.

Beide Nebennieren normal.

Magenschleimhaut dünn, ohne Falten, locker; Dünndarmschleimhaut dünn, blass; Solitärfollikel deutlich zu unterscheiden; Dickdarm etwas atrophiert.

Harnblase mit Harn gefüllt (ca. $400 \mathrm{~g}$ ).

Hoden und Samenbläschen unverändert; ebenso Rachen und Kehlkopf.

Plexus coeliacus atrophiert, schlaff, ist hinter dem Pankreas und der Bursa omentalis minor unmittelbar auf der vorderen Hälfte des Umfanges der Bauchaorta gelegen. gelappt.

Pankreas von normaler Form, blassgelb; von ziemlich fester Consistenz; Bau

Mikroskopische Untersuchung des Pankreas. Nach der Bearbeitung der Pankreasstückchen nach den allgemein beliannten Rogeln ergab sich bei der Betrachtung der Präparate unter dem Mikroskop folgendes Bild: die Endröhrchen der Drüse bestehen aus Zellen, welche auf den ersten Blick von ungleicher Form, ungleicher Grösse und sogar ron ungleichem Bau erscheinen. Diese Erscheinung hängt zum Teil von dem Zustande der Funktionstätigkeit der Zellen ab, zum Teil jedoch auch von der Richtung des durch die Endröhrchen geführten Schnittes. Wenn ein Längsschnitt durch die sekretorische Drüsenzelle vorliegt, so erscheint sie konisch oder pyramidenförmig, wobei sich ihre abgerundete Spitze dem Lumen des Drüsenrohres zuwendet, wäbrend die breite Basis zur Peripherie des letzteren gerichtet ist. Wenn hingegen die Zelle schräg oder quer geschnitten ist, so kann sie eine unregelmässige, polygone oder sogar abgerundete Form aufweisen. Falls der Querschnitt näher zur Zellkuppo gelegen ist, so wird die Zelle kleiner orscheinen, als wenn der Schnitt die Zelle näher zur Basis getroffen hat. Die Zellen des Pankreas unterscheiden sich fast durch nichts ron der Norm. Weder fettige Degeneration, noch Vacuolisation, noch Chromatinarmut ihrer Kerne, noch Verringerung ihres Umfangs konnten festgestellt werden. Auch Kernvergrösserung wird nicht beobachtet. Der Zustand der Capillaren ist normal.

Was nun die Langerhans schen Inselchen anbelangt, so übersteigt ibre Menge nicht die Norm. Sie sind nach Form und Umfang verschieden, es sind jedoch überwiegend runde und kleine aus zehn und weniger Zellen bestehende Inselchen vorhanden. Die Inselchen sind inmitten des übrigen Gewebes sogar bei schwacher Vergrösserung recht deutlich zu unterscheiden. Ibr Zellprotoplasma färbt sich mit Safranin rosa, obschon augenscheinlich schwächer als in der Norm. Die Zellen sind kleiner als in der Norm, weshalb ibre Kerne in den Inselchen dicht gelagert sind. Die Kerne der Inselzellen zeigen eine diffuse Färbung, sie erscheinen gleichsam geschrumpft und ihr Umfang hat abgenommen, sio sind aber nicht pyknotisch. Zellgrenzen undeutlich. Die Körnigkeit des Protoplasmas der Inselzellen ist nur in der an der Peripherie des Inselchens gelegenen Minderzahl derselben gut ausgeprägt, in der Mehrzahl derselben ist sie jedoch entweder verringert, oder es sind kaum Spuren von ihr sichtbar. Zustand der Capillaren normal. Es gelang nicht, einen Ausfübrungsgang an den Inselchen zu finden.

Ausser dem Pankreas, dessen mikroskopisches Bild vorstehend geschildert wurde, sind das verlängerte Mark mit der Varolsbrücke, das ganze Rückenmark und Teile der Nn. vagus, radialis, medianus, cruralis, peroneus (rom Unterschenkel und Fuss), tibialis, pudendus, sowie der Plexus coeliacus mikroskopisch untersucht worden.

Die Untersuchung wurde auf verschiedene Weise ausgeführt. Der grösste Teil des entnommenen Materials wurde in Müllerscher Flüssigkeit fixiert und nach Marchi, Weigert-Pal, ran Gieson und Rosin bearbeitet. Ein Teil der peri- 
pheren Nerven wurde in 1 proz. Osmiumsäurelösung fixiert. Ein Teil des Hals- und Lendenabschnitts des Rückenmarks und der Plexus coeliacus werden für die Bearbeitung nach $\mathrm{Nissl}$ in 10 proz. Formalinlösung fixiert.

Die Resultate der mikroskopischen Untersuchung sind karz folgende: In der Varolsbräcke wurden keinerlei scharf ausgeprägte Abweichungen von der Norm gefunden. Die Gefässe waren unverändert. Im verlängerten Mark ebenfalls normaler Zustand der Gefässe. Der Kern des N. vagus, welchem besondere Aufmerksamkeit zugewandt wurde, und die Wurzel dieser Nerven augensoheinlich normal.

Im Halsmark und im oberen Teile des Brustmarks sind die weissen Vorder-, Seiten- und Hinterstränge normal. Der Zustand der Vorderbörner dieser Abschnitte wurde besonders gründlich untersucht. In der Intumescentia cervicalis sowohl des 1 . als auch des II. Segments des Brustmarks war eine beträchtliche Anzahl von Zellen der Vorderhörner (etwa 20-30 pCt. der Gesamtmenge), und zwar besonders der vorderen seitlichen Gruppe angeschwollen. Sie sind weniger deutlich polygonal als unter normalen Bedingungen. Die Menge der kleinen protoplasmatischen Fortsätze ist verringert. Die grossen Protoplasmafortsătze sind bei einigen Zellen abgebrochen. Gewundene Fortsätze sind nirgends $z u$ benerken. Pigmentablagerungen waren nur in verschwindend kleinen Mengen vorhanden. Die NissIschen chromatophilen Körperchen sind in den meisten Fällen diffus gefärbt und in der Nähe des Kerns leicht verflüssigt. Bei einigen Zellen ist der Kern sehr gross, nicht grell gefärbt und weist keine klaren Umrisse auf; bei anderen ist er verkleinert und bat überaus scharfe Conturen. Die Lage des Kerns schien central. Die anderen Zellen, sowohl der Vorderals auch der Hinterbörner und ebenso auch überhaupt die ganze centrale graue Masse waren normal. Die Anzahl der Neurogliakerne, ihre Grösse und Färbung wichen augenscheinlich nicht von der Norm ab. Die Gesamtmasse der faserigen Neuroglia wies keinerlei besondere Veränderungen auf. Die Gefässe hatten ein normales Aussehen, waren leer, nur einige von ihnen enthielten eine mässige Anzahl von Blutkörperchen. Die hinteren und vorderen Wurzeln, wie auch die Rückenmarksganglien der Halssegmente wiesen keine Veränderungen auf.

In der unteren Hälfte des Brustabschnitts des Rückenmarks, angefangen ungefähr vom VII. Segment und im Lendenabschnitt des Rückenmarks liess die Färbung nach Marchi symmetrisch gelegene, und $z$ war in jedem Strange $\mathbf{z w e i f a c h ~ l o k a l i s i e r t e ~}$ Veränderungen der hinteren Stränge erkennen. Eine im Durchmesser breitere Degeuerationszone umfasst den kommaförmigen $\mathrm{Schultzeschen} \mathrm{Bereich} \mathrm{auf} \mathrm{der} \mathrm{Grenze}$ zwischon den Burdachschen und Gollschen Strängen. Eine weniger ausgedehnte Veränderung liegt innerhalb des Burdachschen Stranges ond entspricht im allgemeinen der Lissauerschen Zone. Die obenerwähnte breitere Degenerationszone erreicht hinten nicht die Peripherie des Rückenmarks, vorn nicht die hintere Commissur; am intensivsten ist die Degeneration im Centrum: nach vorn und hinten zu ist sie schwächer ausgeprägt. Die breiteste Fläche nimmt sie in der Höhe des I. Segments des Lendenabschnitts ein. Die weniger ausgedehnte Degenerationszone ist in der Richtung von vorn nach hinten kïrzer und viel schmaler als die breitere und reicht nicht bis zur Peripherie des Wurzelbereichs. Die weniger ausgedehnte Degenerationszone erreicht ihre grösste Ausdehnung und Intensität im I. und II. Lendensegment. Diese degenerierten Stellen zeichnen sich, nach Pal, Weigert gefärbt, auf dem allgemeinen Fond der Hinterstränge durch geringere Intensität des blauen Tones und grössere Durchsichtigkeit aus. Bei der Färbung nach Rosin fällt auf dem orangefarbenen Felde das spärlichere Vorkommen von Nervenfasern auf. Die noch erhalten gebliebenen Achsencylinder dieser Zellen sind schwach gefärbt; einige von ihnen sind sebr angeschwollen und übertreffen auf Querschnitten die benachbarten an Dicke un 4-5 mal. Auf Längsschnitten durch die Hinterstränge ist unter gut erbalten gebliebenen Fasern ein bedeutender Prozentsatz solcher vorhanden, die grobkörnigen Myelinzerfall aufweisen. Ebenso ist eine geringe Anzabl von Fettkörnchenzellen an- 
zutreffen. Die Acbsencylinder dieser Teile (Färbang nach ran Gieson) enthalten stellenweise Anschwellungen; hier und da liessen sich Ueberreste von Achsencylindern erkennen. Die Neuroglia der Hinterstränge weicht nicbt von der Norm ab; ihr Netz ist nicht dichter geworden, ibre Fasern haben sich weder vermehrt, noch verdickt. Die Gerässe dieser Abschnitte des Rückenmarks sind nicht verändert und nur stellenweise mit Blut angefüllt. Blutergüsse in das perivasculäre Gewebe sind nirgends bemerkbar. Ebenso sind weder Hoblräume, noch Spalten zu sehen, die man durch ein bereits bei Lebzeiten eingetretenes Oedem erklären könnte. Viel schärfer waren die Veränderungen in den Vorderbörnern des unteren Brust- und des Lendenmarkabschnitts ausgeprägt, und zwar des X., XI., XII. Brustsegments und des I., II., III. Lendensegments. Diese Veränderungen sind in der seitlichen und medialen vorderen Gruppe sebr dentlich ausgeprägt. Die Anzabl der Nervenzellen ist hier überbaupt rerringert. Von den erbalten gebliebenen Zellelementen sind sebr viele von kleinen Dimensionen; ihre grossen protoplasmatischen Fortsätze sind abgebrocben; ihr Achsencylinderfortsatz ist stark gewunden. Bei der Bearbeitung nach Nissl erschien der Leib einer solchen Zelle diffus gefärbt; die chromophilen Körner sind sehr schlecht differenziert. Der Zellkern ist sehr klein, bat scharfo Umrisse und liegt im Centrum. Zuweilen ist er gar nicht zu sehen. Solche Veränderungen sind in der Minderzabl der Zellen zu vermerken. Ein anderer Toil der in der Lendenanschwellung gelegenen Zellen erscheint hingegen angeschwollen; ibr Protoplasma färbt sich sebr diffus, besonders ihre centralen Teile; der Kern liegt in der Nähe der Peripherie. Die Protoplasmafortsätze sind so blass, dass sie kaum sichtbar sind. Ein Teil der Zellen enthălt ausserdem Vacuolen. Ausser diesen verschiedenartig veränderten und degenerierten Zellen ist noch eine grosse Zabl anderer, augenscheinlich völlig normaler Zellindividuen vorhanden.

Boi der Bearbeitung nach Weigert weist die grave Masse der Vorderhörner eine grosse Verdünnung auf; feine Aestchen resp. Acbsenzylinder- und Protoplasmafortsätze sind in geringerer Zahl zu seben als in der Norm. Hingegen lässt die Färbang nach Marchi eine Degeneration der feinen Fasern im vorderen Teile der Vorderhörner erkennen. Das Neuroglianetz in den Vorderbörnern des Lendenabschnitts des Rückenmarks stellt sich als leicht verdichtet dar (Bearbeitung nach Rosin). Die Zahl der Neurogliakerne ist etwas vergrössert; nirgends sind spinnenförmige Zellen zu bemerken; hier und da kommen in ganz unbedeutender Zahl Fettkörnchenzellen vor. Die Gefässe weisen verdickte Wände auf, haben aber überall ein Lumen und sind meistenteils leer. Die Anzahl ihrer Kerne ist ein wenig vergrössert. Ihre Grösse weicht nicht von der Norm ab. Irgendwelche Blutergüsse in das umgebende Gewebe sind nicht gefunden worden. Die weiche Hülle des Rückenmarks ist völlig normal.

Die Vorder- and Hinterwurzeln weisen (bei der Färbung nach Weigert und Kosin) eine bedeutende Atrophie der parenchymatösen Teile auf. Ibr interstitielles Gewebe und die Gefässe sind unverändert. Die anderen Abschnitte des Lenden- und unteren Brustmarks, und zwar die Vorder- und Seitenstränge weisen keinerlei Veränderungen auf.

Die Rückenmarkshäute in den mikroskopisch untersuchten Segmenten zeigten nirgends Abweichungen von der Norm.

Der in 1 proc. Oscaiumsäurelösung fixierte $\mathcal{N}$. radialis weist folgendes auf: Die Myelinscheiden der Mehrzahl seiner Fasern sind vollständig normal. Bei einer geringen 'Lahl derselben enthält ihr Myelin jedoch feine Körnchen, welche in den den distalen Bereichen der Extremität entnommenen Teilen des Nerven die Intensität des feinkörnigen Zerfalls erreichen. Dieser Zerfall erfasst jedoch nicht die ganze Nervenfaser, sondern nur einzelne ibrer Segmente. Solch ein segmentärer Process ist besonders intensiv im Unterarm und in der Hand ausgeprägt. Das Profil der Myelinfaser ist an diesen Stellen uneben; stellenweise ist es usuriert, hat gezackte unebene Conturen. Die Vasa nervorum eben dieser Nerven (Färbung mit Carmin-Hämatoxyjin) waren ganz 
normal. Epi-, Peri- und Endoneurium weisen gar keine Veränderungen auf. Die Kerne der Schwannschen Scheiden waren nicht vergrössert, ihre Anzahl nicht vermehrt. Der Achsencylinder war nicht unterbrochen, nur bei einer geringen Zahl der Fasern war er stellenweise leicht angeschwollen. Analoge Veränderungen wurden sowohl in den peripheren Teilen, als auch im Humerushereich des N. medianus gefunden (nach Fixierung in Osmiumsäure und Färbung mit Carmin-Hämatoxylin).

Ebenso wies der $\mathrm{N}$. vagus keinerlei merkliche Veränderungen auf.

$\Lambda$ nders verhielten sich die die Geschlechtsapparate und die unteren Extremitäten innervierenden Nerven.

Die mit 1 proc. Osmiumsäure fixierten Nn. pudendus und cruralis enthielten einen ungeheuren Procentsatz von Fasern, deren Myelinscbeiden in Tropfen von beträchtlichen Dimensionen zerfielen oder feinkörnigen Zerfall outbielten. Diese Veränderungen an den einzelnen Fasern bewahrcen die segmentäre Anordnung; infolgedessen waren hier neben den hetroffenen normale Segmente vorhanden; das Myelin der ersteren hatte gezackte usurierte Conturen. Die Färbung mit Carmin-Hämatoxylin liess den normalen Zustand des Epi-, Peri- nnd Endoneuriums und der Vasa nervorum erkennen. Die Wände und Kerne der letzteren waren nicht verändert, ihr Lumen frei. Am Nerven konnten weder Blutergüsse, noch Oedem bemerkt werden. Die Kerne der Schwannschen Scheide weisen eine bedeutende Hypertrophie und Hyperplasie auf. Stellenweise liegen sie zu zweien und sogar zu dreien zusammen. Der Achsencylinder hat bei der Minderzahl der Fasern ein normales Aussehen. Bei der Mehrzahl ist er dagegen angeschwollen, stellenweise in kleine Stiuckchen zeriallen, hier und da vacuolisiert. An manchen Stellen bat er sich aber nicbt im mindesten gefärbt, so dass sich über seinen Zustand nichts aussagen lässt. Was nun die Nervenstämme der Nn. peroneus und tibialis anbelangt, so hatte die Mehrzahl ihrer zum Teil in 1 proc. Osmiumsäure, zum Teil in Müllerscher Flüssigkeit fixierten nnd nach Weigert gefärbten Nervenfasern ihre Markscheide bewahrt, doch war die letztere in den peripheren Teilen einzelner Segmente mit feinkörnigen Zerfallsprodukten übersät, so dass die Faser ein sehr unebenes, leicht zerklüftetes Profil zeigte. Ferner fanden sich Fasern, deren Markscheide ganz normal aussah. Die Zahl dieser letzteren, die auf dem Niveau der Unterschenkelmitte fast die Hälfte der Gesamtmenge der Fasern erreichte, verringerte sich in den distalen Nervenbereichen. Der Achsencylinder der beschriebenen Nerven färbte sich diffus. An vielen Stellen des Unterschenkels waren im Achsencylinder Vacuolen zu sehen; mitunter zerfiel derselbe im Fusse ganz und gar in Teile. Die Schwannschen Kerne und ihr Protoplasma waren beträchtlich angeschwollen. Die Färbung der Nn. peroneus und tibialis mit Carmin-Hämatoxylin liess weder im Fusse, noch auch im oberen Drittel des Unterschenkels irgendwelche Veränderungen seitens des Bindegewebsgerüstes des Nerven erkennen. Die Kerne des Epi-, Peri- und Endoneuriums waren nicht vermehrt; möglicherweise waren sie ein wenig angeschwollen. Im Gewebe des Nervenstammes waren weder Blutergüsse, noch Oedem vorhanden. Die Vasa nervorum wiesen normale Wände auf und waren grösstenteils leer.

In den untersuchten Muskeln des Fusses (M. extensor digit. communis brevis, $\mathrm{Mm}$. interni) und des Unterschenkels (Mm. peronei) waren die Fasern selrr fein, enthielten feine und feinste Fetttröpfchen; die Sarkolemmkerne waren vermehrt. Das Perimysium war überhaupt erweitert und enthielt reichlich Fett.

Der Plexus coeliacus wurde nach der Nisslschen Methode untersucht.

Wenn wir das Präparat bei schwacher Vergrösserung betrachten, sehen wir eine scharf ausgeprägte Verringerung der Zahl der Zellelemente. Die Defelite der letzteren sind durch interstitielles Bindegewebe ersetzt. Die meisten Ganglienzellen erscheinen zusammengeschrumpft, verkleinert. Die Zellen sind nicht sclten schlecht gefärbt und haben des öfteren eine runde oder ovale Form. In den erhalten gebliebenen Zellen besteht hingegen eine partielle Chromatolyse, welche in einem Teile der Zellen im Centrum lokalisiert ist, indem sie hauptsächlich um den Zellkern berum gelegen ist, 
während sie sich in dem anderen Teil der Zellen in Gestalt von einzelnen Flecken über den ganzen Zellkörper ausbreitet. Vacuolen nioht sichtbar. Die Kerne sind verkleinert, liegen im Centrum und sind diffos gefärbt. Die Gefässwände verdickt und einige von ibnen byperämisch.

Das Ganglion mesentericum superius enthielt einen kleinen Bluterguss. Einige von den Zellen wiesen vergrösserte Dimensionen auf und waren angeschwollen.

Die Nisslschen Kernkörperchen derselben hatten sich in der Nähe des Kernes fast vollständig aufgelöst, waren jedoch an der Peripherie der Zelle noch vorhanden. Der Kern lag im Centrum und war diffus gefärbt. Andere 'Lellen, die ebenfalls die chromophile Substanz im Centrum verloren hatten, waren an den Rändern diffus gefärbt; ihr Kern war nicbt an die Peripherie gerückt, abor sebr verkleinert und intensiv gefärbt. Die grössere Hälfte der Zellen dieses Ganglions war verkleinert. Das interstitielle Gewebe war stellenweise angeschwollen und verdickt. Die Gefässwände waren etwas verdickt und einige ron ihnen hyperämisch.

Somit bietet der rorliegende Diabetesfall sowohl rom klinischen als auch rom pathologisch-anatomischen Standpunkt stark ausgeprägte Veränderungen des sympathischen Nerrensystems, des Centralnervensystems und der langerhansschen lnselchen dar. Hingegen weist das Pankreas keinerlei besondere Veränderungen auf.

Intra vitam wurden vermerkt: eine subacut entstandene Parese der unteren Extremitäten, Atrophie einzelner Moskelgruppen, insbesondere an den Füssen und Unterschenkeln, Herabminderung der elektrischen Reaktion der Nerven, Störung aller Formen der Sensibilität in den unteren Extremitäten, Reflexverlust, Ataxie, Verlust der Potenz, Gedächtnisschwäche, trübe weinerliche Gemütsstimmung. Ausserdem wurden durch die Untersuobung von pathologisch-auatomischen Präparaten Affektionen folgender Organe naobgewiesen: 1. der Langerhansschen Inselchen, 2. des Plexus coeliacus, des Ganglion mesentericum superius, 3. des Räckenmarks, der peripheren Nerven und der Muskeln.

Die in den Langerhansschen Inselchen gefundenen Veränderungen, and zwar die Verringerung der Körnigkeit des Protoplasmas, die Undeutlichkeit der Zellgrenzen, das Fehlen der Kernpyknose. der normale Zustand der Capillaren, das Fehlen von Veränderungen seitens des interstitiellen Bindegewebes tragen einen labilen, oberflächlichen Charakter, während die im Plexus coeliacus gefundenen mikroskopischen Veränderungen, und zwar eine scharf ausgeprägte Verminderung der Anzahl der Ganglienzellen, das Ersetztwerden derselben durch interstitielles Bindegewebe, die partielle Cbromatolyse in den Zellen, die Hyperämie einiger Gefässe uns zu der Annahme berechtigen, 1. dass als Ursache dieser Veränderungen des Plexus coeliacus ein entzündlicber Prozess anzusprechen ist (zugunsten einer solchen Annahme spricht auch der Bluterguss in das Bindegewebe des Ganglion mesentericum superius), und 2., dass die Veränderungen des Plexus coeliacus sich im Vergleich zu denen der Langerhansschen Inselchen als tiefgreifender und von früberem Datum darstellen; die Affektion der Langerbansschen Inselchen trägt also in unserm Falle die Anzeichen einer sekundären Erkrankung. Zugunsten einer solchen Bebauptung sprechen auch folgende Daten: 1. ist durch die Arbeiten ron Gentes und Pensa festgestellt, dass bei allen Wirbeltieren die Langerbansschen Inselchen reich an Nerven sind; 2. innerviert das sympathische Nervensystem alle Organe; in seinen Stämmen sind, wie gegenwärtig allgemein anerkannt ist, sensible, motorische, vasomotorische und sekretorische Fasern vorbanden. Der Plexus coeliacus ist die Centralstation, von der Fasern zu den verschiedenen in der Bauchböhle gelegenen Organen, darunter auch zu den Langerbansschen Inselchen abgehen.

Deshalb muss jede Veränderung des Plexus coeliacus unfehlbar an der 'lätigkeit der von ihm innervierten Organe und insbesondere an den Langerhansscben Inselchen zum Ausdruck kommen.

Was nun die pathologisch-anatomischen Veränderungen des Centralnervensystems 
anbelangt, so erwiesen sicb, wie bereits gesagt, im Rückenmark die Vorderhörner und -wurzeln, die Hinterstränge und zum Teil auch die Hinterwurzeln betroffen.

Eine Veränderung der Vorderhörner wurde an zwoi Stellen vermerkt. In der Hals- und Brustanschwellung des Rückenmarks ist sie schwach ausgeprägt. Der von ihr eingenommene Flächenraum sowie die Intensität der Zellveränderung sind hier nicht gross. Zugrunde gegangene Zellen sind gar nicht zu sehen und den Process selbst kann man als noch frisch ansprechen. In der Intumescentia lumbalis ist die Degeneration einzelner Zellen viel stärker ausgeprägt. Viele von ihnen sind ganz verschwunden. Andere sind dem Untergange nahe. Die Veränderung dieser letzteren kommt entweder in einer Verringerung des Umfanges der Zelle, im Verlust der Protoplasmafortsätze und in tiefer Färbung der chromatischen Substanz zum Ausdruck, so dass der Kern schlecht sichtbar ist, oder aber dieZellen erscheinen stark angeschwollen, ibre Conturen sind abgerundet, ihre Protoplasmafortsätze verdickt, während gleichzeitig ihre chromatophile Substanz verflüssigt ist, weshalb die Färbung sehr blass erscheint; die Chromatolyse hat einen diffusen Charakter und ist an der Peripherie der Zello stärker ausgeprägt. Einige von diesen veränderten Zellen baben ein glasartiges Aussehen, weisen augenscheinlich keinen Kern und keinerlei chromatophile Substanz auf, haben Vacuolen, und ihre Dimensionen sind verringert. Die Degenerationsfläche umfasst alle Gruppen des Vorderhorns. Der oben geschilderte Zerstörungsprocess erscheint als friseb. Zu dieser Schlussfolgerang führt uns das Aussehen der Neuroglia und der Gofässe, die in den Halssegmenten gar nicht und im Iendenabschnitt sehr wenig verändert sind. Die Erkrankung der Vorderhörner hat einen atrophischen Charakter. Weder in den Halssegmenten noch in der Lendenanschwellung sind irgendwelche Hinweise auf entzündlicho Processe rorhanden. Wedor Hyperämie, noch Infiltration ait Zellen des benachbarten Gewebes, noch Blutergüsse sind vorhanden. Eine Affektion der Hinterstränge wurde nur auf einer kleinen Strecke der Intumescentia thoraco-lumbalis gefunden und nimmt diejenigen Stellen ein, deren Betroffensein bei Tabes oder bei experimentellen Degenerationen nach Dorchsohneidung der Hinterwurzeln zur Beobachtung gelangt. Die Veränderungen der Fasern dieser Stränge zeigen keinen entzündlichen Charakter. Auch hier hat die Degeneration ein frisches Aussehen, wofür 1. das Fehlen ron Folgeerscheinungen seitens der Neuroglia und 2. die Möglichkeit der Färbung nach Marchi sprechen.

Die Veränderungen der Hinter- und Vorderbörner, wio auch der peripheren Nervenstämme, die zu den Geschlechtsapparaten und den unteren Extremitäten hingehen, sind einander überaus ähnlich und tragen fast einen und denselben Charakter. Fin Unterschied besteht nur in der Intensität des Processes. Es sind hauptsächlich die parenchymatösen T'eile, und zwar die Myelinscheide und der Axencylinder verändert. Das bindegewebige Stützgerüst und die Gefässe sind ganz unverändert. Sehr viele Fasern haben ein normales Ausseben; ibre Degeneration betrifft nur einzelne Segmente. Stellenweise sind in Regeneration begriffene Fasern zu sehen. Die Entartung der Nervenfasern in den Nervenstämmen stellt sich als recht frisch dar; zugunsten des Frühstadiums der Erkrankung spricht der segmentäre Myelinzerfall, das Fehlen von Veränderungen von seiten des bindegewebigen Stützgerüsts und das Vorhandensein einer grossen Menge noch unveränderter Fasern. Die Affektion, sowohl der peripheren Nervenstämme, als auch der Rückenmarkswurzeln zeigt im gegebenen Fall die Anzeichen einer secundären Erkrankung. Die Erkrankung derselben ais entzündlich und dazu als primär anzusprechen, ist angesichts des Feblens von Hyperämie, Blutergüssen, Oedemen, Infiltration und anderer Veränderungen von seiten der Vasa nervorum und des interstitiellen Bindegewebes des Nervenstammes nicht gut möglich. Aus dem gleichen Grunde lassen sich diese Veränderungen schwerlich als Neuritis bezeichnen, da der beschriebene Process alle Anzeichen der Atrophie, nicht aber der Entzündung aufweist. Unter den zur Untersuchung gelangten Nerven erwies sich der $\mathrm{N}$. vagus als normál. 
Die im gegebenen Fall vorgefundenen anatomischen Veränderungen sind in vieler Hinsicht interessant und tragen auf den ersten Blick einen complicierten Charakter. Wir haben hier eine Affektion von beträchtlicher Intensität im Rückenmark und eine solche in den peripheren Nerven der unteren Extremitäten. Diese Affektionen sind nur auf den Bereich des peripheren Neurons beschränkt. Zu einem solchen Schlusse nötigt uns gerade der Umstand, dass die betroffenen Zellen der Vorderhörner des Rückenmarks und die entarteten motorischen peripheren Nerven mit den Muskeln der unteren Extremitäten das periphere motorische Neuron bilden. Die gleiche Erwägung lässt sich auch auf das Halsmark anwenden, wo die Veränderungen nur auf die Vorderhörner begrenzt sind und sich folglich ebenso zum Teil im Bereich des peripheren Neurons befinden. Diese Erwägung vereinlacht einerseits das Verständnis des uns beschäftigenden Falles und nötigt uns andererseits dazu, die Frage nach der Entwicklung und dem Verlauf der Erkrankung selbst aufzuwerfen. D. h. man hat zu entscheiden, ob das Neuron seiner ganzen Ausdehnung nach gleichzeitig betroffen wird, oder ob man es hier mit einer auf- oder endlich einer absteigenden Erkrankung zu tun hat.

Nach der Meinung von Oppenheim, Strümpell, Raymond u.a. kann das aus der Nervenzelle mit dem Axencylinder resp. mit der Nervenfaser der peripheren Nerven bestehende Neuron schädlichen Einflüssen in seinen einzeluen Abschnitten einen verschiedenen Widerstand entgegensetzen. In einer Reihe von Beobachtungen kann sich die Erkrankung im Kopfteil des Neurons, seinen Anfang, d. i. hauptsächlich in der Nervenzelle selbst äussern; in einer anderen Reihe kann der distale Teil des Neurons, in einer dritten Reihe endlich der distale und centrale Abschnitt desselben gleichzeitig betroffen werden.

In dem Falle, wenn die Ursache der Nervenaffektion einen diffusen und localen Charakter trägt, z. B. wenn dieselbe im Blute kreist, sind günstige Bedingungen für das gleichzeitige Erkranken des Neurons in seinem ganzen Bestande gegeben. Wenn jedoch ein gewisses Neuron einen Locus minoris resistentiae besitzt - nehmen wir an, dass derselbe in der als tropisches Centrum dienenden Zelle, oder in den distalen peripheren Teilen des Neurons gelegen sei, - so wird das gegebene diffuse Agens seine schädliche Wirkung auf das letztere nur local ausüben; eine Veränderung wird sich gerade in diesen am meisten zugänglichen Teilen äussern und in den widerstandsfähigeren Teilen weniger ausgeprägt sein; diese letzteren können sogar unter gewissen Bedingungen wie sonst funktionieren und imstande sein, soweit das z. B. die peripheren Endigungen des Neurons betrifft, Reize weiterzuleiten. Bei Vergiftungen mit tierischen Giften, dje im Blut kreisen, ist z. B. des öfteren beobachtet worden, dass die Zellen der Vorderhörner sich als mehr oder weniger verändert erwiesen, während die zu erwartende Entartung der von ihnen ausgehenden peripheren Nerven sogar vollkommen fehlte und die von ihnen besorgten Funktionen ohne irgendwelche Störungen ausgeübt wurden. So z. B. waren in den Versuchen von Flatau und Goldscheider die Funktionen der Muskelgruppen trotz völliger Degeneration der Zellen der Vorderhörner unverändert. Scharf ausgeprägte Entartung 
derselben Zellen war in den Versuchen und klinischen Beobachtungen von $\mathrm{Zwetajew}$, Popoff, Dotlo, Tirelli u. a. mitunter nicht von den geringsten Veränderungen der Axencylinder resp. der peripheren Nerven begleitet, und diese letzteren waren imstande, ihre Funktion auszuüben.

Diese Beobachtungen weisen auf die verschiedene Widerstandsfähigkeit der einzelnen Teile des Neurons hin und gestatten die Annahme, dass das Neuron anfänglich entweder nur an seiner Peripherie oder nur in seinem Centrum betroffen wird, so dass in dem einen Fall das Leiden einen aufsteigenden, in dem anderen einen absteigenden Charakter zeigt. Wenn wir nun unseren Patienten in dieser Richtung untersuchen, so ergibt die ins Einzelne gehende Betrachtung der an ihm zur Beobachtung gelangenden Symptome keinerlei überzeugende Beweise zugunsten der Annahme von der Gleichzeitigkeit der Erkrankung des Neurons seiner ganzen Ausdehnung nach. Wir betrachten daher die Frage von der gleichzeitigen Erkrankung des ganzen Neurons als in verneinendem Sinne gelöst. Was nun aber die Voraussetzung einer aufsteigenden Erkrankung einzelner Neurone anbelangt, so spricht hiergegen erstens der normale Zustand der Nerven der oberen Extremitäten unseres Patienten, während die ihnen entsprechenden Segmente der Intumescentia cervicalis veränderte Zellen in den Vorderhörnern aufweisen, und zweitens der Cmstand, dass die für den aufsteigenden Verlauf in den unteren Extremitäten typischen, durch die Untersuchungen von Gudden, Vulpian, Nissl, Marinescou. a. festgestellten Veränderungen der Rückenmarkszellen in der Intumescentia lumbalis fehlen. Nach diesen Autoren unterscheidet man histologisch primäre Veränderungen der Rückenmarkszellen, die sich infolge der primären Einwirkung eines schädlichen Agens auf die Zellen selbst herausbilden und sekundäre, als Folgeerscheinung bei den Affektionen der peripheren Nerven zur Beobachtung gelangende Veränderungen, die nur als Fernreaktion seitens der Nervenzelle auf die an irgend einer Stelle der Peripherie eingetretene Degeneration ihres Achsencylinders erscheint.

Im ersteren Falle, bei der sogenannten autochthonen Erkrankung der Zellen des Rückenmarks, unterliegen dieselben der Hayem-F orelschen Entartung. In ihnen bildet sich eine von den peripheren Teilen (ausser bei der Arsenikentartung, wo sie im Centrum beginnt [Popoff]) ausgehende Chromatolyse, ein Anschwellen des Zellleibes und seiner Fortsätze heraus. Diese letzteren brechen mitunter ab; einige Nisslsche Körperch ^n nähern sich dabei einander und häufen sich bisweilen in der Nähe des Kerns an. Interessant ist die Tatsache, dass die achromatische Substanz der Zelle bei der autochthonen Degeneration auch betroffen ist, wobei sie sich entweder zu färben beginnt, oder eine glasartige Veränderung erfährt und farblos bleibt. Bei dieser Art von Affektion der nervösen Zellelemente leiden auch die anliegenden Teile, und zwar fangen die Neurogliazellen an, in die Nähe der veränderten Nervenzellen zu proliferieren. Bei der sekundären Degeneration der Zellen beginnt die Chromatolyse im Bereich des Achsencylinderfortsatzes, setzt sich in die centralen Teile der Zelle fort und ist von einer Wanderung des Kernes nach der Peripherie, Atrophie desselben und Achromatismus der Zelle begleitet. Hierbei beobachtet man mehrere Stadien, von denen die An- 
häufung der Nisslschen Körperchen an der einen Seite des Kerns als das wichtigste gilt. In unserem Falle konnten wir trotz der sorgfältigsten Beobachtung der Präparate keinerlei dergleichen Anzeichen einer sekundären Entartung der Nervenzellen finden, weshalb die Frage von der aufsteigenden Affektion des Nerrensystems im vorliegenden Falle doch wohl als im verneinenden Sinne gelöst zu gelten hat. Aus dem gleichen Grunde kann man schwerlich der Meinung von Aucbé beipflichten, der dem Diabetes die specifische Eigenschaft, nur die peripheren Nerven in Mitleidenschaft zu ziehen, zuschreibt. In einer seiner bereits oben citierten Beobachtungen fand dieser Autor unter dem Mikroskop eine scharf ausgeprägte Degeneration der distalen Abschnitte der peripheren Nerven und hielt das Centralnervensystem, ohne dasselbe einer Untersuchung unterworfen zu haben, für normal und überhaupt für durch Diabetes nicht alficierbar. Etwas anders steht es mit der Frage von der absteigenden Aflektion des Nervensystems in unserem Falle.

In der diesbezüglichen Literatur besteht die Meinung, dass die Veränderung der peripheren Nerven und Muskeln nicht primären Ursprungs sein könne, dass derselben eine Erkrankung ihrer Rüekenmarkscentren, resp. der Zellen der Vorderhörner voraufgehen müsse. Diese Anschauung hat viele Anhänger gefunden. Erb, Remak, Anfimow, Eisenlohr, Marie-Babinsky, Joffroy und Lemeller und mit ihnen noch viele andere Autoren nehmen eine primäre Affektion der Ganglienzellen der Vorderhörner überall da an, wo Muskelatrophie und Veränderung der peripheren Nerven vorliegen. Wenn eine solche Degeneration der Nervenzellen sich unter dem Mikroskop nicht feststellen lässt, so schlagen die Autoren vor, dieselbe als dynamische zu betrachten, und verlegen jedenfalls in die Nervenzellen des Rückenmarks die Ursachen auch der Muskelentartung. Unbedingt aber beziehen sie alle diejenigen Fälle, wo die peripheren Nerven unter dem Mikroskop atrophisch und nicht entzündlich verändert erscheinen, auf die primäre Erkrankung der Vorderhörner. Babinsky nimmt für eine ganze Gruppe von Neuritiden unbedingt die primäre Affektion der Nervenzellen der Vorderhörner an. Als typisch für dieselben sieht er die Neuritis der Hemiplegiker an, bei denen die Zellen der Vorderhörner des Rückenmarks atrophiert sind. Anfimow schlägt entschieden vor, jede Polyneuritis als Poliomyelitis anzusehen und dieselbe zum Unterschied von derjenigen des Kindesalters Poliomyelitis adultorum zu nennen.

In unserem Falle spricht zugunsten des abstejgenden Verlaufes der Erkrankung, d. h. der primären Affektion des centralen Abschnitts des Neurons und der secundären Atrophie der peripheren Nerven gerade die Veränderung der Zellen der Vorderhörner des Lendenmarks, die sich im Anschwellen derselben und ihrer Fortsätze usw. äussert. Diese Veranderungen entsprechen bekanntlich dem von Hayem-Forel bei der primären Zelldegeneration beschriebenen Bilde. Ferner wird der Gedanke von der absteigenden Entartung auch durch den atrophischen Charakter der Veränderungen der von den betroffenen Segmenten abhängenden peripheren Nerven selbst bestätigt. Auch der Unterschied im Grade der Erkrankung der Zellen des Rückenmarks und der peripheren Nerven 
spricht zugunsten einer solchen Annahme. Besonders denıonstrativ tritt das im Halsmark hervor: die erstgenannten Zellen zeigen bereits Veränderungen, während sich die letztgenannten (und zwar in den oberen Extromitäten) noch ihrem normalen Zustand angenähert erweisen.

$V_{0 n}$ anderen im gegebenen Fall vorliegenden Eigentümlichkeiten der Erkrankung des Centralnervensystems beansprucht die Tatsache ein besonderes Interesse, dass die Affektion ausschliesslich auf die parenchymatösen Teile, d. h. auf die Nervenzellen und -fasern begrenzt bleibt. Gerade nur diese erwiesen sich als betroffen. Hingegen war das interstitielle Gewebe verschont geblieben. Eine analoge Erscheinung wird auch von den Autoren erwähnt. So z. B. bestanden die Veränderungen der grauen Substanz des Rückenmarks in den Fällen von Bonardi, Sonques und Marinesco, Nonne, Williamson, Pryce, Sandmeyer in einer Affektion nur der Zellen allein, ohne dass die Neuroglia eine festere Consistenz aufwies, ohne Beteiligung der Gefässe, ohne Auftreten von entzündlichen Erscheinungen, ohne Infiltration. Ebenso fanden Kalmus, Sonques und Marinesco, Hensay in ihren Fällen von Affektion der weissen Stränge die Anzeichen einer primären Affektion nur der Nervenfasern, während Neuroglia und Gefässe unverändert geblieben waren. Im Falle von Nonne erwies sich die Neuroglia als verdickt; doch der Autor sieht hierin nur eine secundäre, nicht aber eine primäre Erscheinung. Bei der Mehrzahl der peripheren Nerven, die Erwähnung gefunden haben, gelangt dasselbe zur Beobachtung: es sind nur die parenchymatösen Teile des Nerven betroffen, sein interstitielles Gewébe und die Gefässe erwiesen sich als intakt. In einigen Fällen betraf die Affektion nur die Myelinscheide. Als sehr wertvolle Beispiele lassen sich hier die Beobachtungen von Bruce und von Auché (Fall IV) anführen.

Uebrigens sind in der Literatur (Nonne, Pryce) Hinweise auch auf Erkrankung des interstitiellen Gewebes des Nervensystems bei der Zuckerkrankheit vorhanden; doch unterscheiden sich die Veränderungen desselben wesentlich von denen des Nervenparenchyms: Während die Nervenzellen und -fasern beim Diabetes atrophieren und zu Grunde gehen, trägt die Veränderung der Neuroglia in den obenerwähnten von Nonne und Bruce beobachteten Fällen keinen regressiven, sondern einen progressiven Charakter. Statt einer Atrophie weist dieses Gewebe eine festere Consistenz auf; einzelne Fasern desselben sind verdickt. Sogar neugebildete Elemente werden vermerkt. Der Zusammenhang aller dieser Veränderungen mit dem Diabetes ist jedoch zweifelhaft. Gegenwärtig ist es noch völlig unaufgeklärt, $o b$ man die beschriebene Veränderung der Neuroglia ausschliesslich der Einwirkung der beim Diabetes im Blut circulierenden allgemeinen toxischen Stoffe zuzuschreiben hat, oder ob man in derselben das Resultat der lokalen Reizung durch die an der Stelle, wo die Nervenzelle zugrunde geht, gebildeten Zerfallselemente zu sehen hat, oder ob man endlich dieses Consistenterwerden des interstitiellen Gewebes als einen, weder mit den Diabetestoxinen, noch mit den lokalen Zerfallsprodukten in Zusammenhang stehenden secundären Process, als eine Folgeerscheinung nur mechanischer Momente, und zwar als das Resultat des Auftretens eines leeren Raumes an Stelle des ver- 
schwundenen Nervenparenchyms aufzufassen hat. Man hat schliesslich nicht ausser Acht zu lassen, dass die gleichen Affektionen der Neuroglia auch von Syphilis, Alkoholismus, Arteriosklerose und anderen mit dem Diabetes durchaus in keinem Zusammenhang stehenden, aber äusserst häufig gleichzeitig mit ihm vorhandenen Momenten herrühren können.

Die Betrachtung der bei unserem Patienten beobachteten Veränderungen des Plexus coeliacus berechtigt uns zu der Schlussfolgerung, dass als unmittelbare Ursache seiner Erkrankung ein durch ein Trauma hervorgerufener Bluterguss zu gelten hat, während wir die Veränderungen der Langerhansschen Inselchen als secundäre Erscheinung auffassen. Was nun die unmittelbaren Ursachen der Affektion des Centralnervensystems anbelangt, so lässt sich hierüber folgendes sagen: im gegebenen Falle haben wir keinen Anlass, die Erkrankung des Centralnervensystems durch eine Gefässentartung zu erklären, selbst wenn sich die letztere während der Zuckerkrankheit entwickelt, haben sollte, denn erstens wurden die Blutgefässe normal befunden und zweitens ist bei einer Gefässerkrankung (und zwar einer chronischen, wie das in unserem Falle zu erwarten wäre) das klinische und pathologisch-anatomische Bild, insbesondere das des peripheren Nervensystems, ein völlig anderes. Auch kann man die im Rückenmark vorgefundenen Veränderungen nicht durch eine von den verdickten und infiltrierten Rückenmarkshäuten hervorgerufene Compression der Wurzeln und Atrophie der letzteren erklären, da sich diese Hüllen als völlig normal erwiesen. Ebenso kann man auch der Blutarmut unseres Patienten keine grosse Bedeutung beimessen, denn erstens erreichte dieselbe keinen hohen Grad und zweitens tritt diese Erkrankung - und zwar gerade dann, wenn sie im höchsten Grade ausgeprägt ist, bei den sogenannten letalen Anämien - in einzelnen Herden auf, und obschon mitunter die Lokalisation der secundären Entartungsbereiche die Degeneration eines Systems vortäuschen kann, so weisen doch einzelne Herde die Anzeichen der acuten disseminierten Myelitis (Boedeker, Juliusberger, Nonne, Minich) auf, die sich grösstenteils in der Nähe der Gefässe lokalisiert, während die Lissauersche Zone und die hinteren Wurzeln verschont bleiben. Die graue Substanz pllegt hierbei äusserst selten und ausserdem nur in chronischen Fällen betroffen zu sein. Uebrigens hängt die Affektion des Rückenmarks bei Anämien offenbàr nicht unmittelbar von der Anämie, sondern von zufällig hierbei entstehender Sepsis ab (Russel). In unserem Falle ergaben aber die unter dem Mikroskop gefundenen Veränderungen nichts Derartiges. Die gleichen Erwägungen gestatten uns, die Bedeutung der Kachexie und des Marasmus unter den sonstigen ätiologischen Momenten der Degeneration des Nervensystems im gegebenen Falle gering anzuschlagen. Die gleichen unter dem Mikroskop festgestellten Daten sprechen auch gegen eine lokale infektiöse Erkrankung des Rückenmarks. Eine infektiöse Ursache hätte, wie auf dem Wege des Experiments (Homen) und klinischer Beobachtungen festgestellt worden ist, eine Reihe von Veränderungen seitens der Gefässe (Hyperämie, Austritt der weissen Blutkörperchen, Infiltration des umgebenden Gewebes) hervorrufen müssen, während hier nichts Derartiges zu bemerken war. 
Wir schreiben in unserem Falle die Affektionen des Centralnervensystems der Einwirkung derjenigen schädlichen Produkte zu, die beim Diabetes im Blute circulieren und dadurch, dass sie in enge Berührung mit den Zellen des Gehirns und Rückenmarks gelangen, deren Lebenstätigkeit alterieren. Was nun die Frage anbelangt, warum denn die schädlichen Produkte in den Rückenmarkszellen scharf ausgeprägte Veränderungen hervorriefen, während die peripheren Teile in den oberen Extremitäten verschont geblieben waren, so erklären wir das durch das Vorhandensein eines locus minoris resistentiae in der als trophisches Centrum dienenden Zelle des Rückenmarks, weshalb das gegebene in Blut kreisende Agens auf dasselbe eine nur lokale Wirkung ausgeübt hat, während wir das Absterben einzelner Fasern des peripheren Nervensystems ohne Beteiligung des bindegewebigen Stützgerüstes des Nerven in den unteren Extremitäten als kachektische Atrophie einzelner Nervenfasern infolge anhaltend wirkender Intoxikationen von geringerer Intensität auffassen.

Klinisch entspricht der gegebene Fall bis zu einem gewissen Grade dem Bilde der Pseudotabes diabetica. Hiermit stimmen die sensorischen Störungen im unteren Teile des Rumpfes, die Ataxie und der Verlust der Sehnen- und Hautreflexe überein. Vollkommen würden hiermit das Erhaltensein der Pupillenreflexe auf Jicht und der Verlust der Geschlechtsfunktion im Einklang stehen. Bei der Classificierung der vorliegenden Erkrankung rom pathologisch-anatoınischen Standpunkt kommen zwei typische Erkrankungen in Betracht, mit denen die unsere eine gewisse Aehnlichkeit aufweist, und zwar Poliomyelitis anterior subacuta und Tabes dorsalis. Zugunsten der Annahme, dass wir es hier mit einem Fall von Poliomyelitis anterior subacuta zu tun haben mögen, spricht die Atrophie einzelner Gruppen der Muskeln der unteren Extremitäten und der Untergang der Zellen der Vorderhörner. Diese Hypothese findet aber vom klinischen Standpunkt keinerlei Unterstützung, da Sensibilitätsstörungen und Ataxie gar nicht zu dem Bilde dieser Erkrankung gehören. Noch mehr gegen diese Erkrankung sprechen die durch die histologische Untersuchung gewonnenen Ergebnisse, und zwar widerspricht dieser Diagnose die Affektion der Burdachschen Stränge. Die vorhandenen vereinzelten Beobachtungen von Poliomyelitisfällen, wo bei der Autopsie isolierte Affektionen der Burdachschen Stränge gefunden wurden (JoffroyLelesson, Oppenheim) sind eine grosse Seltenheit und berechtigen jedenfalls nicht $z u$ Verallgemeinerungen. Ferner spricht gegen die Diagnose Poliomyelitis anterior subacuta noch das Fehlen von entzündlichen Veränderungen in den Vorderbörnern und der normale Zustand der Rückenmarksgefässe. Ebenso ist das Vorhandensein von diffusen Veränderungen des Rückenmarks und das Fehlen von Erkrankungsherden in demselben mit der hier vorausgesetzten Diagnose unvereinbar. Es sind jedenfalls mehr Gründe vorhanden, hier eine der Tabes analoge Rückenmarkserkrankung zuzugeben; freilich erscheint diese Analogie auf den ersten Blick schlecht mit dem Untergang der Zellen in den Vorderhörnern des Rückenmarks bei unserem Patienten übereinzustimmen, um so mehr, als eine solche Autorität wie Déjérine die Möglichkeit einer 
Veränderung der Vorderhörner bei reiner und typischer Tabes vollkommen in Abrede stellt, doch haben andere durchaus vertrauenswürdige Beobachter unstreitig eine Degeneration der Zellen der Vorderhörner und überhaupt der motorischen Kerne (mit Muskelatrophie) bei Tabes vermerkt. Leyden hat bei Tabes Muskelatrophie, Sklerose, Pigmentation und Schrumpfung der Ganglienzellen der Vorderhörner gefunden. Derselbe Autor fand die gleiche Erscheinung in noch einem Falle, wo ausserdem dio Nervenfasern atrophiert waren. Dasselbe fanden Charcot-Pierret und Eisenlohr.

Raymond und Artaud vermerkten bei einem Diabetiker Atrophie der Zunge, des $\mathbf{N}$. hypoglossus und des Kerns dieser Nerven. Da nun ausserdem bei Tabes vielmals Affektionen der peripheren Nerven mit Muskelatrophie von solchen Autoren wie Pierret-Vaillard, Déjérine, Oppenheim, Raymond-Artaud, Goldscheider beobachtet worden sind, so wäre das Leiden unseres Patienten nicht als Pseudotabes, sondern einfach als Tabes diabetica zu bezeichnen.

\section{Beobachtung.}

In Ergänzung unserer I. Beobachtung fügen wir in gedrängter Kürze noch eine Untersachung des Plexus coeliacus, der Langerhansschen Inselchen, des Rückenmarks und des peripheren Nervensystems eines im diabetischen Coma verstorbenen Patienten hinzu. Die Präparate verdanken wir der ganz besonderen Liebenswürdigkeit des Herrn Dr. N. Michailow, Assistenten des Herm Prof. W. Obraszow, Kiew.

Die klinische Beobachtung des Patienten ist überaus kurz. Im Krankenjournal der Kiewer therapeutischen Klinik rom 25. 9.1912 ist verzeichnet, dass ein kachektischer Patient von mittlerem Alter, dessen Stand, Vor- und Familienname in Ermangelung der betreffenden Dokumente nicht eingetragen sind, der früher an der Zuckerkrankheit gelitten hatte, im Zustande des diabetischen Coma in die Klinik eingebracht wurde, wo er nach 28 Stunden, ohne zu vollem Bewusstsein gekommen zu sein, starb. Es wurden 10 pCt. Zucker im Harn nachgewiesen. Von Störungen des Nervensystems war intra vitam vom bebandelnden Arzt Pupillenerweiterung, schlechto (träge) Reaktion derselben auf Licht und Incontinentia urinae festgestellt. Die motorische Sphäre, die Sensibilität, Haut- und Sehnenreflexe und elektrische Reaktion wurden nicht untersucht. Die 18 Stunden nach dem Tode vorgenommene Sektion ergab Atrophie des Plexus coeliacus, ein normales Pankreas und keine Arteriosklerose.

Mikroskopisch untersucht wurden: Plexus coeliacus, Pankreas, das Rückenmark in seiner ganzen Ausdehnung uud ein Teil der peripheren Nerven, worunter sich auch der N. pudendus befand.

Die Untersuchung des Plexus coeliacus nach Niss l ergab den Schwund eines Teiles der Zellelemente. Die Defekte der Zellelemente sind durch Bindegewebe ersetzt. Die Mehrzahl der Zellen des Ganglions stellt sich als dem Umfang nach verringert dar, während in der Minderzahl der Zellen eine partielle Chromatolyse zur Beobachtung gelangt. Die Kerne baben an Umfang eingebüsst, liegen im Centrum und sind diffns gefärbt. Gefässe hỵperämisch.

Nach Bearbeitung der Pankreasstücke nach den allgemein bekannten Regeln liessen die Präparate unter dem Mikroskop folgendes erkennen: die Zellen des Pankreas unterscheiden sich in nichts van der Norm. Es konnten weder fettige Degeneration, noch Vacuolisation, noch Chromatinarnut ihrer Kerne, noch Abnahme ihres Umfanges 
heobachtet werden. Ebensowenig bestand eine Vergrösserang der Kerne. Zustand der Gefässe normal. Was die Langerhan ssoben Inselohen anbelangt, so ergibt die Besichtigung der Schnitte eine normale Anzahl und Grösse derselben. Bei schwacher Vergrösserung treten die Langerbansschen Inselchen infolge der spezifischen Färbung recht deutlich inmitten des Drüsengewebes hervor. Das Protoplasma ihrer Zellen färbt sich recht intensiv. Die Körnigkeit der letzteren ist im Vergleiche zur Norm merklich vermindert. Zellgrenzen deutlich. Die Kerne der Inselzellen sind chromatinreich und färben sich diffus. Eine Pyknose derselben wird nicht beobachtet. Kerngrenzen sichtbar. Die Zellen selbst sind gleichsam zusammengedrückt, ihrem Umfang nach verringert, insbesondere an den Stellen, wo viel Zymogen erhalten geblieben ist. Capillaren normal. Ein Ausführungsgang oder eine besondere Bindegewebshülle konnte nicht festgestellt werden.

Das Rückenmark wurde in mehrere Abschnitte geteilt und zum Teil in Müllerscher Flüssigkeit für die Untersuchung nach Woigert, van Gieson und Marchi, zum Teil aber auch in Alkohol oder Sublimat zar Untersuchung nach Nissl fixiert. Was die Resultate der Untersuchung anbelangt, so ergab die Färbung der Präparate nach Weigert und van Gieson keinerlei Veränderungen der weissen Rückenmarksstränge. Die Bearbeitung des Rückenmarks nach Marchi liess diffuse, ihrer Lokalisation nach recht unbestimmte Veränderungen der Peripherie des kückenmarks erkennen. Hingegen wurden bei der Färbang des Rückenmarks nach $\mathrm{Nissl}$ scharf ausgeprägte Veränderungen gefunden.

Auf vielen aus der Lendenansohwellung, aus einigen Segmenten des Brustuarks und aus dem Halsmark stammenden Präparaten wurde Folgendes bemerkt: die Zahl der Vorderhornzellen ist im Vergleich zur Norm nicht verringert. Viele derselben haben ibre Protoplasmafortsätze eingebüsst, sind von leeren Räumen umgeben und vielleicht von geringerem Umfang als in der Norm. Einige Zellen enthalten Anbänfungen von gelben Pigmentschollen, die entweder nur im Fortsatz allein oder am Zellrande zwisohen 2 Fortsätzen zerstreut sind. In diesen pigmentierten Zellen sind die $\mathrm{Niss}$ ischen Körnchen diffus und überaus blass gefärbt, die Kerngrenzen solcher Zellen sind undeutlich, die Färbung der Kerne ist überaus blass, ein Kernkörperchen ist gar nicht sichtbar. Einige derartige ihrer Fortsátze beraubte Zellen haben ibre dreieckige Form eingebüsst und sind fast vollkommen rund.

Ein Teil der Zellen ist durchweg mit gelbem Pigment durchsetzt; die Körnchen dieses letzteren sind jedoch überaus klein. Die Nisslschen Körnchen solcher Zellen sind recht deutlich zu unterscheiden und gut gefärbt. Die Kerne solcher Zellen sind durch Pigment verdeckt; die Fortsätze sind wenig geschrumpft; rund um die Zelle jst ein leerer Raum zu sehen. Einige Zellen haben einen überaus angeschwollenen und äusserst blassen Kern; hingegen ist das Kernkörperchen intensiv gefärbt.

Die Untersuchung der peripheren Nerven geschah mit Hilfe der Färbung mit 1-2 proc. Osmiumsäurelösung, wio auch mit Carmin-Alaun-Hämatoxylin und nach Weigert. Hierbei stellte sich heraus, dass die Myelinscheiden der Fasern des N. pudendus leichte Anschwellungen zeigten, stellenweise körnigen Zerfall in ihren peripheren Schichten aufwiesen und dass ibre Färbung, sowohl die mit Osmiumsäure, als auch die nach Weigert nicht genügend intensiv war. Das interstitielle Bindegewebe des N. pudendus, seine Vasa nervorum, sowie seine Schwannschen Kerne erwiesen sich als völlig unverändert. Die anderen in derselben Weise untersuchten peripheren Nerven liessen unter dem Mikroskop keinerlei Veränderungen erkennen.

Wenn wir das vorstehend Erörterte zusammenfassen, so sehen wir im vorliegenden Falle eine scharf ausgeprägte Affektion des Plexus coeliacus, der Langerhansschen Inselchen und der Rückenmarkszellen, 
während das periphere Nervensystem, den leicht degenerierten $\mathrm{N}$. pudendus ausgenommen, sich in normalem Zustande befindet.

Obschon diese Beobachtung in vieler Hinsicht durchaus ungenügend ist, führen wir dieselbe doch als Beweis dafür an, dass, ebenso wie in Beobachtung I, beim Diabetes betroffen sind: der Plexus coeliacus, die Langerhansschen Inselchen und das Rückenmark, wobei die Affektion des Centralnervensystems im Rückenmark beginnen und einen absteigenden Verlauf nehmen kann. Was nun die Entwicklung und den Verlauf der Affektion im Plexus coeliacus und in den Langerhansschen Inselchen anbetrifft, so können wir diesbezüglich nur das anlässlich der ersten Erkrankung Gesagte wiederholen.

\section{Experimentelle Daten.}

In unseren weiteren Erwägungen werden wir bei der Betrachtung der Frage von der Glykosurie auf nervöser Grundlage unsere Aufmerksamkeit ausschliesslich auf die experimentelle Glykosurie richten.

Als erster Forscher auf diesem Gebiet ist $\mathrm{Cl}$. Bernard zu nennen, der einen schnell vorübergehenden Diabetes nach einem Stich in den Boden des IV.Ventrikels entdeckte. Man wusste allerdings bereits früher, dass diabetische Veränderungen des Harns auch bei Affektion der Nervencentren auftreten können. Diesbezügliche Aeusserungen haben Gregory im Jahre 1807, Frank im Jahre 1812 und Stosch im Jahre 1828 getan. Doch Cl. Bernard gebührt die Ehre der Entdeckung des ursächlichen Zusammenhanges zwischen der Affektion des Nervensystems und dem Auftreten von Zucker im Harn. In seinen „Vorlesungen über Physiologie und Pathologie des Nervensystems" ${ }^{\prime}$ sagt Cl. Bernard, dass ein Stich in die Mitte derjenigen Stelle, wo der N. acusticus und N. vagus entspringen, d. h. in dem Boden des IV. Ventrikels, gleichzeitig ein Anwachsen der Harnmenge und das Auftreten von Zucker in demselben bedingt; wird aber der Stich etwas oberhalb der oben bezeichneten Stelle ausgeführt, so gelangt weniger Harn zur Absonderung, wobei derselbe aber in diesem Falle oft Eiweiss enthält. Valentin gibt an, dass Gräffe dadurch Diabetes hervorrief, dass er Flüssigkeit in den IV. Ventrikel einspritzte. Die Stelle für den Diabetes hervorrufenden Stich nimmt Cl. Bernard (beim Kaninchen) als stecknadelkopfgross an, während Schrader dieselbe für $5 \mathrm{~mm}$ gross hält. Als eine interessante Ergänzung zu der von Cl. Bernard festgestellten Tatsache erscheint eine von Schiff gemachte Entdeckung. Derselbe gelangte, von der Annahme ausgehend, dass die Einwirkung des Nervensystems auf die Zusammensetzung des Harns durch eine Veränderung des Gefässtonus erreicht wird, zu der Schlussfolgerung, dass eine Verletzung der das Gehirn mit den Baucheingeweiden verbindenden Nerven gleichfalls Diabetes hervorrufen müsse. Und es gelang ihm in der Tat durch Zerstörung des Rückenmarks vermittels einer Nadel, die er in verschiedenen Richtungen bewegte, bei Fröschen einen ebensolchen Diabetes hervorzurufen, wie der nach dem Stich in den Boden des IV. Ventrikels beobachtete. Im gegebenen Fall wird ebenderselbe CI. Bernardsche Stich ausgeführt; die Notwendigkeit, einen grösseren Bereich dos Rückenmarks zu zerstören 
wird jedoch nur durch den Umstand bedingt, dass die Nervenfasern, die im IV. Ventrikel bei den Säugetieren in enger Berührung stehen, im Rückenmark auf eine längere Strecke verteilt sind.

Bei seinen Forschungen, die darauf gerichtet waren, die Ursache der Wirkung des Stiches in den Boden des IV.Ventrikels zu ergründen, unternahm Cl. Bernard eine Reihe von Versuchen, die zeigten, dass nicht sämtliche dem verlängerten Marke beigebrachten Schädigungen Diabetes zur Folge haben: so z. B. riefen beim Kaninchen die Beschädigungen der keilförmigen Körper keinen Diabetes hervor, sondern es schien sogar, als hörte die Harnabsonderung hiernach auf. Die Durchschneidung des Kleinhirns mit dem Messer rief jedoch bei vielen Kaninchen eine Veränderung des Harns in dem Sinne hervor, dass sich nach der Operation in ihm ein Zuckergehalt nachweisen liess. Diese Beobachtung wird auch von Schiff bestätigt, der unter den gleichen Verhältnissen einen starken, bis zum Tode anhaltenden Diabetes sah. Auf der Suche nach den Wegen begriffen, auf denen die Wirkung des Stiches vom verlängerten Marks zur Leber als dem Hauptorgan für die Glykogenbildung gelangt, fand $\mathrm{Cl}$. Bernard, dass die Durchtrennung des Rückenmarks die Wirkung des Stiches aufhob.

Somit erwies es sich, ${ }_{n}$ dass die Wirkung der Reizung durch das Rückenmark übermittelt wird“" und die Annahme, dass als die diese Reizung übermittelnden Bahnen der N. vagus und der N. sympathicus zu betrachten sind, stellte sich als falsch heraus, da ibre Durchtrennung die Bildung eines zuckerhaltigen Harns nach dem Stich in den Boden des IV. Ventrikels nicht verhindert, während die Reizung der centralen Abschnitte des $\mathrm{N}$. vagus durch Galvanisation das Auftreten einer beträchtlichen Zuckermenge im Harn nach sich zieht. Es ist interessant zu vermerken, dass den Beobachtungen von Cl. Bernard zufolge bei durch Hunger und Krankheit geschwächten Tieren ein künstlicher Diabetes sich nicht hervorrufen lässt. Seine Versuche hat Cl. Bernard an Kaninchen und Hunden angestellt; als er dieselben aber an Vögeln (Tauben) vornahm, erwies es sich, dass sich bei ihnen vermittels des Stiches kein solcher Effekt erzielen liess. Kühne und Schiff beobachteten eine positive Wirkung des Stiches bei Fröschen, während Thiel, der als Versuchstiere Hühner gewählt hatte, keine Zuckerausscheidung nach dem Cl. Bernardschen Stich zu verzeichnen hatte. Somit sollte man meinen, dass die Vögel auf den Cl. Bernardschen Stich nicht reagieren, wenn nicht durch die Bernhardtschen Versuche an T'auben das Gegenteil bewiesen worden wäre.

Ueberhaupt ist zu bemerken, dass nicht alle Tierarten in gleichem Masse auf die das Auftreten von Zucker im Harn bedingenden Ursachen reagieren. Als deutlicher Beweis hierfür dienen die Versuche von Böhm und Hoffmann, die bei Katzen einen schnell vorübergehenden Diabetes als Folgeerscheinung einer durch eine geringfügige Operation (Tracheotomie) oder sogar durch einfaches Fesseln an den Operationstisch hervorgerufenen Nervenerschütterung beobachteten. Die Dauer dieser von ihnen als Fesselungsdiabetes bezeichneten Erscheinung pflegt verschieden zu sein und zwar währt dieselbe $3-13$ Stunden, wobei der Zucker an- 
fangs in mässiger oder geringer Menge abgesondert wird, worauf die Absonderung schnell ihr Maximun erreicht, um sodann schnell wieder zu sinken.

Pavy war zuerst bemüht, klarzustellen, ob Schädigungen des sympathischen Nervensystems Einfluss auf die Entstehung des Diabetes haben. Dieser Forscher behauptet, dass die Durchschneidung gewisser Teile des N. sympathicus eine starke diabetische Wirkung habe. Bei Durchschneidung sämtlicher Halsnerven mit nachfolgender künstlicher Atmung fand Pavy im Harn des Tieres eine beträchtliche Zuckermenge. Nach diesem Versuch und einer Reihe von anderen, in denen auf beiden Seiten des Halses gleichzeitig die aufsteigenden Aeste des oberen Brustganglions unterbunden wurden, gelangte er zu der Schlussfolgerung, dass eine derartige Operation ungefähr nach $1 / 2$ Stunde einen scharf ausgeprägten Diabetes hervorraft.

Die Durchtrennung des aufsteigenden Astes nur auf einer Seite des Halses hatte nach $1 / 2$ Stunde nur das Auftreten von Zuckerspuren zur Folge. Die sodann auch auf der anderen Seite in gleicher Weise vorgenommene Operation ruft bereits nach $1 / 2$ Stunde eine reichliche Zuckerausscheidung hervor. Die weitere Verfolgung des Einflusses von an den Nn. sympathici vorgenommenen Operationen auf die Zuckerausscheidung im Harn gab ihm Gelegenheit festzustellen, dass beim Hunde der stärkste Diabetes in kürzester Frist durch die Entfernung des oberen Halsganglions erzielt wird. Nach der Entfernung des einen Ganglions wurde der Urin intensiv zuckerhaltig befunden und bewahrte diesen Charakter im Laufe des nächsten Tages. Die darauffolgende Entfernung des anderen Ganglions hatte nach einigen Tagen einen stark ausgeprägten zeitweiligen Diabetes zur Folge. Die Durchschneidung des Brustabschnitts, des N. sympathicus, rief mitunter Zuckerharn hervor, während in anderen Fällen ein kaum merklicher oder überhaupt gar kein Effekt erzielt wurde. Bei Landois und Ploch finden wir Hinweise auf die Versuche von Gräffe, der behauptet, dass er eine kurzdauernde Glykosurie nach Durchschneidung des N. splanchnicus beobachtet habe. Diese Beobachtung wird von Hensen, der allerdings keine präcisen Daten angibt, bestätigt; ebenso sagt Ludwig in seinem Handbuch der Physiologie, dass nach der Durchschneidung des N. splanchnicus Zucker im Harn auftritt.

$\mathrm{Zu}$ bis zu einem gewissen Grade gleichen Schlussfolgerungen gelangte auch Ploch, und zwar sagt er auf Grund von vorzugsweise an Kaninchen angestellten Versuchen, dass bei der Durchschneidung des N. splanchnicus in einigen Fällen deutliche Glykosurie eintritt, während in einigen anderen hierbei die Veränderungen des Harns im angegebenen Sinne undeutlich und unbestimmt, oder aber gar nicht vorhanden sind. Ueber ähnliche Resultate, und zwar, dass die Durchschneidung des N. splanchnicus nicht immer eine Glykosurie ergibt, berichtet auch Brücke in seiner Physiologie. Eckhard, der die Durchschneidung dieses Nerven an vielen Stellen - von der Durchbruchsstelle desselben durch das Diaphragma bis zum ersten Intercostalraum, vorgenommen bat, erhielt stets ein positives Resultat. 
Er war der der Meinung, dass die Bedeutung des N. splanchnicus für die Entstehung des Diabetes sich auf den Zusammenhang dieses Nerven mit den sympathischen und Spinalganglien gründet und folglich bei mechanischer Reizung dieser Ganglien, z. B. bei ihrer Durchschneidung Diabetes auftreten müsse.

Ferner fand Eckhard, dass die Durchschneidung des oberen Halsganglions beim Kaninchen und die Exstirpation desselben beim Hunde keinen Diabetes hervorruft, während die Durchschneidung des unteren einen stark ausgeprägten Diabetes nach sich zieht, der nach dem gleichen Zeitraum auftritt, wie nach dem Cl. Bernardschen Stich. Während der ersten 2 Stunden nach der Operation wird er in am stärksten ausgeprägter Form beobachtet; nach 5 Stunden verringert er sich merklich, doch Spuren desselben sind mitunter noch 24 Stunden nach der Operation vorhanden. Nach der Durchschneidung des I. und Il. Brustganglions erweist sich der Diabetes als schwächer als nach der des unteren Halsganglions, wobei er nach der Durchschneidung des II. Brustganglions schwächer ausgeprägt zu sein pflegt als nach der des I. Durch die aufeinanderfolgende Durchschneidung zuerst des unteren Hals- und sodann des I. und III. Brustganglions bei einem und demselben Kaninchen gelang es dem Autor, nacheinander diabetische Erscheinungen hervorzurufen, wobei dieselben nach fast völligem Verschwinden von neuem annäherd die gleiche Höhe erreichten. Diese Versuche gelangen nicht immer, da die Tiere mitunter eingingen. Die niedriger gelegenen . Ganglien hat Eckhardt nicht durchschnitten.

Sehr interessant in dieser Hinsicht sind die Untersuchungen von Cyon und Aladoff, die die letzten Hals- und verschiedene Brustganglien des Sympathicusgeflechts durchschnitten und nach $1-11 / 2$ Stunden seit dieser Operation Glykosurie beobachteten. In der Absicht klarzustellen, welche Nerven denn eigentlich diese Wirkung ausüben, durchschnitten sie der Reihe nach die einzelnen mit dem I. Brust- und letzten Halsganglion in Verbindung stehenden Fasern und fanden, dass Diabetes nach der Durchschneidung der vertebralen $\Lambda$ este und der Ansa Vieussenii erhalten wird. Ferner gelangen sie nach der Durchschneidung des N. sympathicus zwischen der X. und XI. und der XI. und XII. Rippe zu der Ueberzeugung, dass die Durchschneidung des Nervenstranges auf diesem Niveau fast niemals Diabetes erzeugt.

Nach der Ansicht dieser Forscher spielen bei der Entstehung des Diabetes die mit der Ansa Vieussenii in Verbindung stehenden vasomotorischen Lebernervon eine Rolle. Die Paralyse der gefässverengernden Lebernerven bedingt dadurch, dass sie einen verstärkten Blutzufluss zur Leber hervorruft, eben die Entstehung des Diabetes.

Im Jahre 1879 erschien eine Arbeit von Suchanow, in der die Eckhardschen Versuche einer Nachprüfung unterworfen wurden. Suchanow beobachtete Diabetes bei der Durchschneidung des unteren Halsganglions (in allen 6 Versuchen), und mit etwas geringerer Beständigkeit nach der Durchschneidung des ersten Brustganglions (unter 9 Fällen $6 \mathrm{mal})$. Die durch diese Operationen hervorgerufene Veränderung der Zusammensetzung des Harns erfolgt ungefähr 50 Minuten, eine oder zwei 
Stunden nach der Operation und verschwindet nach 2, 3 oder 4 Stunden. Gleichzeitig hat er die Cyonschen Versuche über die Einwirkung der Durchschneidung der Ansa Vieussenii - und zwar der ganzen und ihrer einzelnen Fasern - auf die Entstehung des Diabetes nachgeprüft, ohne jedoch die Beobachtungen dieses Autors bestätigen zu können, ebensowenig wie auch Pavy die Beobachtungen desselben Forschers bezüglich der Durchschneidung der Spinalnerven zu bestätigen vermochte.

Schliesslich sind noch die Untersuchungen von Külz zu erwähnen, der den Ausspruch tut: „Nach Durchschneidung des Halssympathicus scheint kein Autor Diabetes beobachtet zu haben", und gleichzeitig die folgenden Resultate seiner Versuche aufführt. Er durchschnitt bei zehn Kaninchen den Halssympathicus bei sorgfältiger Harnuntersuchung vor und während des Versuches. Nach der Vernähung der Wunde wurde das Ende des Nerven mit dem Induktionsstrom gereizt. Man erhielt folgendes Resultat: Nach der Durchschneidung beobachtete man in 2 Fällen cine leichte Reduktion und in 2 Fällen eine deutliche Reaktion auf Zucker. In 6 Fällen wurde nach der Reizung Glykosurie constatiert.

Schon früher hatten Klebs und Munk gefunden, dass bei Hunden die Durchschneidung der die Leberarterie begleitenden Nervenstränge oder aber die partielle Exstirpation des Plexus coeliacus Glykosurie hervorruft; sie haben sogar die Voraussetzung ausgesprochen, dass der Diabetes als das Resultat von in diesem Geflecht erfolgten Veränderungen erscheinen kann.

Lustig, der sich mit der Frage vom Einfluss des Plexus coeliacus. auf die Entstehung der Glykosurie beschäftigte, hat zu diesem Zwecke Versuche an Hunden und Kaninchen angestellt. Er operierte 7 Hunde, von denen nur 2 am Leben blieben; bei einem derselben bestand 2 Tage lang Glykosurie, während im Harn des anderen nur am ersten Tage Spuren von Zucker nachgewiesen wurden. An Kaninchen führte er 11 mal die Operation aus und hatte nur in 2 Fällen keine Glykosurie zu verzeichnen. Auf Grund dieser Ergebnisse gelangt er zu dem Schlusse, dass eine zeitweilige Glykosurie, die bekanntlich bei der Beschädigung der sympathischen Halsganglien beobachtet wird, auch nach der Entfernung des Plexus coeliacus beobachtet wird. Die hierbei im Harn auftretende Zuckermenge war in den verschiedenen Fällen eine verschiedene: bald wurden nur Spuren, bald beträchtliche Quantitäten nachgewiesen. Das Auftreten der Glykosurie lässt sich nach der Meinung des Autors einer Gleichgewichtsstörung der Vasomotoren in der Leber zuschreiben und erscheint als „der Ausdruck einer tiefgreifenden Veränderung des Stoffwechsels". In demselben Jahre hat derselbe Autor zur weiteren Klarstellung der Rolle, die diesem Geflecht zukommt, dasselbe exstirpiert und hierauf den Cl. Bernardschen Stich ausgeführt. Im Gegensatz zu Schiff, der unter den gegebenen Umständen keine Glykosurie hervorrufen konnte, hatte Justig ein positives Resultat in dieser Hinsicht zu verzeichnen und folgerte hieraus, dass sich der künstliche Diabetes auch bei Tieren entwickeln kann, deren Plexus coeliacus exstirpiert worden. Weitere Beobachtungen auf diesem Gebiet hat Peiper ausgeführt. Von den 15 operierten Versuchstieren, denen er den 
Plexus coeliacus entfernte, blieben 11 am Leben. Alle operierten Kaninchen ${ }_{n}$ zeigten am Operationstage die Anzeichen einer scharf ausgeprägten Depression" und nahmen kein Futter zu sich. Unter den Ueberlebenden wurde nur bei 3 (Nr. 6, 14, 15) überhaupt kein Zucker beobachtet. Bei 2 (Nr. 10, 12) stellte sich die Glykosurie am 1. Tage nach der Operation ein; am 2. Tage wurde der Zucker in 3 Fällen (Nr. 2, 4, 13) festgestellt, doch muss hier bemerkt werden, dass in diesen Fällen am ersten Tage nach der Operation überhaupt kein Harn abgesondert wurde, so dass die Glykosurie im Grunde auch hier schon am 1. Tage des Auftretens von Harn nach der Operation vorhanden war. Dagegen wurde in 2 Versuchen (Nr. 9 und 11) der Zucker am 3. Tage nach der Operation nachgewiesen, doch auch in diesen Fällen handelte es sich um eine Harnverhaltung bei den Tieren, und zwar wurde im Fall Nr. 9 am 2., und im Fall Nr. 11 am 1. Tage nach der Operation kein Harn ausgeschieden. Endlich wurde in Versuch Nr. 1 Glykosurie am 16. Tage beobachtet, so dass dieselbe hier doch wohl nicht auf die Operation, sondern auf zufällige Umstände zurückzuführen ist. Die Zuckermenge war nicht in allen Fällen die gleiche, ebenso wie auch die Frist, während welcher der Zucker nachgewiesen werden konnte, verschieden war. Nur in einem einzigen Fall (Nr. 4), wo, ausser der Entfernung der Ganglien auch die Resektion eines $2 \% \mathrm{~cm}$ langen Stückes des $\mathrm{N}$. splanchnicus erfolgt war, trat eine lange währende, anfänglich einen intermittierenden Charakter aufweisende Glykosurie ein. Dieselbe währte bis zum Tode des Tieres, der nach 4 Wochen erfolgte. Die Zuckermenge erreichte in diesem Falle mitunter $4 \mathrm{pCt}$. Ich habe die Peiperschen Versuche aus dem Grunde mit solcher Ausführlichkeit besprochen, weil einige Autoren darauf hinweisen, dass die Ergebnisse dieser Versuche die Tatsache der Entstehung der Glykosurie nach der Entfernung des Plexus coeliacus widerlegen. Lustig hat im Jahre 1891 wieder eine Arbeit über den Einfluss der Entfernung des Plexus coeliacus auf die Entstehung der Glykosurie veröffentlicht; er bestätigt in derselben, gestützt auf 10 an Hunden und 6 an Kaninchen angestellte Versuche, seine früheren Schlussfolgerungen. Gleichzeitig fand er (auf Grund von 20 Versuchen), dass die Durchschneidung des N. splanchnicus mitunter eine leichte Glykosurie ergibt, - ein Effekt, der ebenso auch durch die Entfernung des Plexus aorticus erzielt wird. Gleichzeitig mit Lustig hat $0 \mathrm{ddi}$ seine die Beobachtungen des ersteren bestätigenden Ergebnisse veröffentlicht. Bei 4 Hunden, denen der Plexus coeliacus entfernt worden war, beobachtete er Glykosurie verschiedenen Grades. Oddi operierte, im Gegensatz zu Lustig, ohne Anwendung von antiseptischen Mitteln, um den Verdacht auszuschliessen, dass gerade die Reizung des Peritoneums durch diese Mittel eine zeitweilige Glykosurie ergibt. Oddi gelangt sehliesslich zu dem Resultat, dass die Entfernung des Plexus coeliacus eine zeitweilige Glykosurie von verschiedener Stärke und von nicht mehr als 2 tägiger Dauer hervorruft. Fast gleichzeitig mit den Arbeiten von Lustig und Oddi erschien eine Arbeit von Viola, der fand, dass bei der Entfernung des Plexus coeliacus die zeitweilige Glykosurie keine beständige Erscheinung ist und vielleicht von durchaus 
zufälligen, im Moment der Operation gerade bestehenden Bedingungen abhängt. Er hat deshalb in seinen Versuchen auch nicht immer eine Untersuchung in dieser Richtung angestellt; trotzdem stellt er aber die Entstehung der Glykosurie nach der Entfernung des Plexus coeliacus in Abrede.

Oddi setzen die von Viola erhaltenen, den Beobachtungen von Lustig, ihm selbst, Munk und Klebs widersprechenden Ergebnisse in Erstaunen. Doch auch Lewin und Boer, die den Plexus coeliacus bei 4 Kaninchen und Klecki, der denselben bei 4 Katzen entfernte, vermochten keine Glykosurie bei ihren Versuchen nachzuweisen. Die Versuchsergebnisse von Klecki erscheinen uns unerklärlich, wenn man die Beobachtungen von Böhm und Hoffmann (Fesselungsdiabetes) in Betracht zieht.

Die Frage von der Veränderung der Zusammensetzung des Harns bei der Entfernung des Plexus coeliacus berührt übrigens auch $\mathrm{Po-}_{0}$ pelsky (1903) in seiner Untersuchung über die Physiologie dieses Geflechts. Nach seiner Exstirpation hat dieser Forscher keine Glykosurie auftreten sehen. Im folgenden Jahre erschien eine Arbeit von Strehl, die der Untersuchung des Einflusses von Seiten der Nerven der Bauchhöhle im allgemeinen und des Plexus coeliacus im besonderen auf den Puls bei Peritonitis gewidmet war. Bei der Besprechung der Physiologie des Plexus coeliacus führt Strehl die diesbezügliche Literatur an, in der, worauf wir auch schon selbst hingewiesen, einander widersprechende Daten anzutreffen sind. So z. B. erwähnt er die Arbeiten von Ald ehoff und Mering, die in einigen Fällen nach der Entfernung des Plexus coeliacus eine vorübergehende Glykosurie fanden. Nach sorgfältiger Prüfung der Schlussfolgerungen aller Autoren gelangt Strehl zur Meinung, dass man nach der Entfernung des Plexus coeliacus neben anderen Störungen der physiologischen Funktionen auch eine zeitweilige Glykosurie und sogar Diabetes mellitus beobachten kann. Schliesslich finden wir im Jahre 1906 eine Arbeit von Bürger und Churchmann, in der die Rolle des Plexus coeliacus und mesentericus beim Abdominalshock untersucht wird. Die genannten Autoren nahmen bei 9 Hunden eine Exstirpation vor und untersuchten bei 2 von ihnen den Harn während einer Woche, ohne Zucker in demselben nachweisen zu können. Doch haben diese Autoren, wie sie selbst äussern, es angesichts der einander widersprechenden Angaben der verschiedenen Forscher in der Frage vom Einfluss des Plexus coeliacus auf die Entstehung. der Glykosurie nicht für nötig gehalten, diese Seite der Frage genauer zu untersuchen. Ausser den obenerwähnten Versuchen, in denen eine unmittelbare Verletzung des sympathischen Nervensystems und insbesondere des. Plexus coeliacus, vorgenommen wurde, haben einige Autoren, wie z. B. Lustig und die Gebrïder Cavazzani Versuche mit der Reizung des Plexus coeliacus durch den elektrisehen Strom angestellt. Lustig hat hierbei mitunter Glykosurie erhalten; diese Erscheinung war aber unbeständig und schnell vorübergehend. Die Gebrüder Cavazzani haben bei der Reizung desselben Plexus durch den elektrischen Strom eine Hyperglykämie beob- 
achtet, wobei sie annehmen, dass dieselbe ihre Entstehung einer Ueberproduktion von Glukose seitens der Leber verdankt, da infolge der Reizung eine Zunahme des Zuckers im Leberblut and eine Abnahme des Glykogens in den Leberzellen beobachtet wird. Dieselben Autoren weisen darauf hin, dass beim Diabetes nach Exstirpation des Pankreas ausser den in der Jeber erfolgenden Veränderungen auch noch solche im Plexus coeliacus zu verzeichnen sind. Endlich ist noch eine Arbeit von Mac-Leod (1908) zu nennen, der fand, "dass eine 30 Minuten währende Reizung des N. splanchnicus eine Hyperglykämie hervorruft, die bei viele Stunden lang fortgesetzter Reizung ihr Maximum nach etwa 2 Stunden erreicht. Dasselbe hat auch für die als Begleiterscheinungen auftretende Diurese und Glykosurie Geltung. Als Resultat der Reizung sind zu verzeichnen: 1 . eine sensorische Reizung des Centrums in der Medulla, 2. eine vasomotorische Veränderung in der Leber, 3. eine Reizung der sekretorischen Fasern, denen die Kontrolle der Glykogenese zusteht". Leider stand mir die Originalarbeit nicht zur Verfügung, so dass ich dieselbe nacb einem Referat citiere.

Im Jahre 1909 erschien eine Mitteilung von Gaurelet und Thomas, die fanden, dass in der Tat bei Hunden eine $1 / 2$ stündige Reizung des N. splanchnicus durch einen Induktionsstrom von mittlerer Stärke Hyperglykämie und Glykosurie ergibt, während bei entkapselten Tieren nach der gleichen Reizung keine Glykosurie auftritt.

Das ist alles, was ich in der mir zugänglichen Literatur über diese Frage habe finden können. Wie ersichtlich, gelangt die Mehrzahl der Autoren zu der Schlussfolgerung, dass Verletzungen oder Reizungen der verschiedenen Abschnitte des sympathischen Nervensystems Glykosurie hervorrufen.

Zur Nachprüfung dieser Ergebnisse und zur präzisen Klarstellung des Charakters der Glykosurie bei Entfernung des Plexus coeliacus habe ich bei 3 Hunden die Entfernung dieses Ganglions vorgenommen, wobei ich folgende Resultate zu verzeichnen hatte:

\section{Versuche mit der Entfernung des Plexus coeliacus.}

Versueh I. Schwarzer Hund von $10 \mathrm{~kg}$ Körpergewicht.

18. 6. 1912. $100 \mathrm{ccm}$ Harn aufgefangen. Spec. Gew. 1006; der Harn ist fast farblos. Kein Zucker.

19. 6. Unter Morphium- und leichter Chloroformnarkose warde die Laparotomie ausgeführt. Der bequemeren Weiterführung der Operation balber wurde der Längsschnitt längs dem Rande des linken M. rectus abdom. geführt; die Gedärme wurden aus der Bauchhöhle herausgenommen, der Magen nach oben zurückgezogen. Sodann wurde die linke Niere aufgefunden, dio als Orientierungspunkt diente, wonach man mit Leichtigkeit die Art. coeliaca und Art. mesenterica superior finden und über ihnen durch das Peritoneum hindurch die Geflechte des sympathischen Systems erblicken konnte. Das über der Art. mesenterica superior gelegene Ganglion (Plexus coeliacus) wurde exstirpiert. Die Operation währte 20 Minuten.

Gleich nach der Operation wurden $40 \mathrm{ccm}$ Harn erhalten. Spec. Gew. 1005.

Weder am Tage der Operation, noch am folgenden wurden irgend welche Spuren von Zucker nachgewiesen. 
Nach einer Stunde wurden $15 \mathrm{ccm}$ Harn aufgefangen. Spec. Gew. 1017. Deutliche Reduktion. Beim Verdünnen von $10 \mathrm{ccm}$ Harn mit $2 \mathrm{ccm}$ essigsaurem Blei zeigte der Saccharineter $0,4 \mathrm{pCt}$. Zucker. Am folgenden Tage wurden in der $\mathrm{H}$ a in esschen und Nylanderschen Probe eine deutliche Reduktion festgestellt.

Nach 2 Stunden wurden $8 \mathrm{ccm}$ Harn erhalten. Spec. Gew. 1020. Sehr scharf ausgeprägte Reduktion. Bei Verdünnung von $5 \mathrm{ccm}$ Harn in $5 \mathrm{ccm}$ Wasser zeigte der Saccharimeter 1 pCt. Zuclier.

Nach 4 Stunden $18 \mathrm{ccm}$ trüben Harn erbalten. Spec. Gew. 1022. An diesem Tage ergaben die Hainessche, Nylandersche und die Worm-Müllersche Probo nur Spuren einer Reduktion, während am folgenden Tage eine deutlicbe Reduktion zu verzeichnen war, wobei dieselbe in der Worm-Müllerschen Probe weniger bemerkbar war als bei den beiden anderen: die Hainessche Probe färbte die obere Schicht blau und die untere blassgrün; die Nylandersche Probe gab eine deutliche schwarze Färbung der unteren Schicht, während die Worm-Müllersche den Harn entfärbte und ihm einen gelblichen Farbenton verlieh.

Sach 6 Stunden $14 \mathrm{ccm}$ trüben Harn aufgefangen. Spec. Gew. 1017. An diesem Tage kaum merkliche und an nächsten 'Tage deutliche Spuren ron Zucker im Harn. Auch in diesem Falle wiesen die Hainessche und Nylandersche Probe den Zucker deutlicher nach als die Worm-Müllersche.

20. 6. Um $8 \mathrm{Uhr}$ morgens $170 \mathrm{ccm}$ klaren, strohgelben Harn erhalten. Spec. Gew. 1012. An diesem Tage gaben alle 3 Proben auf Zucker ein negatives Resultat, am näcbsten Tage Spuren einer Reduktion. Um 12 Ubr $165 \mathrm{ccm}$ Harn von fast olivgrünem Farbenton gesammelt. Spec. Gew. 1014. Die Haines sche Probe ergab eine leichte Veränderung in der Farbe; die Nylandersche und Worm-Müllersche bewirkten keinerlei Veränderung; am nächsten Tage färbte die Worm-Müllersche Probe die untere Schicht gelblich. Befinden des Hundes zufriedenstellend.

21. 6. In 24 Stunden $1000 \mathrm{ccm}$ Harn erbalten. Spec. Gew. 1007. An diesem Tage kein Zucker; am nächsten Tage gab die Worm-Müllersche Probe eine Veränderung in der Färbung der unteren Schicht. Befinden des Hundes zufriedenstellend. Er erhält nur flüssige Nabrung und frisst viel.

22. 6. Harnmenge in 24 Stunden $900 \mathrm{ccm}$. Spec. Gew. 1009. Kein Zucker.

23. 6. Harnmenge in 24 Stunden $1100 \mathrm{ccm}$. Spec. Ger. 1012. Die WormMüllersche Probe ergab eine leichte Färbung der unteren Schicht, die übrigen Proben ein negatives Resultat. Der Hund erhält sein gewöhnliches Futter.

24. 6. Harnmenge in 24 Stunden $950 \mathrm{ccm}$. Spec. Ger. 1007. Kein Zucker.

25. 6. Harnmenge in 24 Stunden $450 \mathrm{ccm}$. Spec. Gew. 1014. Kein Zucker.

26. 6. Harnmenge in 24 Stunden $790 \mathrm{ccm}$. Der Harn ist hell, sein spec. Gew. 1016 ; er enthält keinen Zucker.

27. 6. Harnmenge in 24 Stunden $950 \mathrm{ccm}$. Färbung hellgelb. Spec. Gew. 1012. Kein Zucker.

28. 6. Harnmenge in 24 Stunden $500 \mathrm{ccm}$. Spec. Gew. 1017. Die WormMüllersche Probe gab eine leiche Färbung der unteren Scbicht; die anderen Proben negatir.

29. 6. Harnmenge in 24 Stunden $650 \mathrm{ccm}$. Spec. Gew. 1020. Die W ormMüllersche Probe gibt eine leichte Färbung der unteren Schicht; die übrigen Proben negativ.

30. 6. Harnmenge in 24 Stunden $800 \mathrm{ccm}$. Harn gesättigt. Spec. Gew. 1018. Die Worm-Müllersche Probe zeigt scheinbar Spuren von Zucker an. Die übrigen Proben, wie auch die Gährungsversuche, ergeben ein negatives Resultat.

1. 7. Harnmenge in 24 Stunden $700 \mathrm{ccm}$. Spec. Gew. 1016. Reaktion auf Zucker wie an lage vorher. Die Gärungsprobe gab ein negatives Resultat.

2. 7 . Harnmenge in 24 Stunden $850 \mathrm{ccm}$. Spec. Gew. 1013. Kein Zucker.

3. 7 . Harnnenge in 24 Stunden $450 \mathrm{ccm}$. Spec. Gew. 1020. Kein Zucker. 
Ueber die gegenseitigen Beziehungen zwischen Nervensystem u. Zuckerkrankheit. 209

4. 7. Harnmenge in 24 Stunden $900 \mathrm{ccm}$. Spec. Gew. 1017. Die Worm. M üllersche Probe gab am folgenden Tage eine leichte Gelbfärbung der unteren Schicht.

5. 7. Der Hund wurde getötet. Sektionsbefund: Bauchböble frei; entzündliche Erscheinungen und Verlötungen nicht vorhanden.

Versuch II. Schwarzer, rötlich gesprenkelter junger Hund von $6 \mathrm{~kg}$ Körpergewicht.

9. 7. 1912. $60 \mathrm{ccm}$ Harn aufgefangen. Spec. Gew. 1008. Kein Zucker. Nach $1 / 2$ Stunde Laparotomie. Seitlicher Schnitt längs dem Rande des M. rectus abdom. Der Plexus coeliacus wurde leicht gefunden und exstirpiert. Irgendwelche Störungen wurden hierbei nicht hervorgerufen. Die glatt verlaufende Operation wäbrte 15 Minuten.

Gleich nach der Operation kein Harn erhalten. 1 Stunde nach derselben $30 \mathrm{ccm}$ trüben Harns erhalten. Spec. Gew. 1042. Deutliche Reduktion. Boi Verdünnung ron $25 \mathrm{ccm}$ Harns mit $21 / 2 \mathrm{ccm}$ essigsauren Bleis wies der Saccharimeter 0,3 pCt. Zucker nach; Gärungsprobe $1 / 4 \mathrm{pCt}$.

Nach 2 Stunden $16 \mathrm{ccm}$ Harn erbalten. Spec. Gew. 1038. Deutliche Reduktion. Saccharimeter zeigt $0,4 \mathrm{pCt}$. Zucker. Gärungsprobe nach 24 Stunden ca. $1 / 2 \mathrm{pCt}$.

Nach 4 Stunden $28 \mathrm{ccm}$ trüben Harns erbalten. Spec. Gew. 1037. Deutliche Reduktion. Saccharimeter zeigt 0,2 pCt. Zucker; Gärungsprobe ca. $1 / 1$ pCt. Nach 7 Stunden $17 \mathrm{ccm}$ trüben Harns. Spec. Gew. 1032. Die Hainessche und Worm. Müllersche Probe ergaben ein negatives Resultat; am Tage darauf ergab die Hain essche Probe eine Veränderung der Färbung und ein gelbrotes Sediment, die Worm $M$ üllersche Probe ein Gelbwerden der Flüssigkeit.

10. 7. Am Morgen $29 \mathrm{ccm}$ trüben Harns erhalten. Spec. Gew. 1031. An diesem Tage ergaben die Hainessche und die Worm-Müllersche Probe eine unbedeutende, am folgenden Tage aber eine deutliche Veränderung der Farbe. Tagsüber $45 \mathrm{ccm}$ trüben Harns aufgefangen. Spec. Gew. 1028. Kein Zucker. Befinden des Hundes schlecht.

11. 7. $95 \mathrm{ccm}$ Harn erbalten. Spec. Gew. 1011. Kein Zucker. Der Hund erhält flüssige Nahrung; Befinden schlecht.

12. 7. $40 \mathrm{ccm}$ etwas trüben Harns erbalten. Spec. Gew. 1014. Die Haines. sche und Worm-Müllerscbe Probe ergaben eine leichte Veränderung in der Farbe. Der Hund scheint sich besser zu fühlen.

13. 7. $30 \mathrm{ccm}$ Harn erhalten. Spec. Gew. 1016. Die Hainessche und WormMüllersche Probe ergaben eine leichte Färbung der unteren Schicht. Der Hund frisst nicht; er trinkt nur Wasser.

14. 7. Tags ging der Hund ein. Sektionsbefund: eiterige Peritonitis.

Versuch III. Graver Hund ron $8,35 \mathrm{~kg}$ Körpergewicht.

17. 7. 1912. $50 \mathrm{~cm}$ gesättigten Harn herausgelassen. Spec. Gew. 1040. Kein Zucker. Laparotomie. Plexus coeliacus leicht gefunden und entfernt, wobei eine Blutung erhalten wurde, die wir zuerst vermittelst der T'orsionspinzette und sodann durch Anlegen einer ausser dem blutenden Gefässe wahrscheinlich zugleich auch Aeste des Sympatbicusgeflechts erfassenden Ligatur stillten. Die Operation dauerte 15 Minuten.

Mit etwas Verspätung erhielten wir 10-15 Minuten nach der Operation $15 \mathrm{ccm}$ Harn. Spec. Gew. 1032. Sehr scharf ausgeprägte Reduktion. Bei Verdünnung von einem Teil Harn mit einem Teil Wasser zeigte der Saccharimeter 1,5 pCt. Zucker; Gärungsprabe nach 6 Stunden ergab mehr als $1 \mathrm{pCt}$. Nach 1 Stunde $30 \mathrm{ccm}$ Harn erhalten. Spec. Gew. 1038. Eine sehr grosse Zuckermenge nachgewiesen: der Saccharimeter zeigte $6 \mathrm{pCt}$; Gärungsprobe bei Verdünnung 1 Teiles Harns mit 6 Teilen Wasser nach 6 Stunden 1 pCt. Nach 2 Stunden $20 \mathrm{ccm}$ bellen klaren Harns erhalten. Spec. Gew. 1040. Derselbe enthält eine sehr grosse Zuckermenge. Der Saccharimeter 
zeigte $9,5 \mathrm{pCt}$; Gärungsprobe bei Verdünnung 1 Teiles Harn mit 8 Teilen Wasser mehr als 1 pCt. Nach 4 Stunden $30 \mathrm{ccm}$ Harn. Spec. Gew. 1052. Sehr viel Zucker. Mit dem Saccharimeter 7 pCt. nachgewiesen; Gärungsprobe bei Verdünnung von 1 Teil Harn mit 6 Teilen Wasser ca. 4 pCt. Nach 6 Stunden $19 \mathrm{ccm}$ trüben Harns aufgefangen. Spec. Gew. 1050. Sehr viel Zucker. Der Saccharimeter zeigte 5,2 pCt. Zucker; Gärnngsprobe bei Verdünnung von 1 Teil Harn mit 5 Teilen Wasser ca. $3 /{ }_{4} \mathrm{pCt}$.

18. 7. Um $12 \mathrm{Uhr}$ mittags $70 \mathrm{ccm}$ gesättigten Harns erhalten. Spec. Gew. 1054. Nach dem Kochen desselben und seiner Fällung mit essigsaurem Blei ergab die Hainessche Probe eine geringfügige Veränderung der Farbe; die Wor aı-M üllersche Probe ergab Gelbfärbung. Die Hainessche Probe gab mit unverdünntem Harn eine deutliche Veränderung der Farbe. Gärungsprobe ca. $1 / 4 \mathrm{pCt}$. Zucker.

19. 7. In 24 Stunden $100 \mathrm{ccm}$ trüben gesättigten Harns aufgefangen. Spec. Gew. 1042. Deutliche Reduktion. Saccharimeter zeigt 0,2 pCt.; Gärungsprobe ergibt nach 24 Stunden ca. $1 / 4 \mathrm{pCt}$. Zucker. Der Hund erhält flüssige Nahrung.

20. 7. In 24 Stunden $300 \mathrm{ccm}$ trüben gesättigten Harns gesammelt. Spec. Gew. 1030. Deutliche Reduktion.

21. 7. In 24 Stunden $500 \mathrm{ccm}$ Harn erhalten. Spec. Gew. 1018. Die Worm Müllersche Probe ergab eine recht starke Färbung; die Ha in esscbe und die Gärungsprobe ein negatives Resultat. Der Hund erhält das gewöhnliche Futter.

22. 7. In 24 Stunden $550 \mathrm{com}$ hellgelben Harns erhalten. Spec. Gew. 1015. An diesem Tage kein Zucker in demselben enthalten; am folgenden Tage ergaben die Hainessche und die Worm-Müllersche Probe eine gelbe Färbung der unteren Schicht.

23. 7. In 24 Stunden $500 \mathrm{ccm}$ hellgelben Harns gesammelt. Spec. Gew. 1016. An diesem Tage sind keine Spuren von Zucker nachweisbar; am folgenden Tage ergab die Hainessche Probe eine Gelbfärbung der unteren Schicht.

24. 7. In 24 Stunden $600 \mathrm{ccm}$ Harn erbalten. Spec. Gew. 1020. Kein Zucker.

25. 7. In 24 Stunden $330 \mathrm{ccm}$ Harn aufgefangen. Spec. Gew. 1015. Die Hainessche und Worm-Müllersche Probe ergaben eine gelblicbe Färbung der unteren Schicht.

26. 7. In 24 Stunden $300 \mathrm{ccm}$ Harn aufgefangen. Spec. Gew. 1030. Die gleiche Färbung.

27. 7. Harnmenge $450 \mathrm{ccm}$. Spec. Gew, 1028. Kein Zucker.

28. 7. $500 \mathrm{ccm}$ Harn aufgefangen. Spec. Gew. 1025. Die Hainessche und Worm-Müllersche Probe ergaben am folgenden Tage eine Veränderung der Farbe der unteren Schicht.

29. 7. $400 \mathrm{ccm}$ Harn gesammelt. Spec. Gew. 1022. Kein Zucker.

30. 7. $600 \mathrm{ccm}$ Harn aufgefangen. Spec. Gew. 1030. Die $\mathrm{Ha}$ a in essche und Worm-Müllersche Probe ergaben eine Veränderung (Gelbwerden) in der Färbung der unteren Schicht, während die Gärnngsprobe negativ ausfiel.

31. 7. Aufgefangene Harnmenge $450 \mathrm{ccm}$. Spec. Gew. 1028. Die Hainessche und Worm-M üllersche Probe ergaben eine Veränderung der unteren Schicht; Gärungsprobe negativ.

1. 8. Harnmenge $650 \mathrm{ccm}$. Spec. Gew. 1024. Kein Zucker.

2. 8. Der Hund wurde getötet. Sektionsbefund: Bauchböble frei; entzündliche Prozesse und Verlötungen nicht vorhanden. Es gelang nicht, die Stelle der ligatur $z u$ finden.

Somit haben wir 3 Versuche angestellt, in denen wir uns bemühten, den Plexus coeliacus zu exstirpieren. Die beiden ersten Versuche ergaben fast gleiche Resultate: Bald nach der Operation stellte sich 
Glykosurie ein, deren Spuren auch noch am folgenden Tage vorhanden waren. Im ersten Versuche war gleich nach der Operation kein Zucker im Harn nachzuweisen; nach 1 Stunde waren ca. $0,4 \mathrm{pCt}$, nach 2 Stunden 1 pCt. und nach 4-6 Stunden und am folgenden Tage Spuren desselben vorhanden. Im zweiten Versuche wurde gleich nach der Operation kein Harn erhalten; nach 1 Stunde erwiesen sich fast 0,3 pCt. Zucker in ihm; nach 2 Stunden $0,4 \mathrm{pCt}$. nach 4 Stunden $0,2 \mathrm{pCt}$. und sodann nur Spuren von Zucker, die auch am folgenden Tage noch nachweisbar waren. Im dritten Versuche, wo wir ausser der Exstirpation des Plexus coeliacus auch noch die Ligatur eines blutenden Gefässes ausführen mussten, beobachteten wir eine sehr scharf ausgeprägte und viel länger andauernde Glykosurie, und zwar erhielten wir gleich nach der Operation 3 pCt. Zucker, nach 1 Stunde 7 pCt., nach 2 Stunden $91 / 2$ pCt.; sodann sinkt die Zuckermenge ebenso wie in den beiden vorhergehenden Versuchen allmäblich, und zwar beträgt sie nach 4 Stunden $7 \mathrm{pCt}$, nach 6 Stunden 5,2 pCt., am folgenden Tage $1 / 4$ pCt., am 3. Tage $0,2 \mathrm{pCt}$., und am 4. Tage sind noch deutliche Spuren von Zucker vorhanden. Ferner beobachteten wir in allen Versuchen eine zeitweilige Veränderung der Farbe des Harns bei der Hainesschen und Worm-Müllerschen Reaktion, die grösstenteils am folgenden Tage verzeichnet wurde; diese Veränderungen waren jedoch so geringfügig, dass wir uns nicht entschliessen können, dieselben als Anzeichen der Gegenwart von Zuckerspuren gelten zu lassen.

Durch die Ergebnisse dieser unserer Versuche werden die Beobachtungen derjenigen Autoren, die nach Verletzungen oder Reizung verschiedener Abschnitte des sympathischen Nervensystems Glykosurie auftreten sahen, bestätigt. Insbesondere vermerken wir das in die Augen springende Zusammenfallen der von uns erhaltenen Ergebnisse mit denen der Versuche von Eckhard, Suchanow, Oddi, Mac-Leod, sowohl im Sinne des zur Entwicklung des Maximums der Glykosurie erforderlichen Zeitraumes (gegen 2 Stunden seit dem Momente des Beginnens der Reizung), als auch was die Dauer ihres Verlaufes (gegen 2 Tage) anbelangt.

Ferner unternahmen wir es, zur Aufklärung der Frage, ob die Glykosurie vorzugsweise auf die Reizung der Aeste des sympathischen Nervensystems zurückzuführen ist, oder ob bei ihrer Entstehung auch dem N. vagus eine Rolle von Bedeutung zukommt - da er ja auch die Bauchorgane innerviert und Fasern von verschiedener Funktion aufweist einige untenstehend beschriebene Versuche anzustellen. Wir resezierten beide Vagusstämme oberhalb des Diaphragmas, doch unterhalb der Stelle, wo sich die zu den Lungen und dem Herzen gebenden Aeste abzweigen, damit die T'ätigkeit dieser Organe ungestört bliebe und der Zustand des Tieres ein Fortführen des Versuches zuliesse. Wir exstirpierten nämlich nach Ablauf einer gewissen Zeit den Plexus coeliacus.

Versuch I. 9. 8. 1912. Scheckiger Hund von $21 \mathrm{~kg}$ Körpergewicht. Vor der Operation $50 \mathrm{ccm}$ trüben gesättigten Harns aufgefangen. Specifisches Gewicht 1040. Nach dem Filtrieren wurde bei der Hainesschen Probe eine Farbenveränderung, und 
zwar eine dunkelgrüne Färbung erhalten, während die Nylandersche Probe keine Veränderung ergab.

Die Operation währte 30 Minuten. Vor allem wurde die Tracheotomie ausgeführt und die Canüle mit dem Lindemannschen Apparat, durch den Luft unter einem gewissen Druck in die Lungen gepumpt wird, verbunden. Das Tier bat actio nur die eintretende Luft wieder auszuatmen. Mit Hilfe dieses Apparates wird das Zusammenfallen der Lungen nach der Eröffnung der Brusthöhle rermieden, wobei die während der Operation eingetretene Luft nach der Schliessung der Thoraxwunde schnell resorbiert wird. Sodann wurde ein viereckiger Hautmuskellappen, dessen Basis an der Wirbelsäule gelegen war, herausgeschnitten, die IX. und X. Rippe reseciert und die Pleurahöhle eröffnet. Die Speiseröhre wurde mit Hilfe eines Fingers in die Wunde hineingezogen und an ihr mit Leichtigkeit der linke und rechte Stamm des $\mathrm{N}$. vagus gefunden und durchscbnitten. Die Brusthöhle wurde durch Nähte völlig verschlossen. Nach der Operation sind in der Atmung des Tieres keinerlei Störungen zu bemerken, und das Allgemeinbefinden desselben ist gut. Sofort nach der Operation wurden $4 \mathrm{ccm}$ trüben Harns aufgefangen. Reaction auf Zucker wie ror der Operation.

Nach 1 Stunde kein Harn erbalten. Xach 3 Stunden $5 \mathrm{ccm}$ Harn gesammelt. Kein Zucker. Nach 6 Stunden kein Harn erhalten. Nach 8 Stunden kein Harn. Es traten Krämpf $\theta$ in den Extremitäten auf.

In der Nacht auf den 10. August ging das 'lier ein. Sectionsbefund: Bauchund Brusthöble frei. Beide Vagusstämme und die sie verbindende Anastomose sind durchschnitten.

Versuch II. 17. 9. 1912. Schwarzer Hund von $15 \mathrm{~kg}$ Körpergewicht. Vor der Operation $190 \mathrm{ccm}$ etwas trüben Harns von strohgelber Farbe aufgefangen. Specifisches Gewicht 1042. Kein Zucker.

Die Operation dauerte 35 Minuten. Resection der X. und XI. Rippe. Durchschneidung beider Vagusstämme und der Anastomose. Während der Operation fiel die den Luft in die Lungen des Versuchstieres hineinpumpenden Apparat mit der Canüle verbindende Röhre heraus. Sofort traten die Anzeichen von Asphyxie und Krämpfe auf. Nach der Operation verstärkten sich die Krämpfe bis zum Opisthotonus. Man war gezwungen, die Canüle einzuführen und Luft in die Lungen hineinzupressen, wonach das Tier besser zu atmen begann und die Krämpfe abnahmen, obwohl sie immer noch stark waren.

Gleich nach der Operation $3 \mathrm{ccm}$ Harn erbalten, der in der Hainesschen und Nylanderschen Reaction eine deutliche Reduction ergab.

Nach 1 Stunde $2 \mathrm{ccm}$ Harn aufgefangen, der auch eine sehr scharf ausgeprägte Reduction ergab. Die Krämpfe dauern fort. Nach 3 Stunden $20 \mathrm{ccm}$ trüben hellgelben Harns erhalten. Specifisches Gewicht 1052. Die Reactionen auf Zucker ergeben eine noch schärfer ausgeprägte Färbung als früher. Die Krämpfe dauern fort. Nach 5 Stunden $15 \mathrm{ccm}$ trüben Harns aufgefangen. Specifisches Gewicht 1050. Die Harnuntersuchung ergab eine sehr starke Reduction. Die Krämpfe dauern fort.

18. 9. Harn weder morgens noch tagsüber erbalten. Der Käfig ist trocken. Keine Krämpfe. Allgemeinzustand des Tieres unbefriedigend.

In der Nacht auf den 19.9. ging das Tier ein. Sectionsbefund: Blase leer. In der Brasthöhle an der Stelle der Operation blutige Flüssigkeit. Beide Vagusstämme und die Anastomose durchschnitten.

Versuch III. 22. 9. 1912, Weisser Hund von 14,2 kg Körpergewicht. Vor der Operation $200 \mathrm{ccm}$ gesättigten etwas trüben Harns gesammelt. Specifisches Gewicht 1046. Kein Zucker.

Dauer der Operation 25 Minuten. Resection der X. und XI. Rippe. Durch- 
schneidung der Stämme und der Anastomose der N. ragi. Gleich nach der Operation treten Asphyxieerscheinungen und Krämpfe auf.

Gleich nach der Operation $5 \mathrm{ccm}$ strohgelben Harns erhalten. Specifisches Gewicht 1054. Die Hainessche und Nylandersche Reaction ergeben eine scharf ausgeprägte Reduction. Nach 1 Stunde $2 \mathrm{ccm}$ Harn aufgefangen, dessen Untersuchung auf Zucker eine scharf ausgeprägte Reduction ergibt. Nach 2 Stunden kein Harn erhalten. Die Krämpfe dauern fort.

Nach 4 Stunden $15 \mathrm{ccm}$ trüben Harns aufgefangen. Specifisches Gewicht 1050. Bei den Reactionen auf Zucker scharf ausgeprägte Reduction. Die Krämpfe dauern fort. Nach 6 Stunden $20 \mathrm{ccm}$ Harn erhalten. Specifisches Gewicht 1048. Scharf ausgeprägte Reduction. Die Krämpfe dauern fort.

23. $9.85 \mathrm{~cm}$ hellgelben Harns aufgefangen. Specifisches Gewicht 1025. Die Hainessche, Nylandersche und Worm-Müllersche Reaction ergeben auch am folgenden Tage keine Veränderung der Färbung. Keine Krämpfe. Tagsüber noch $350 \mathrm{ccm}$ keinen Zucker enthaltenden Harns erhalten. Abends ist das Allgemeinbefinden des Tieres schlecht.

In der Nacht auf den 24. 9. ging das Tier ein. Sectionsbefund: Bauch- und Brusthöhle frei. Beide Stämme und die Anastomose des N. vagus sind durchschnitten.

Versuch IV. 27.9. 1912. Hellgelber Hund von $13 \mathrm{~kg}$ Körpergewicht. Vor der Operation $40 \mathrm{ccm}$ gesättigten klaren Harns aufgefangen. Spec. Gew. 1050. Die Hainessche und Nylandersche Probe ergaben eine leichte Veränderung in der Färbung. Die Operation wurde nach dem oben klargelegten Plane ausgeführt. Bei der Operation war man gezwungen, den Magen sehr weit in die Bauchwunde hineinzuziehen, um die Speiseröhre gut unterbinden zu können. Nach der Unterbindung wurde die Speiseröbre zwischen 2 Ligaturen durchschnitten. Wăhrend aller dieser Manipulationen atmete der Hond schlecht.

Gleich nach der Operation wurde kein Harn erhalten.

Nach 1 Stunde $8 \mathrm{ccm}$ trüben Harns aufgefangen. Spec. Gew. 1052. Haines sche und Nylandersche Reaktion ergaben die gleiche Veränderung in der Färbung, wie vor der Operation. Nach 2 Stunden $10 \mathrm{ccm}$ trüben Harns erbalten. Spec. Gew. 1058. Hainessche und $\mathrm{Nylandersche} \mathrm{Reaktion} \mathrm{ergaben} \mathrm{keinerlei} \mathrm{Hinweis} \mathrm{auf} \mathrm{die}$ Gegenwart von Zucker. Nach 3 Stunden $5 \mathrm{ccm}$ trüben Harns erhalten. Spec. Gew. 1050. Kein Zucker.

Hierauf beschlossen wir den Plexus coeliacus zu exstirpieren, wobei wir die A. mesenterica sup. verwundeten. Starke Blutung.

1 Stunde naeh dieser zweiten Operation $8 \mathrm{ccm}$ trüben Harns erhalten. Kein Zucker. Am nächsten Tage eine nur wenig bemerkbare Veränderung in der Farbe des Harns. Nach 2 Stunden $2 \mathrm{ccm}$ Harn aufgefangen. Die Hainessche und Yylandersche Probe ergaben am folgenden Tage deutliche Spuren einer Reduktion. 21/2 Stunden nach der zweiten Operation ging der Hund ein. Sektionsbefund: Harnblase leer. Bluterguss in die Bauchböhle.

Versuch V. 2. 10. 1912. Rotbrauner Hund von $13 \mathrm{~kg}$ Körpergewicht.

Vor der Operation $35 \mathrm{ccm}$ klaren Harns von grünlicher Farbe erhalten. Spec. Gew. 1009. Kein Zucker. Die Ha in es sche Reaktion bewirkte eine leichte Entfärbung der Lösung.

Operation, wie im Versuch IV. Dauer derselben 9 Minuten.

Gleich nach der Operation kein Harn erbalten.

Nach 1 Stunde $7 \mathrm{ccm}$ klaren gesättigten Harns aufgefangen. Spec. Gew. 1024. Kein Zucker. Nach 2 Stunden $10 \mathrm{ccm}$ etwas trüben gesättigten Harns erhalten. Spec. Gew. 1022. Kein Zucker.

Hierauf wurde der Plexus coeliacus exstirpiert, wobei keinerlei Störungen verursacht wurden. 
1 Stunde nach dieser zweiten Operation wurden $6 \mathrm{ccm}$ trüben Harns orhalten. Die Hainessche Reaktion ergab eine sehr grell orange, die Nylandersche eine dunkle Färbung (deutliche Reduktion). Nach 3 Stunden $30 \mathrm{ccm}$ trüben Harns aufgefangen. Spoc. Gew. 1042. Deutliche Reduktion. Beim Verdünnen von $25 \mathrm{ccm}$ Harn mit $21 / 2 \mathrm{ccm}$ essigsauren Bleis zeigte der Saccharimeter $0,3 \mathrm{pCt}$. Zucker; die Gährungsprobe ergab 1/4 pCt. Nach 4 Stunden ging der Hund ein. Sektionstefund: Bluterguss in die Bauchböhle. Die Ligatur ron der Speiseröhre abgeglitten.

Auf Grund dieser Versuche kann gefolgert werden, dass die Durchtrennung der Vagusstämme keine stark ausgeprägte Glykosurie hervorruft, in den Versuchen I, IV und V gelangte keine Reduktion zur Beobachtung, während wir in den Versuchen II und III scheinbar entgegengesetzte Daten finden. Doch wenn wir unsere Aufmerksamkeit einerseits auf die in diesen beiden Versuchen erhaltenen Resultate des operativen Eingriffs, d. $h$ auf die von Krämpfen begleiteten Asphyxieerscheinungen, wodurch bekanntlich stets Glykosurie hervorgerufen wird, richten, und anderseits die in den übrigen Versuchen erhaltenen Ergebnisse in Betracht ziehen, wo derartige Erscheinungen nicht vorhanden waren, so erweist es sich, dass man keinen hinreichenden Grund dazu hat, in diesen Fällen (II, III) die so beträchtliche Zuckerausscheidung in unmittelbare Abhängigkeit von der Durchschneidung der Vagusstämme zu bringen.

Ein hervorragendes Interesse beansprucht Versuch $V$, wo nach der Durchschneidung der Speiseröhre mit den Vagusstämmen während 2 Stunden nach der Operation keine Glykosurie vorhanden war, wo aber nach der Exstirpation des Plexus coeliacus Glykosurie eintrat, obschon von einer Einwirkung der Verletzung der Aeste des N. vagus doch keine Rede mehr sein konnte.

Schwächer ausgeprägt bestand dasselbe Bild auch in Versuch IV.

Wenn wir nun alle auf Grund unserer sämtlichen Versuche erhaltenen Ergebnisse zusammenfassen, so gelangen wir zu der Schlussfolgerung, dass die nach der Entfernung des Plexus coeliacus auftretende Glykosurie ausschliesslich auf die Wirkung der traumatischen Reizung des sympathischen Nervensystems zurückzuführen ist.

\section{Schlussfolgerangen.}

1. Eine Verletzung oder irgend eine Reizung des Plexus coeliacus ruft nicht nur eine schnell vorübergehende, sondern auch eine andauernde Glykosurie hervor.

2. Beim Diabetes erkrankt primär der Plexus coeliacus und erst secundär entwickeln sich Veränderungen in den Langerhansschen Inselchen des Pankreas.

3. Die beim Diabetes im Blut kreisenden unbekannten Agentien afficieren das Centralnervensystem ohne bestimmte Prädilektion des einen oder anderen funktionell, anatomisch und embryologisch unterschiedenen Abschnittes desselben.

4. Die Affektion des Centralnervensystems ist beim Diabetes auf die parenchymatösen Teile beschränkt. 


\section{Literatur.}

1. Aldeh off, Tritt auch bei Kaltblütern nach Pankreasexstirpation Diabetes mellitus auf? Zeitschr. f. Biol. 1891. Bd. 28.

2. Althaus, Neuritis of the circumplex nervi in diabet. Lancet. 1890.

3. Ambrosiani, eit. nach Cl. Bernard.

4. Anfimow, Ueber Neuritiden. Arbeiten der Charkower med. Gesellsch. 1898. (Russisch.)

5. A uché, Des altérations des nerfs. Arch. de méd. expériment. 1890.

6. Ausobor, cit. nach Thiroloix.

7. Babinski, Nérrites. Traité de méd. Vol. V.

8. Barth, Union méd. 1883.

9. Baumel, Pancréas et diabète. Montpellier méd. 1881 et 1882.

10. Derselbe, Cas de diabète traité par la pancréatine et le régime azoté. Ibid. 1886. p. 213.

11. Derselbe, Nouvelle théorie pancréatique du diahète sucré. Ibid. 1889.

12. Derselbe, Un mot d'historique sur le diabète sucré. La théorie pancréatique. Gaz. hebdom. 1891. Nr. 29.

13. Berger, Breslauer ärztl. Zeitschr. 1882.

14. Bernard, Cl., Leçons de physiologie eypérimentale. Paris 1855 . p. 418.

15. Derselbe, Vorlesungen über Physiologie and Pathologie des Nervensystems. Russische Uebersetzung. St. Petersburg 1866.

16. Derselbe, Leçons sur le diabète et la glycogénèse animale. Paris 1877.

17. Bernard-Féré, Des troubles nerveux chez les diabétiques. Areh. de neurol. 1883. IV.

18. Bernhardt, Berl. klin. Wochenschr. 1892.

19. Besançon, cit. nach Thiroloix.

20. Binswanger, Arch. f. Psych. Bd. 29. S. 987.

21. Boedeker, Mendels Jahresbericht. 1897. S. 224.

22. Böhm und Hoffmann, Beiträge zur Kenntnis des Kohlenhydratstoffwechsels. Fesselungsdiabetes der Katze. Arch. f. exper. Pathol. u. Pharmakol. 1878. Bd. 8.

23. Bonardi, Sclérose diffuse de la moëlle dans un cas de diabète. Ref. in Revue neurol. 1897. p. 694.

24. Bond, Mendels Jahresbericht über Neurologie. 1898.

25. Bouchardat, Gaz. méd. de Paris. 1847.

26. Derselbe, cit. nach Lapierre, S. 9.

27. B o u iss on, Diabète maigre et aiguë. Lithiase du pancréas. Oblitération du canal de Wirsung. Bull. do la Soc. anat. 1890. p. 1.

28. Buzzard, Brit. med. Journ. 1890.

29. Brauer, Der Einfluss des Quecksilbers auf das Nervensystem des Kaninchens. Deutsche Zeitschr. f. Nervenheilk. 12.

30. Bright, oit. nach Lapierre.

31. Brücke, Lehrbuch der Physiologie. Russische Uebersetzang. St. Petersburg 1876.

32. Bruns, Ueber neuritische Lähmungen bei Diabetes. Berl. klin. Wochenschr. 1890. Nr. 23.

33. Buch et Vanderlinden, Notes sur un cas du mal perforant. Belgique méd. 1897.

34. Bürger und Churchman, Der Plexus coeliacus und mesentericus und ihre Rolle bei Abdominalshock. Mitteil. aus d. Grenzgebieten d. Med. u. Chir. 1906. Bd. 16.

35. Cantani, Der Diabetes mellitus. Berlin 1877.

36. Caplick, Ueber Diabetes mellitus. Diss. Kiel. 
37. Cavazzani fières, Sur les causes de l'hyperglycémie relativement à la pathologie du diabite. Arch. ital. de Biol. XIX. 2. p. 270.

38. Charcot, Sur un cas de paraplégie diabétique. Arch. de Neurol. 1890. Vol. 19. Nr. 57.

39. Charpantier, Annal. méd. psychol. 188ז. Vol. VII. p. 436. 1890. Vol. XII. S. 230.

40. Chopart, cit. nach Orths.

41. Christi de Buoli, Notes sur quelques points de diabète. Thèse de Paris. 1873.

42. Corneille, L'aphasie dans le diabète. Gaz. hebdom. 1898.

43. Cornillon, Revue de méd. 1884.

44. Cowley, cit. nach Lapierre.

45. Cruppi, eit. nach Schmidts Jahrbüchern. 1880. S. 189.

46. Cy on und Alad off, Die Rolle der Nerren bei Erzeugung ron künstlichem Diabetes mellitus. Ballet. de l'Acad. des Sciences de St. Pétersbourg. 1871. T. XVI.

47. Déjérine, De l'atrophie musculaire des tabétiques. Soc. de Biol. 1888. II. 25.

48. Derselbe, Paralysie au cours de tabes. Méd. moderne. 1890. No. 13.

49. Derselbo, Mendels Jahresbericht über Psych. u. Neurol. 1897.

50. Dotlo, cit. nach Brauer.

51. Drouineau, Observation d'un cas d'hémiplégie diabétique. Gaz. des hòp. 1897.

52. Duffey and Abraham, On the connexion of acute diabetes with disease of the pancreas. Dublin Journ. 1884. May.

53. Eckhard, Beiträge zur Anatomie und Physiologie. Bd. III. S. 125. Bd. IV. S. 70. Bd. Vll. S. 70.

54. Eichhorst, Bauchspeicheldrüse, in Eulenburgs Realencyklopädie. Bd. 2.

55. Derselbe, Neuritis diabetica. Virchows Archiv. 1892. Bd. 127. S. 1.

56. Eisenlohr, Ueber progressive atrophische Lähmung. Nourol. Centralbl. 1884.

57. Derselbe, Centralbl. f. Nervenheilk. 1879. Nr. 5.

58. Derselbe, Deutsche med. Wochenschr. 1884. S. 554.

59. Elliotson, cit. nach Orths, S. 12.

60. Erb, Neurol. Centralbl. 1888.

61. Derselbe, Bemerkungen über gewisse Formen der neuritischen Atrophie. Ebenda. 1883. Nr. 23.

62. Fassy, Thèse de Bordeaux. 1887.

63. Féré-Bernard, Arch. de Neurol. 1882. IV. p. 353.

64. Fischer, Ueber die Beziehungen zwischen Tabes und Diabetes mellitus. Centralbl. f. Nervenheilk. 1886.

65. Flata u, Fortschritte d. Med. 1897. No. 8.

66. Derselbe, Deutsche med. Wochenschr. 1897. Nr. 19.

67. Fleiner, Zur Pathologie der calculösen und arteriosklerotischen Pankreascirrhose und der entsprechenden Diabetesfornen. Berl. klin. Wochenschr. 1894. Nr. 1.

68. Fles, cit. nach Orths, S. 10.

69. Frank, cit. nach Reprew.

70. Fraser and Bruce, A case of multiple diabetic neuritis with pathological specimens. Brit. med. Journ. 1895.

71. Frerichs, Ueber den Diabetes. Berlin 1884. S. 212.

72. Derselbe, Traité pratique des maladies du foie et des voies biliaires. 3 me éd. p. 147.

73. Derselbe, Verdauung, in Wagners Handwörterbuch der Physiologie. 1864. Bd. III. S. 741 .

74. Freyhan, Diabetes infolge von Pankreasstein. Berl. klin. Wochenschr. 1893.

75. Friedreich, cit. nach 0rths, S. 11.

76. Gaurelet et Thomas, Chez le chien décapsulé l'excitation du splanchnique ne produit pas de glycosurie, C. K. de la Soc. de Biol. 1909. 'T. 67. Nr. 26. 
Ueber die gegenseitigen Beziehungen zwischen Nerrensystem u. Zuckerkrănkbeit. 217

77. Gentes, Morphologie et structure des ilots de Langerbans chez quelques mammifères. Evolution et signification des ilots en général. Thèse. Bordeaux 1901.

78. Derselbe, Note sur les terminaisons nerveuses des ilots de Langerhans du pancréas. C. R. de la Soc. de Biol. 1902. p. 202.

79. Derselbe, llots de Langerbans du pancréas du lion. Ibid. 1902. p. 535.

80. Gille, cit. nach Lapierre, S. 11.

81. Guelliot, Glycosurie et inositurie; dégénérescence graisseuse du pancréas. Gaz. méd. de Paris. 1881.

82. Goldscheider, Berl. klin. Wochenschr. 1894. Nr. 19.

83. Derselbe, Zeitschr. f. klin. Med. 1891.

84. Goodmann, cit. nach Lapierre, S. 81.

85. Gregoire, De la paralysie faciale chez les diabétiques. Thi'se de Paris. 1883.

86. Gregory, cit. nach Reprew.

87. Griesinger, Studien über Diabetes. Arch. f. physiol. Heilk. 1859. S. 44.

88. Grossmann, Doppelseitige Neuroretinitis descendens usw. Berl. klin. Wochenschrift. 1879 .

89. Grube, Tabes dorsalis oder Diabetes mellitus. Neurol. Centralbl. 1895.

90. Derselbe, Ueber das Verhalten der Sehnenreflexe bei Diabetes mellitus. Ebenda. 1893.

91. Häusler, Zur Theorie der Zuckerbarnruhr. Russki Wratsch, 1907. Nr. 33. (Russisch.)

92. Harley, cit. nach Lapierre.

93. Derselbe, Pathogen. of pancr. diabet. Brit. med. Journ. 1892. 27. 8.

94. Harnack, Zur Pathogoneso des Diabetes mellitus. Deutsches Arch. f. klin. Med. Bd. 13. S. 593.

95. Hartsen, cit. nacb 0 rths.

96. Hensay, Untersuchongen des Centralnervensystems bei Diabetes mellitus. Diss. Strassburg. 1897.

97. Hösslin, Ueber diabetische Nearalgien. Münch. med. Wochenschr. 1886. 14.

98. Holste in, La paralysie générale d'origine diabétique. Sem. méd. 1897.

99. Jaccoud, Sur le cancer du pancr. Journ. méd. et chir. prat. 1885. p. 394.

100. Jaksch, Ein Fall von Coma diabeticum. Prager med. Wochenschr. 1880.

101. Jacoby, Neurol. Centralbl. 1896. II. 15.

102. Jarussow, 4 Fälle von Zuckerharnruhr mit Veränderungen des Pankreas. Wratsch. 1894. S. 249. (Russisch.)

103. J offroy, Arch. de physiol. 1879. p. 172 .

104. Israel, 2 Fälle von Nekrose innerer Organe bei Diabetes mellitus. Virchows Arch. 1881. Bd. 83. S. 181.

105. Juliusburger, Aroh. f. Psych. Bd. 32. S. 284.

106. Derselbe, Mendels Jahresbericht f. Psych. 1898.

107. Kalmus, Zeitschr. f. klin. Med. Bd. 30.

108. Klebs und Munk, cit. nach Schmidts Jahrbücher. 1880.

109. Klecki, Die Beziebung des Plexus coeliacus zur Acetonurie. Ref. in Centralbl. f. Physiol. 1896. Nr. 2.

110. Kühne, cit. nach Naunyn.

111. Derselbo, Lehrbuch der pbysiologischen Chemie. Uebers. unter der Red. von Setschenow. Lief. 4. (Russisch.)

112. Külz, Beitrag zur Pathologie und Therapie des Diabetes mellitus. Marburg 1874 .

113. Derselbe, Ist der Traubenzucker ein normaler Uarnbestandteil? Arch. f. d. ges. Physiol. 18i6. Bd. 13.

114. Dersolbe, Beiträgo zur Lehre vom künstlichen Diabotes. Ebenda. 1881. Bd. 24. S. 107 . 
115. Lancereaux, Notes et réflexions à propos de deux cas de diabète suoré arec altération du pancréas. Bull. de l'Académie. 1877. 2. S. VI.

116. Derselbe, Nouveaux faits de diabete sucré avec altération du pancréas. Ibid. 1877. 3. S. XIX. p. 588.

117. Derselbe, Trois formes de diabète. Union méd. 1890.

118. Landenheimer, Paralytische Geistesstörung infolge von Zuckerkrankheit. Arch. f. Psych. Bd. 29.

119. Landois, Lehrbuch der Physiologie des Menschen. Charkow. 1886. Russische Uebers.

120. Lapierre, Sur le diabète maigre dans ses rapports avec les altérations du pancréas. Paris. 1879.

121. Lecorché, De la cataracte diabétique. Arch. gén. de neéd. 1861. T. 18. p. 70 .

122. Derselbe, Troubles nervenx dans lo diabète chez les femmes. Arch. de Neurol. 1883. IV.

123. Legrand du Saulle, Gaz. d. Hòp. 1884. Nr. 21.

124. Leichtentritt, Ein Beitrag zur Erkrankung peripherer Nerven bei Diabetes. Diss. Berlin. 1893.

125. Lemoine et Lanno is, Contributions ì l'átude des lésions da pancréas dans le diabète. Arch. de méd. exp. 1891.

126. Lépine, Lésions du pancréas dans lo diabète. Lyon méd. 1890. T. 64 . p. 546.

127. Derselbe, Sur la pathogénie du diabète consécutif ì l'exstirpation du pancréas. Archives de méd. exp. 1891.

128. Dersolbe, Diabète maigre avec intégrité du pancréas. Lyon méd. 1892. LXXI. p. 591.

129. Lépine et $\mathrm{Blanc}$, Hémiplégie diabétique. Kevue de mód. 1896.

130. Leva, Klinische Beiträge zur Lehre vom Diabetes mellitus. Deutsches Archiv f. klin. Med. 1891. S. 151.

131. Leval-Piqucheff, Des pseudotabes. Thèse de Paris. 1885.

132. Lewin and Boor, Quetschung und Ausrottang des Ganglion cooliacum. Deutsche med. Wochenscbr. 1894. Nr. 10.

133. Leyden, Klinik der Rückenmarkskrankbeiten. II. Teil. S. 331.

134. Derselbe, Ueber die Beteiligung der Muskel-Nerven-Apparate bei T'abes. Dentsche Zeitscbr. f. prakt. Med. 1877.

135. Derselbe, Wiener med. Wochenschr. 1893.

136. Derselbe, Entzündung der Nerven. Berlin 1881.

137. Lichtheim, Zur Diagnose der Pankreasatrophie durch Steinbildung. Berliner klin. Wochenschr. 1894. Nr. 8.

138. Loewy, Eine neue Funktion des Pankreas und ihre Beziehung zum Diabetes mollitus. Archiv f. exp. Path. u. Pharm. 1908. Bd. 59.

139. Ludwig, Lebrbuch der Pbysiologie des Mensohen. Bd. II. Leipzig.

140. Lusk, oit. nach Blan. Schmidt's Jahrbücher. 1870.

141. Isustig, Sur les effets de l'exstirpation du plexus coeliaque. Arch. ital. de biol. 1889. T. XII.

142. Derselbe, Recherches ultérieures sur les fonctions du plexus coeliaque. Ibidem.

143. Derselbe, Zur Kenntnis der Funktion des Plexus coeliacus. Centralbl.f. Physiol. 1889. Nr. 13.

144. Derselbe, Sull' acetonuria sperimentale. Ref. in Arch. ital. de biol. 1892. T. XVII. p. 122.

145. Mac-Leod, Studies in experimental glycosuria. Some experiments bearing on the nature of the glycogenolytic fibres in the great splanchnic nerve. Ref. in Biochem. Centralbl. 1908. Nr. 10.

146. Maréchal de Calvi, Recherches sur les accidents diabétịues. Paris 1864. 
Ueber die gegenseitigen Beziehungen zwischen Nervensystem u. Zuckerkrankheit. 219

147. Marie, Considérations sur le diabète sucré. Thèse de Paris. 1881.

148. Marie et Guignon, Sur la perte du reflexe rotul. dans le diabète. Rev. de méd. 1886.

149. Marinesco, Société de biologie. 1896.

150. Derselbe, Revue neurologique. 1896. No. 5. p. 15.

151. Derselbe, Ibidem. 1896. p. 54.

152. Derselbe, Société de biol. 1895. Oct.

153. Derselbe, Presse méd. 1897. p. 41.

154. Martson, Americ. journ. of med. sciences. 1854 .

155. Meyer, Glycolyse, Hyperglycémie, Glycosurie et Diabète. Annales de l'Institut Pasteur. 1908. No. 10.

156. Mering und Minkowski, Diabetes mellitus nach Pankreasexstirpation. Archiv f. exp. Path, u. Pharm. 1889. Bd. 26.

157. Minich, Deutsche Klin. f. innere Med. 1892-93.

158. Mollard, Diabète maigre; absence de sclérose constatée par M. Rénaut. Soc. sc. méd. de Lyon. 1891. p. 238.

159. Munk, Atrophie bei Diabetes. Tagebl. d. 43. Naturforschervers. 1869. S. 112.

160. Nau n y n, Diabetes mellitus. Spez. Path. u. Ther., her. v. Nothnagel. VII. 1.

161. Nonne, Einige Befunde bei Mangel der Patellarreflexe. Festschr. zur Eröffnung des nenen Krankenhauses in Hamburg. 1899.

162. Derselbe, Ueber Poliomyelitis anterior chronica. Berliner klin. Wochenschr. 1896.

163. Derselbe, Arch. f. Psychiatrie. 1888.

164. Derselbe, Deutsche Zeitschr. f. Nervenbeilk. 1899.

165. Notta, Observation de diabète maigre; mort; altération du pancréas. L'Union méd. 1881. No. 25.

166. Oddi, Sur quelques récentes recherches touchant l'acétonurie et la glycosurie expérimentales. Ref. in Arch. ital. de biol. 1892. T. XVII.

167. Oppenheim, Archiv f. Psychiatrie. Bd. 19.

168. Derselbe, Beiträge zur Pathologie der multiplen Neuritis. Zeitschr. f. klin. Med. Bd. 11.

169, Orths, Ueber Diabetes pancreaticus. Bonn 1883. Diss.

170, Pary, Die Lehre von der Nahrung. Russ. Uebersetzung. St. Petersburg 1876.

171. Derselbe, On lesions of the nervous system producing diabetes. Proceed. of the Royal Soc. 1860. Vol. X.

172. Peiper, Experimentelle Studien über die Folgen der Ausrottung des Plexus coeliacus. Zeitschr. f. klin. Med. 1890. Bd. 17.

173. Pensa, Osservazioni sulla distribuzione dei vasi sanguigni dei nervi del pancreas. Bollett. della Soc. med.-chir. di Pavia. Seduta del 24. giugnio 1904.

174. Pflüger, Untersuchungen über den Pankreasdiabetes. Arch. f. d. ges. Physiol. 1907. Bd. 118.

175. Derselbe, Ueber die Zuverlässigkeit der Zuckerproben von HammarstenNylander und Worm-Mäller. Ebenda. 1907. Bd. 116.

176. Derselbe, Ueber den Duodenaldiabetes der Warmblüter. Ein vorläufiges Wort. Ebenda. 1908. Bd, 122.

177. Derselbe, Experimentelle Untersuchang über den Darmdiabetes. Ebenda. 1909. Bd. 128.

178. Pierret et Vaillard, Revue de méd. 1886.

179. Poniclo, Anatomische Veränderungen des Sympathicus bei Diabetes. Ref. in Berl, klin. Wochenschr. 1878. S. 182.

180. Popoff, Ueber Veränderungen im Rückenmark nach Vergiftung mit Arsen. Virchows Archiv. 1893. Bd. 93, S. 351.

181. Pryce, The Lancet. 1888. II. p. 59. 
182. Pryce, Brit. med. Journ. 1888.

183. Derselbe, On diabetic neuritis with a clinical description. Brain. 1893.

184. Derselbe, Brit. med. Journ. 1889.

185. Rayer, cit. naoh Jaccoud.

186. Raymond, Maladies du système nerreux. 1897. II P.

187. Raymond et Artaud, Arch. de Physiol. 1884.

188. Recklinghausen, Drei Fälle von Diabetes mellitus. Virchows Archiv. 1864. Bd. 30.

189. Reprew, Die Grundlagen der allgemeinen und experimentellen Pathologie. Cbarkow 1908. (Russisch.)

190. Kicher, Cancer ventriculi et glycosurie. Bull. de la Soc. anat. 1878. p. 488.

191. Rühle, cit. nach Orths.

192. Russel, Lancet. 1898. VIII.

193. Salomon, Geschichte der Glykosurie von Hippokrates bis zum Anfange des XIX. Jahrhunderts. Deutsches drcb. f. klin. Med. 1871. Bd. 8.

194. Sandmeyer, Beitrag zur Pathologie und Anatomie des Diabetes. Ebenda. 1892. Bd. 50. S. 381.

195. Saundby, The Bradshaw lecture on the morbid anatomy of diabetes mellitus. Ref. Lancet. 1890.

196. Schabad, Ein Fall ron Zuckerbarnruhr mit Affektion des Pankreas. Medizinskoje Obosrenije. 1891. Nr. 21. (Russisch.)

197. Schaper, Ein Fall ron Diabetes mellitus, entstanden durch Trauma. Inaug.Dissert. Göttingen 1873.

198. Scheube, 2 Fälle ron diabetischem Cuma. Arch. d. Heilk. 1877. Bd. 18.

199. Schiff, Untersuchung über die Zuckerbildung in der Leber und den Finfluss des Nervensystems auf die Erzeugung des Diabetes. Würzburg 1859.

200. Schrader, cit. nach Schiff.

201. Schüle, Seotionsergebnisse. 1874. S. 710 .

202. Scoda, cit. nach Jaccoud.

203. Se ogen, Diabetes mellitus. Berlin 1875.

204. Derselbe, Der Diabetes mellitus. Berlin 1893. 3. Aull.

205. Sekeyan, Contribution à l'étude du diabète levulosorique. Thèse de Paris. 1897.

206. Servaix, Berl, klin. Wochenschr. 1878. S. 716 .

207. Sommer, Diagnostik der Geisteskrankheiten. 1894. S. 18.

208. Sonques et Marinesco, Lésions de la moëlle épinière dans un cas de diabète. Rev. de méd. 1897.

209. Sottas, Polyarie, Glycosurie, amaigrissement rapide. Mort. Litbiase pancréatique. Bull. de la Soc. Anatom. 1891. S. 635 .

210. Steinthal, Ein seltener Ausgang von Diabetes mellitus. Deutsche Klinik. 1858. S. 160.

211. Stosch, cit. nach Reprew.

212. Strohl, Ueber die Nerven der Bauchhöhle, insbesondere den Plexus coeliacus und ihren eventuellen Einfluss auf die Pulsfrequenz bei Peritonitis. Arch. f. klin. Chir. 1904. Bd. 75 .

213. Strümpell, Neurol. Zentralbl. 1884. Nr. 11.

214. Derse be, Multiple Neuritis und Ataxie. Ibid. 1889. Ni. 21.

215. Derselbe, Arch. f. Psych. 1885. Bd. 14.

216. Suchanow, Zur Frage von den Beziehungen der sympathischen Ganglien und Nerrenfäden zum künstlichen Diabetes. Kiew 1879.

21i. Sylver, cit. nach Lapierre.

218. Thiel, cit. nach Naunyn.

219. Thiroloix, Le diabète pancréatique. Paris 1892. 
Ueber die gegenseitigen Beziehungen zwischen Nervensystem u. Zuckerkrankheit. 221

220. Tirelli, Surl'anatomie pathologiquedes éléments nerveux. Arch. ital. de biol. 1896.

221. Tollemer, Diabète sucré avec altération du pancréas. Bull. de la Soc. Anat. 1891. S. 675.

222. Viola, Sur quelques récentes recherches touchant l'acétonurie et la glycosurie expérimentales. Arch. ital. de Biol. T. 17. 1882.

223. White, On the treatment of Diabetes mellitus by fuding on raw-pancrees and by the subcutane injection of liçuor pancreaticus. Brit. med. Journ. 1893.

224. Williamson, Diabetes mellitus and lesions of the pancreas. Ref. in Med. Chronicle. Manchester. 1892. 367-368.

225. Derselbe, cit. nach Wratsct, 1894. Nr. 7. (Kussisch.)

226. Derselbe, On the Knee Ferks. Med. Chronicle. 1893.

227. Derselbe, Changes in the posterior columns of the spinal cord in Diabetes mellitus. Brit. med. Journal. 1894.

228. Willis, cit. nach Salomon.

229. Wind le, The morbid anatomy of diabetes mellitus. Dublin Journal. 1883. S.112.

230. Worms, Des neuralgies symmétriques dans le diabète. Acad. de Méd. 1880.

231. Derselbe, Gaz. hebdomad. de Méd. ot Chirurg. 1880.

232. Zenker, cit. nach Blau. Schmidts Jahrbücher.

233. Ziemssen, Neuralgia u. Neuritis bei Diabetes. Aerztl. Intelligenzbl. 1885. Nr.44.

234. Z $\mathrm{w} \theta \operatorname{taj} \theta \mathrm{w}$, Pathologisch-anatomische Veränderungen des Nervensystems des Hundes bei Arsenikrergiftung. Newrologitscheski Westnik. 1898. Bd. 6. Nir. 2. (Russisch.) 